A Hydrodynamic Study of Davis Pond, Near New Orleans, LA

Tate O. McAlpin, Joseph V. Letter, Jr., and S. Keith Martin

August 2008 


\section{A Hydrodynamic Study of Davis Pond, Near New Orleans, LA}

Tate O. McAlpin, Joseph V. Letter, Jr., and S. Keith Martin

Coastal and Hydraulics Laboratory

U.S. Army Engineer Research and Development Center

3909 Halls Ferry Road

Vicksburg, MS 39180-6199

Final report

Approved for public release; distribution is unlimited.

Prepared for U.S. Army Engineer District, New Orleans

PO Box 60267

New Orleans, LA 70160-0267 


\begin{abstract}
This study characterizes water levels in the Davis Pond floating marsh created by the diversion of fresh water from the Mississippi River. The model was validated to observed field data collected from November 2003 to January 2004. After model validation, eight alternatives were tested to determine the benefits of extending the diversion canal (Alternatives 1-3), increasing the size of the cuts through the gabion weir (Alternatives 4-6), and creating breaches in the Cypress Lumber Canal (Alternatives 7-8). These eight initial alternatives were analyzed and used to create four additional alternatives (Alternatives 9-12) consisting of the most beneficial aspects of each of the initial alternatives. The final four alternatives were tested to determine their expected benefits to the system.
\end{abstract}

DISCLAIMER: The contents of this report are not to be used for advertising, publication, or promotional purposes. Citation of trade names does not constitute an official endorsement or approval of the use of such commercial products. All product names and trademarks cited are the property of their respective owners. The findings of this report are not to be construed as an official Department of the Army position unless so designated by other authorized documents. 


\section{Contents}

Figures and Tables........................................................................................................................

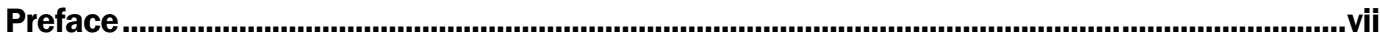

Unit Conversion Factors.........................................................................................................................viii

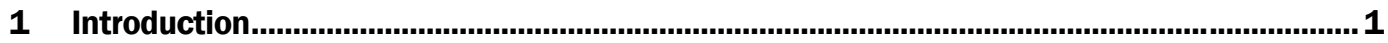

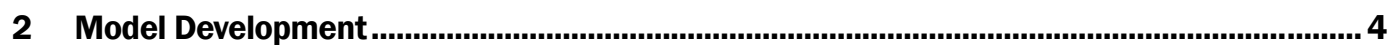

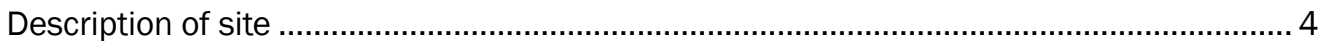

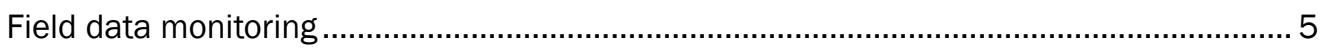

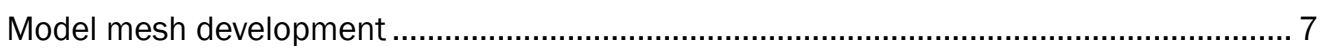

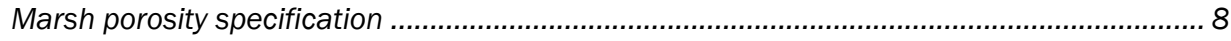

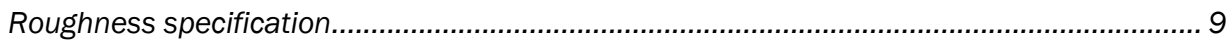

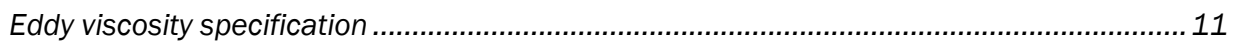

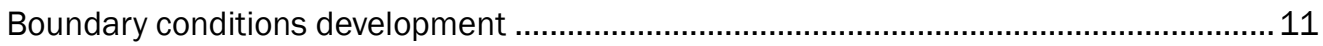

Hydrodynamic model validation ................................................................................... 14

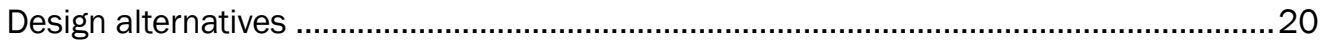

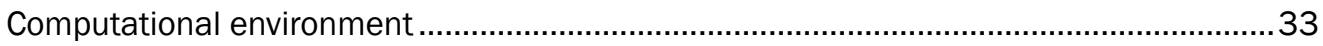

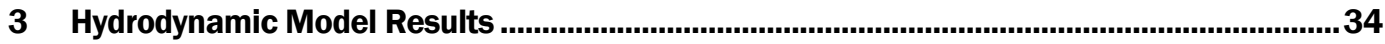

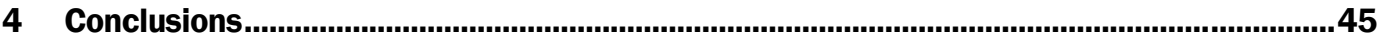

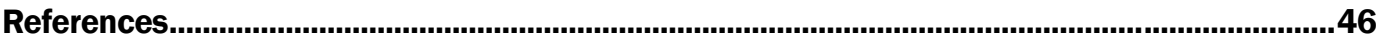

Appendix A: Description of Marsh Porosity and Its Application to Floatant Marsh ....................48

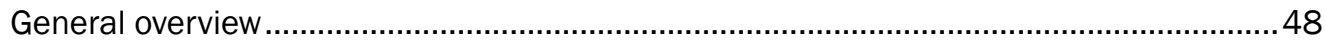

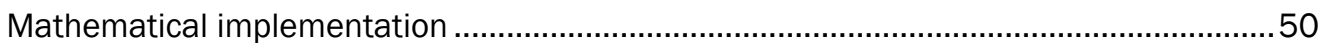

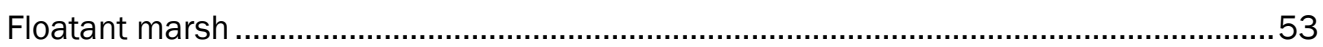

Combined effect of floating marsh and conventional marsh porosity ...............................60

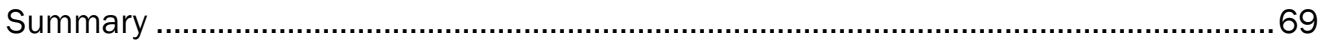

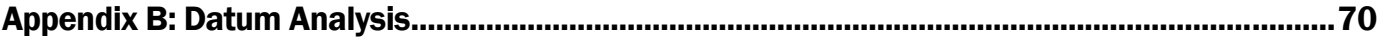

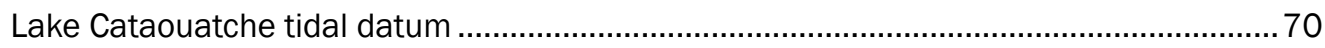

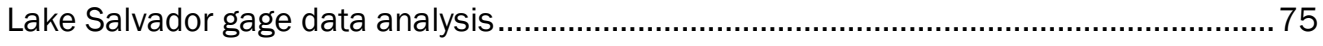

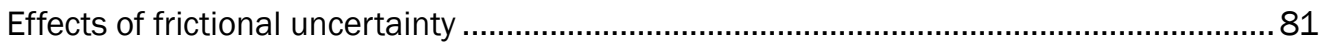

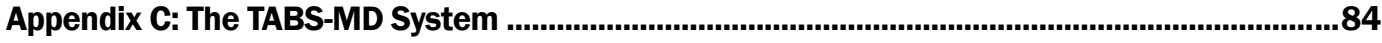

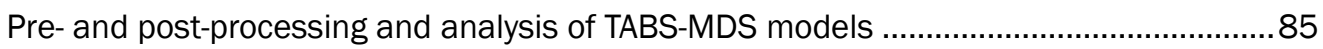

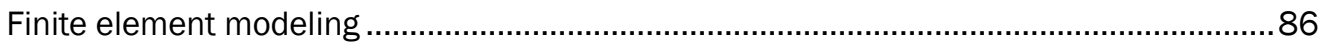

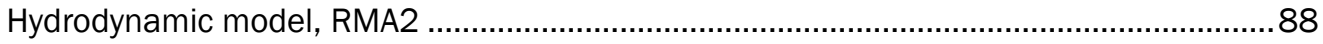

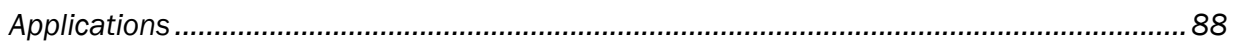

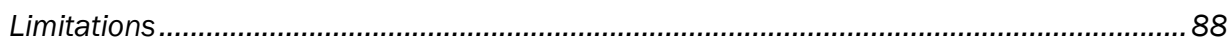




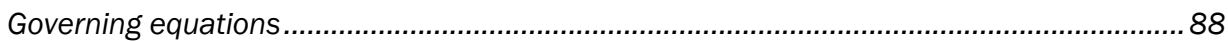

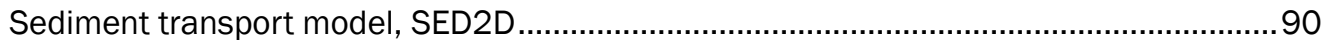

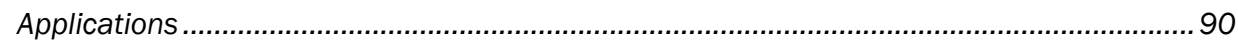

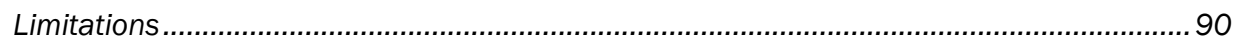

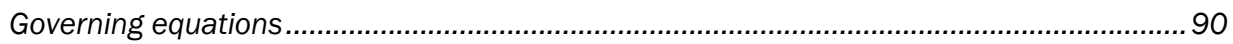

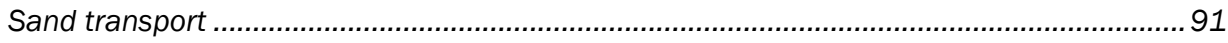

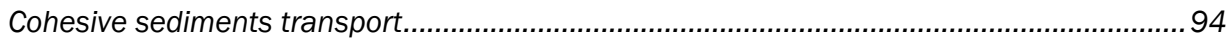

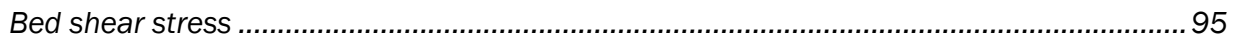

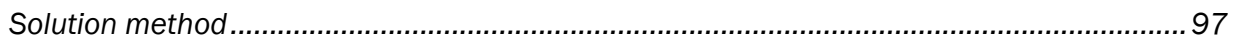

Water quality transport model, RMA4 .................................................................. 97

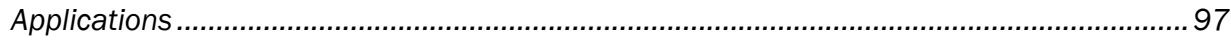

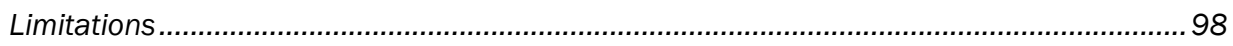

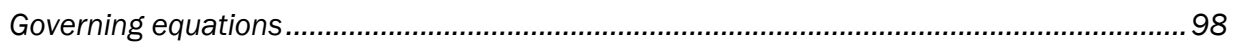

\section{Report Documentation Page}




\section{Figures and Tables}

\section{Figures}

Figure 1. Barataria Basin area benefitting from the Davis Pond diversion (New Orleans District 2004).

Figure 2. Outline of the model domain. .............................................................................. 4

Figure 3. Locations of water surface elevation gages used to validate the model............................. 5

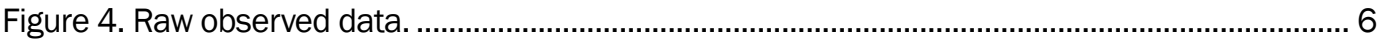

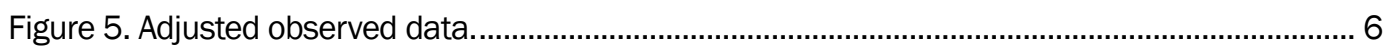

Figure 6. Contour plot of the model domain................................................................................. 7

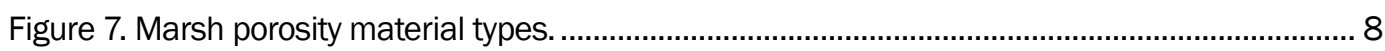

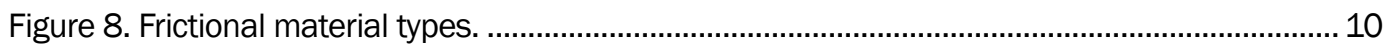

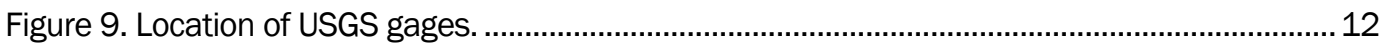

Figure 10. Plot of the boundary conditions............................................................................... 13

Figure 11. Comparison to ensure no significant effects due to applying the Lake Cataouatche gage data at the tidal boundary................................................................................... 13

Figure 12. Plot of the validation comparison at the Highway 90 gage. .......................................... 15

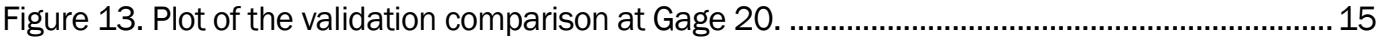

Figure 14. Plot of the validation comparison at Gage 21............................................................... 16

Figure 15. Plot of the validation comparison at Gage 22. ............................................................... 16

Figure 16. Plot of the validation comparison at Gage 23............................................................ 17

Figure 17. Plot of the validation comparison at Gage 27........................................................ 17

Figure 18. Plot of the validation comparison at Gage 28. ........................................................ 18

Figure 19. Plot of the validation comparison at Gage 29. ......................................................... 18

Figure 20. Plot of the validation comparison at Gage 127........................................................... 19

Figure 21. Plot of the validation comparison at Gage 128 ....................................................... 19

Figure 22. Plot of the validation comparison at Gage 129...........................................................2

Figure 23. Contour plots of Alternative 1................................................................................ 21

Figure 24. Contour plots of Alternative 2 ……………….........................................................2

Figure 25. Contour plots of Alternative 3................................................................................. 23

Figure 26. Contour plots of Alternative 4................................................................................ 24

Figure 27. Contour plots of Alternative 5.................................................................................... 25

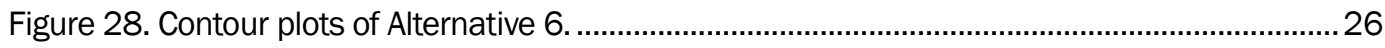

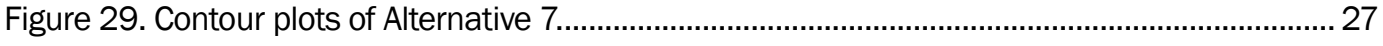

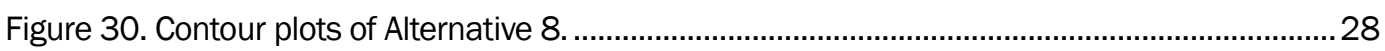

Figure 31. Contour plots of Alternative 9. ……………............................................................... 29

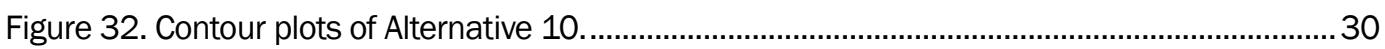

Figure 33. Contour plots of Alternative 11............................................................................. 31 


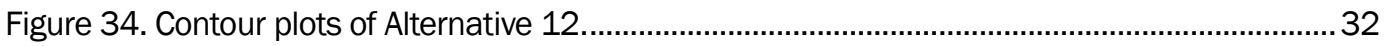

Figure 35. Water surface profile obtained from Alternatives 1-8................................................34

Figure 36. Water surface profile obtained from Alternatives 9-11..............................................35

Figure 37. Water surface profile obtained from Alternative 12.................................................... 35

Figure 38. Water surface elevation for the base conditions in feet NAVD88..................................36

Figure 39. Water surface elevation for Alternative 1 in feet NAVD88. ............................................ 37

Figure 40. Water surface elevation for Alternative 2 in feet NAVD88 ................................................ 37

Figure 41. Water surface elevation for Alternative 3 in feet NAVD88. ..........................................38

Figure 42. Water surface elevation for Alternative 4 in feet NAVD88..............................................38

Figure 43. Water surface elevation for Alternative 5 in feet NAVD88............................................39

Figure 44. Water surface elevation for Alternative 6 in feet NAVD88. .............................................39

Figure 45. Water surface elevation for Alternative 7 in feet NAVD88. .............................................. 40

Figure 46. Water surface elevation for Alternative 8 in feet NAVD88............................................ 40

Figure 47. Water surface elevation for Alternative 9 in feet NAVD88.............................................. 41

Figure 48. Water surface elevation for Alternative 10 in feet NAVD88............................................ 41

Figure 49. Water surface elevation for Alternative 11 in feet NAVD88............................................ 42

Figure 50. Water surface elevation for Alternative 12 in feet NAVD88......................................... 42

Figure 51. Contour difference plots of the base conditions and Alternatives 9-10......................... 43

Figure 52. Contour difference plots of the base conditions and Alternatives 11-12.......................44

\section{Tables}

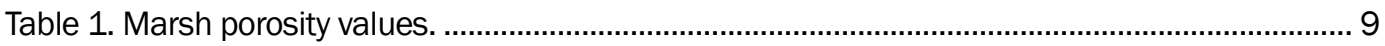

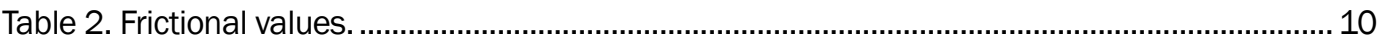




\section{Preface}

The work described herein and the preparation of this report were conducted during the period of May through November 2006 by the Coastal and Hydraulics Laboratory (CHL) of the U.S. Army Engineer Research and Development Center (ERDC, Vicksburg) for the U.S. Army Engineer District, New Orleans (MVN).

Project coordination in MVN was provided by Keely Crowder and Donald M. Alette.

The work was performed under the direct supervision of Bruce A. Ebersole, Chief, Flood and Storm Protection Division, CHL; and Dr. Robert T. McAdory, Chief, Estuarine Engineering Branch (EEB), CHL. Tate O. McAlpin, Joseph V. Letter, Jr., S. Keith Martin, and Darla McVan, all of EEB, CHL, conducted this study and prepared this report. General supervision was provided by Dr. William D. Martin, Deputy Director, CHL, and Thomas W. Richardson, Director, CHL.

COL Gary E. Johnston was Commander and Executive Director of ERDC. Dr. James R. Houston was Director. 


\section{Unit Conversion Factors}

\begin{tabular}{|l|c|l|}
\hline Multiply & By & To Obtain \\
\hline cubic feet & 0.02831685 & cubic meters \\
\hline cubic inches & $1.6387064 \mathrm{E}-05$ & cubic meters \\
\hline cubic yards & 0.7645549 & cubic meters \\
\hline degrees (angle) & 0.01745329 & radians \\
\hline degrees Fahrenheit & $(\mathrm{F}-32) / 1.8$ & degrees Celsius \\
\hline feet & 0.3048 & meters \\
\hline inches & 0.0254 & meters \\
\hline miles (nautical) & 1,852 & meters \\
\hline miles (U.S. statute) & $1,609.347$ & meters \\
\hline miles per hour & 0.44704 & meters per second \\
\hline slugs & 14.59390 & kilograms \\
\hline square feet & 0.09290304 & square meters \\
\hline square inches & $6.4516 \mathrm{E}-04$ & square meters \\
\hline square miles & $2.589998 \mathrm{E}+06$ & square meters \\
\hline square yards & 0.8361274 & square meters \\
\hline yards & 0.9144 & meters \\
\hline
\end{tabular}




\section{Introduction}

The Davis Pond freshwater diversion project is a salinity-control structure located in St. Charles Parish, on the west bank of the Mississippi River, two miles below Luling, LA. Natural and man-made changes had reduced freshwater, sediment, and nutrient inputs from the Mississippi River to the surrounding estuarine-marsh areas. As a result, saltwater intruded further inland into the fresh, intermediate, and brackish water zones, resulting in loss of habitat, erosion, and deteriorating water quality. The primary objective of the Davis Pond project was to combat the saltwater intrusion by diverting freshwater from the Mississippi River into the adjacent estuarine areas.

The Davis Pond project was dedicated as the world's largest freshwater diversion in March 2002. Its estimated total cost was $\$ 106$ million (New Orleans District 2004). The project was designed to divert up to 10,650 cubic feet per second (cfs) of freshwater from the Mississippi River, channeling it through a structure via an outflow canal, into a 9,200 acre ponding area, then out into Lake Cataouatche, and finally into the remainder of the Barataria Basin (New Orleans District 2004). The ponding area is enclosed on the north, east, and west by guide levees with design elevations ranging between 6.63 and $3.63 \mathrm{ft}$ NAVD88 ${ }^{1}$, and by a gabion rock weir on the southern edge, along the shoreline of Lake Cataouatche. At optimum production, the Davis Pond diversion would preserve 33,000 acres of wetlands and benefit an additional 777,000 acres of marshes and bays (Figure 1) (New Orleans District 2004). The cost benefits is estimated at $\$ 15$ million for fish and wildlife and an additional $\$ 300,000$ for recreation per year (New Orleans District 2004). This project will make the Barataria estuary a more prolific producer of oysters, shrimp, crab, and fish, as well as a major habitat for migratory waterfowl, fur-bearing animals and alligators (New Orleans District 2004). The increased harvest (seafood and wildlife) created by this project will generate significant economic benefits for the state of Louisiana.

1 NAVD88: North American Vertical Datum of 1988. 


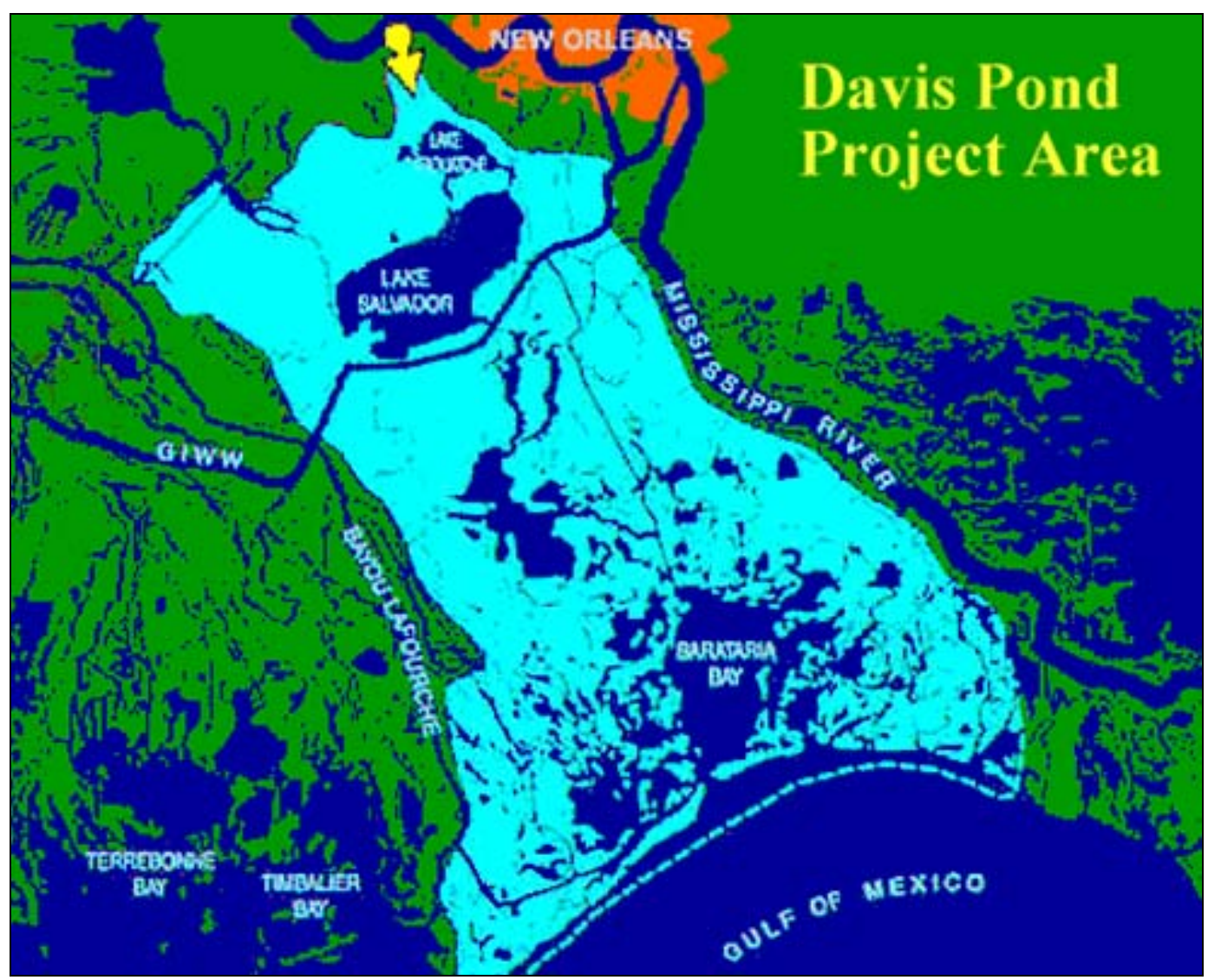

Figure 1. Barataria Basin area benefitting from the Davis Pond diversion (New Orleans District 2004).

When normal operations of the Davis Pond freshwater diversion began, several problems were identified in the ponding area. The first and most significant was that stages in the ponding area rose much higher than anticipated. This issue occasionally resulted in undesired flooding when levee overtopping occurred. The problem was caused in part by a previously unidentified ridge behind the gabion rock weir. Also, that weir was designed with a specific elevation drop to compensate for expected settling after construction. Actual settling of the weir turned out to be significantly less than expected, however, resulting in less flow over the weir. Another factor limiting flow was that the east and west guide levees subsided more than expected, and were overtopped by the higher stages in the ponding area. The U.S. Army Engineer District, New Orleans (MVN) cut several notches into the gabion weir in an attempt to lower the water levels and increase the amount of water that can be diverted. While that action helped, the stages in the ponding area were still too high. MVN has proposed a design to fix these problems that includes widening and deepening the existing channels through the rock weir, cutting additional channels, 
extending the diversion canal farther south, cutting breaches into the Cypress Lumber Canal, and raising the guide levees to design grades.

MVN requested that the U.S. Army Engineer Research and Development Center (ERDC) perform a two-dimensional numerical modeling study of the ponding and surrounding areas to assess the effectiveness of the proposed designs. 


\section{Model Development}

\section{Description of site}

The study area, shown in Figure 2, is located in southern Louisiana, southwest of New Orleans. Davis Pond is located primarily in St. Charles Parish with a small area residing in Jefferson Parish. The Davis Pond freshwater diversion is intended to divert flows of up to $10,650 \mathrm{cfs}$ from the Mississippi River into the 9,200 acre Davis Pond marsh area, which in turn drains into Lake Cataouatche. The Davis Pond area is covered with a significant amount of floating marsh, making accurate modeling of the hydrodynamics of the area very challenging.

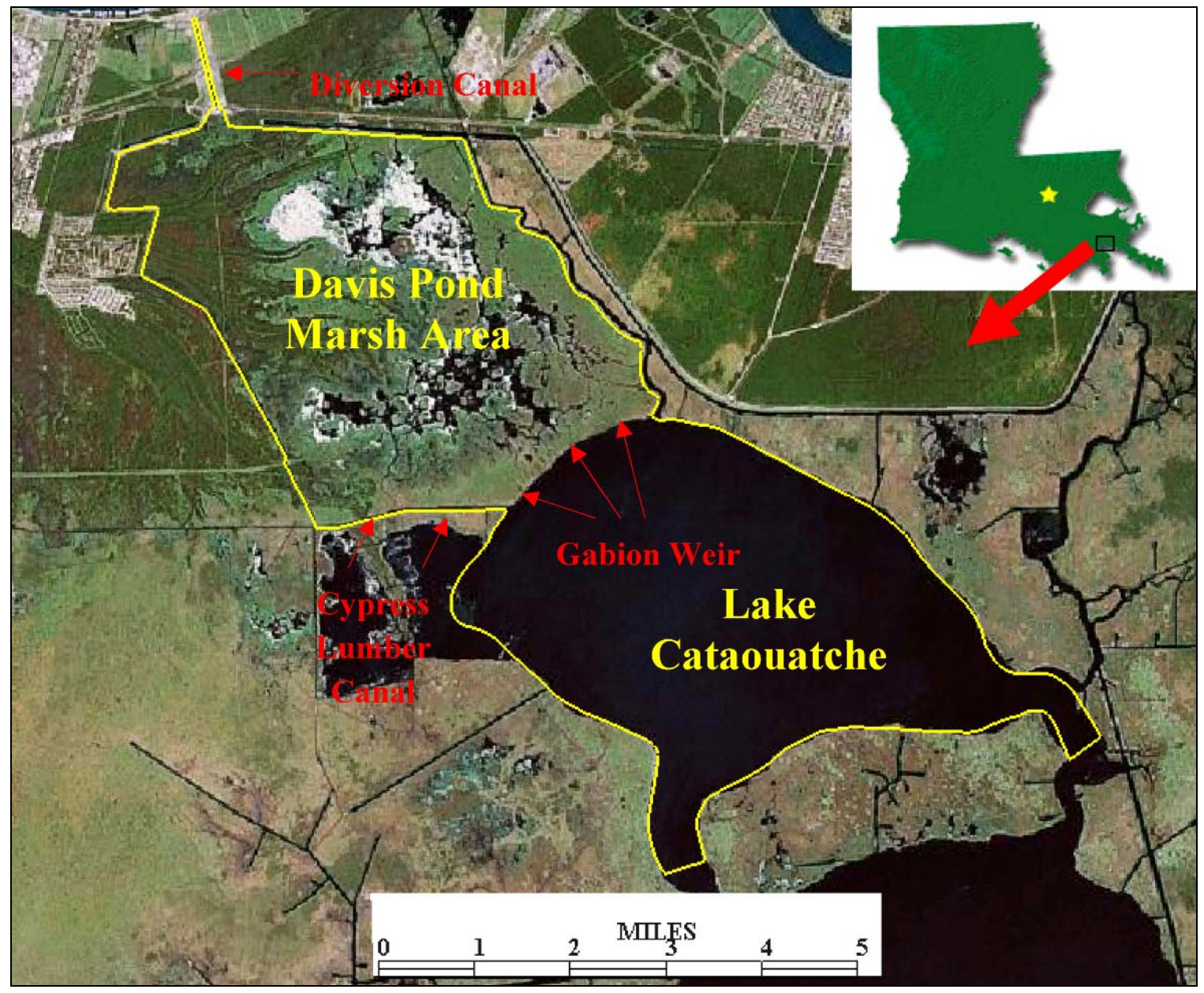

Figure 2. Outline of the model domain. 


\section{Field data monitoring}

Two U.S. Geological Survey (USGS) gages (Highway 90 and Lake Cataouatche, shown in Figure 9) were used for the inflow and tidal boundary conditions. MVN also installed numerous gages, shown in Figure 3, throughout the Davis Pond marsh area. These gages were vital to the validation of the water surface elevations in the model. The MVN gages were in operation from November 30, 2003 to January 13, 2004.

It was determined that the vertical datums for the observed water levels were not in agreement. Upon further investigation, it was determined that there were errors in the vertical datums. Analysis of the datums is presented in Appendix B, along with the method used to determine the most likely vertical datums. The raw observed data are plotted in Figure 4, with the adjusted observed data plotted in Figure 5. These figures are intended to show the spread in water surface elevations due to vertical datum issues for the raw data and the adjusted data, especially around hour 800 .

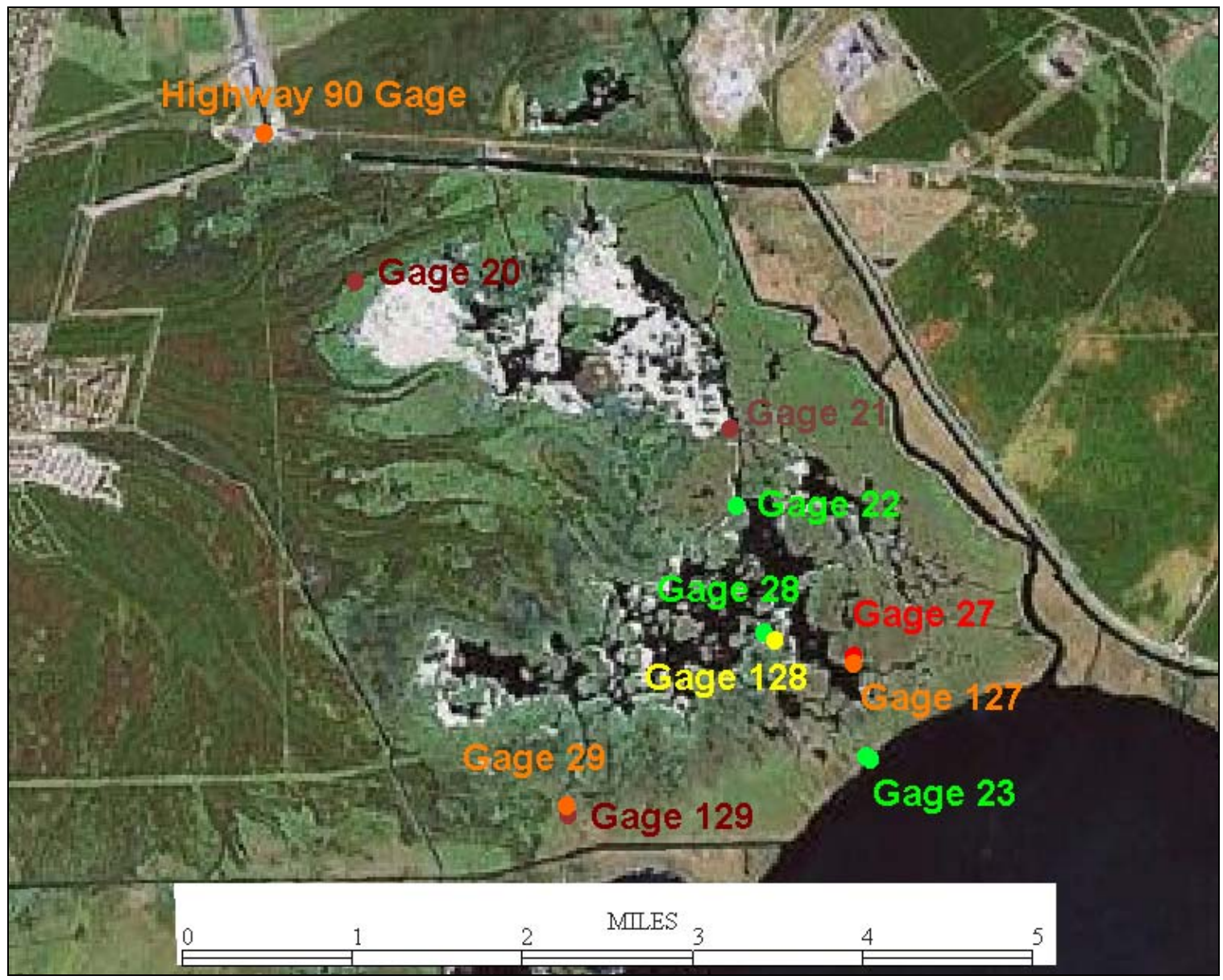

Figure 3. Locations of water surface elevation gages used to validate the model. 


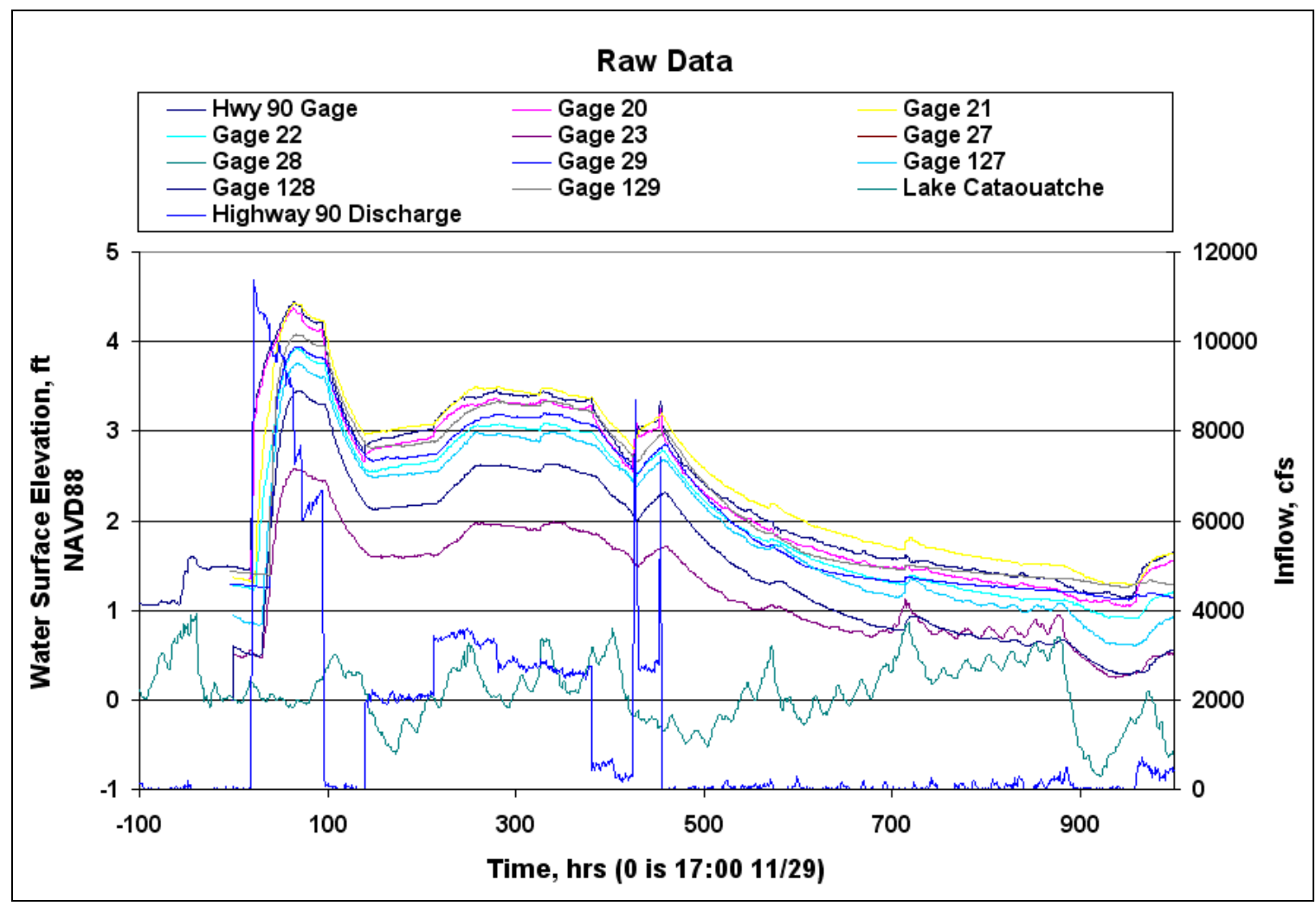

Figure 4. Raw observed data.

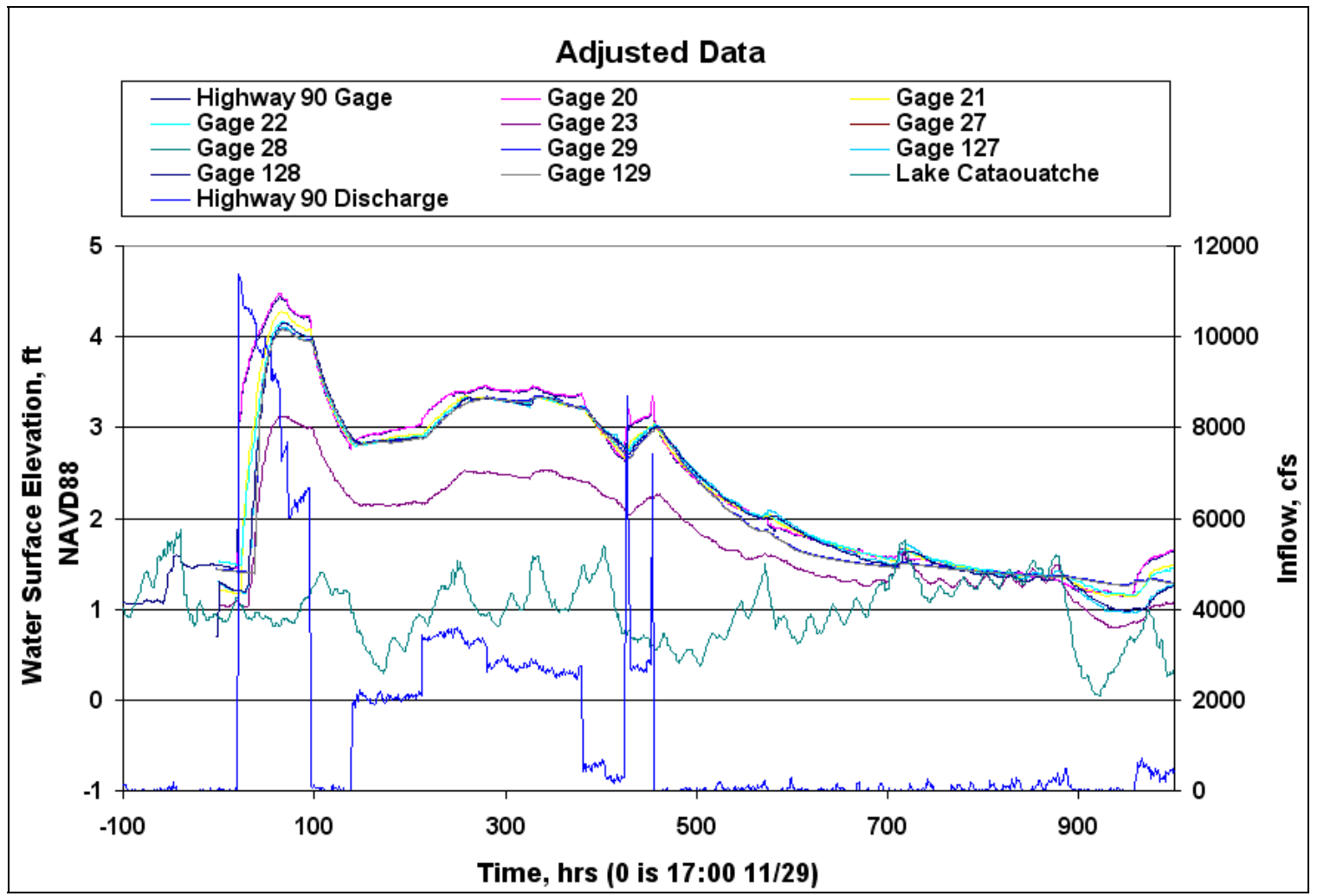

Figure 5. Adjusted observed data. 


\section{Model mesh development}

The numerical model was developed using data derived from several sources. The areas north of the gabion rock weir were defined using LIDAR data and topographic surveys provided by MVN. The LIDAR data covered the areas that are normally dry land (elevations above $\mathrm{oft}$ NAVD88). The topographic surveys covered the east and west guide levees and the gabion weir. Bathymetric surveys covered the nine channel cuts in the gabion weir, which extended approximately $500 \mathrm{ft}$ into the marsh, Lake Cataouatche near the channel cuts, and several survey cross-sections that traversed the project area. Insufficient surveys were available to do a proper interpolation across the upper and lower ponding areas. From the available cross-sectional transects, it was observed that the ponding area had an average elevation of approximately $-1 \mathrm{ft}$ NAVD88. Therefore, this approximate elevation was applied to the entire upper and lower ponding areas. The horizontal coordinate system used in the model was State Plane 83, South Louisiana zone ( $\mathrm{ft}$ ), with the vertical datum of NAVD88 (ft). The overall model domain and mesh contours are presented in Figure 6.

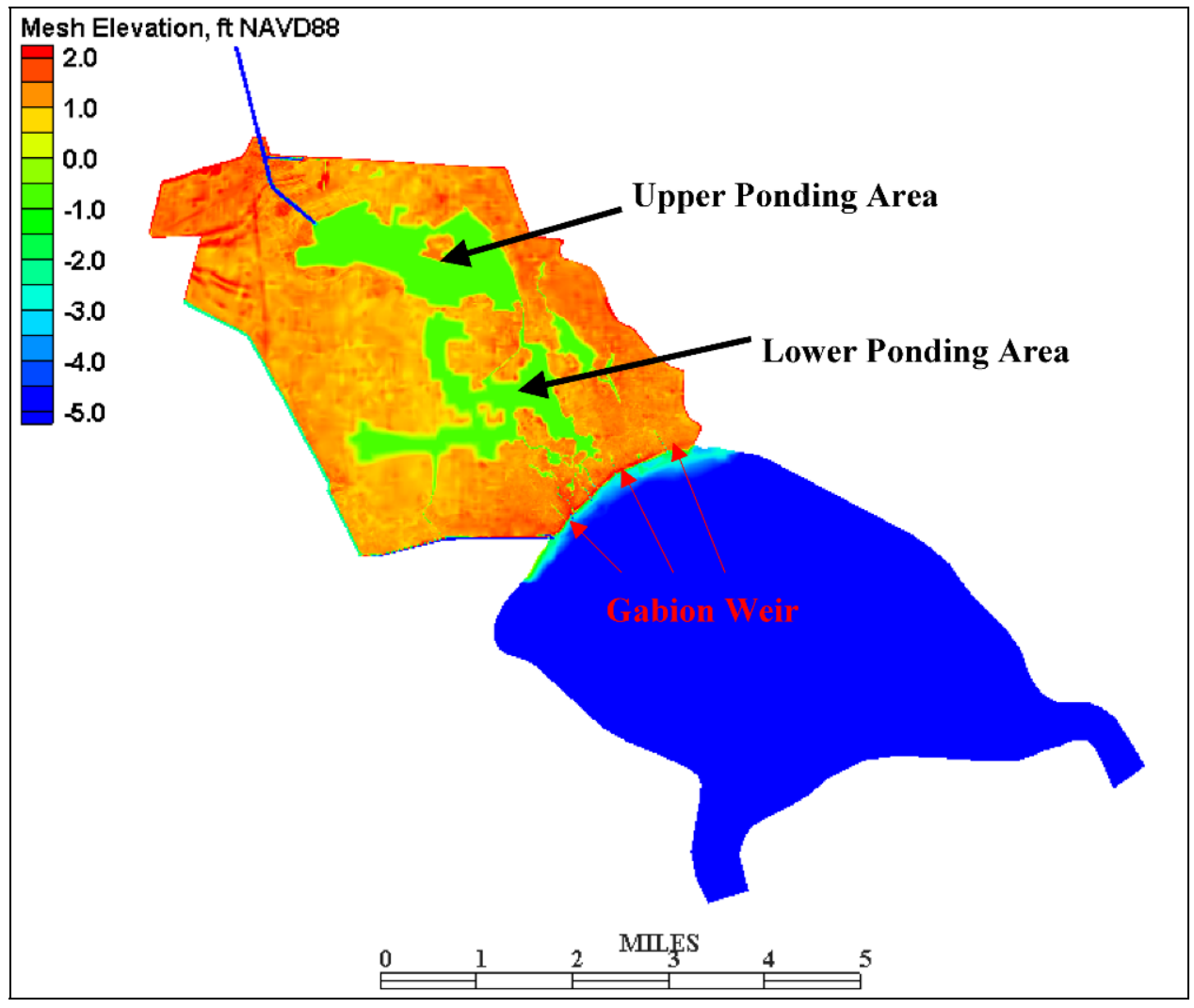

Figure 6. Contour plot of the model domain. 
This study was performed using the TABS-MD numerical modeling system (see Appendix C). RMA2, in particular, was used. The specified model coefficients used in the study were based on the material types for each element. The required coefficients specified in RMA2 include an eddy viscosity turbulent mixing coefficient, a bottom friction (Manning's $\mathrm{n}$ ) and the coefficients for the marsh porosity characteristics. RMA2 version 5.0 consists of a new layering option that allows for the specification of all required coefficients independently. (Each coefficient has its own layer.).

\section{Marsh porosity specification}

The model uses a technique for dealing with wetland topography and intertidal marsh, via a porosity, to allow for a more accurate and realistic representation of the hydrodynamics in such complicated systems. The marsh porosity was specified as a function of water depth such that no elevation would result in a negative depth during the simulation. A more in-depth explanation of marsh porosity and the modeling of floatant marshes using marsh porosity is provided in Appendix A. The specified marsh porosity coefficients are based on material type. Figure 7 shows the marsh porosity materials for the Davis Pond mesh. Table 1 has the actual values used in the model runs.

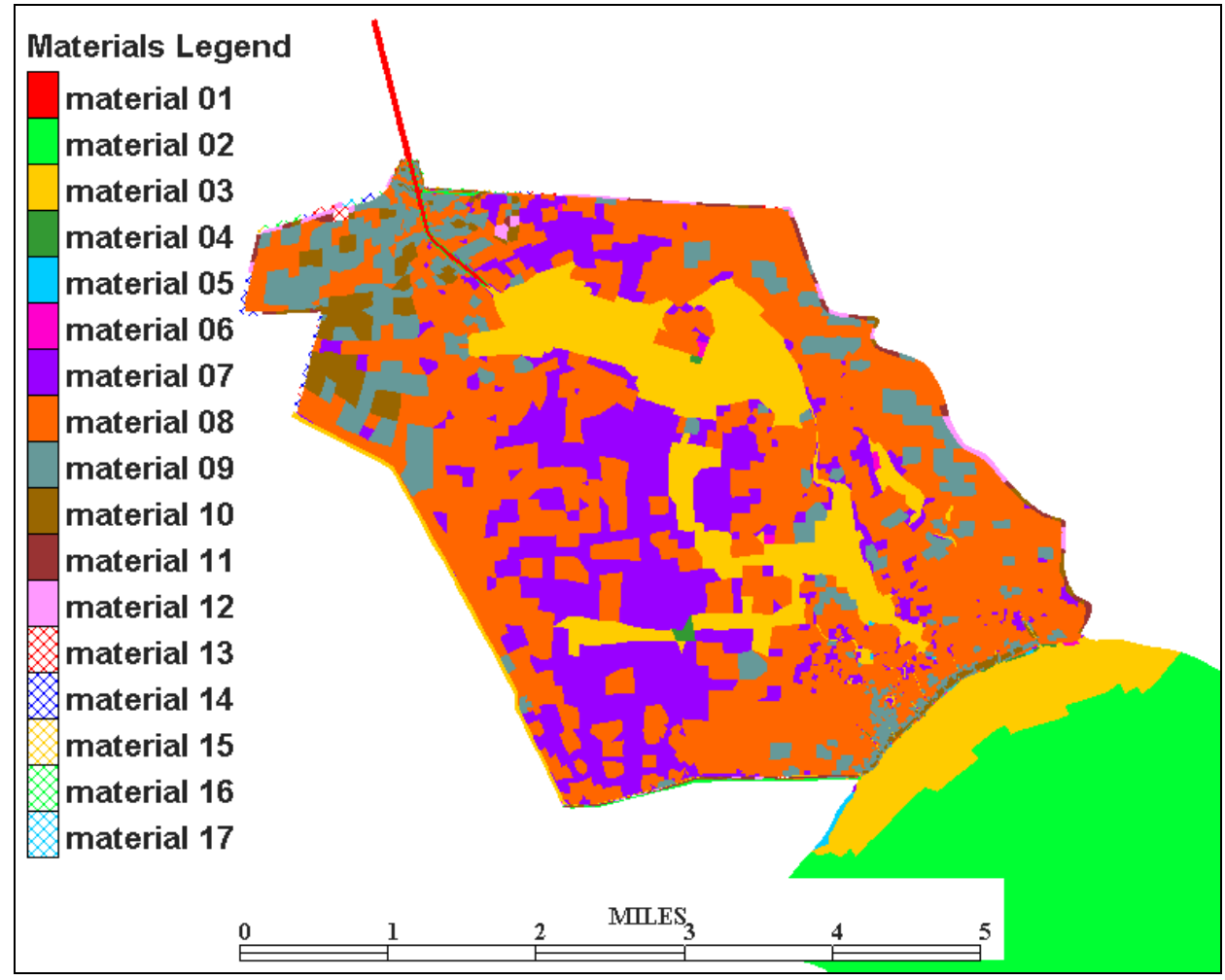

Figure 7 . Marsh porosity material types. 
Table 1. Marsh porosity values.

\begin{tabular}{|l|l|l|l|l|}
\hline Material Type & AC1 & AC2 & AC3 & AC4 \\
\hline 1 & 3.0 & 2 & 0.02 & 0 \\
\hline 2 & 3.0 & 2 & 0.02 & 0 \\
\hline 3 & 3.0 & 2 & 0.02 & 0 \\
\hline 4 & 3.0 & 2 & 0.02 & 0 \\
\hline 5 & 3.0 & 2 & 0.02 & 0 \\
\hline 6 & 3.0 & 2 & 0.02 & 0 \\
\hline 7 & 3.0 & 2 & 0.02 & 0 \\
\hline 8 & 3.0 & 2 & 0.02 & 0 \\
\hline 9 & 3.0 & 2 & 0.02 & 0 \\
\hline 10 & 4.0 & 2 & 0.02 & 0 \\
\hline 11 & 5.0 & 2 & 0.02 & 0 \\
\hline 12 & 6.0 & 2 & 0.02 & 0 \\
\hline 13 & 7.0 & 2 & 0.02 & 0 \\
\hline 14 & 8.0 & 2 & 0.02 & 0 \\
\hline 15 & 9.0 & 2 & 0.02 & 0 \\
\hline 16 & 10.0 & 2 & 0.02 & 0 \\
\hline 17 & 11.0 & 2 & 0.02 & 0 \\
\hline
\end{tabular}

Note: Marsh porosity values used in the numerical model (See Appendix A for an explanation of the meaning of $\mathrm{AC} 1, \mathrm{AC} 2, \mathrm{AC} 3$, and $\mathrm{AC} 4)$.

\section{Roughness specification}

This application of the model code also utilized bottom roughness as a function of the water depth. The mathematical form of the dependence of the Manning's friction coefficient with depth is

$$
n=\frac{n_{o}}{d^{\alpha}}+n_{v} e^{-d / d_{o}}
$$

where:

$$
\begin{aligned}
n_{o} & =\text { scaling friction factor for depth dependence } \\
d & =\text { water depth } \\
\alpha & =\text { exponent on depth dependence }
\end{aligned}
$$




$$
\begin{aligned}
n_{v}= & \text { scaling factor for exponential decay dependence (vegetative } \\
& \text { effects) } \\
d_{o}= & \text { reference depth for exponential decay. }
\end{aligned}
$$

This form was used in the model with two different sets of parameters: one in the channel areas and a separate set in the overbank areas. Figure 8 shows the material types used to specify the frictional values in the model, with Table 2 showing the actual values used in the model runs.

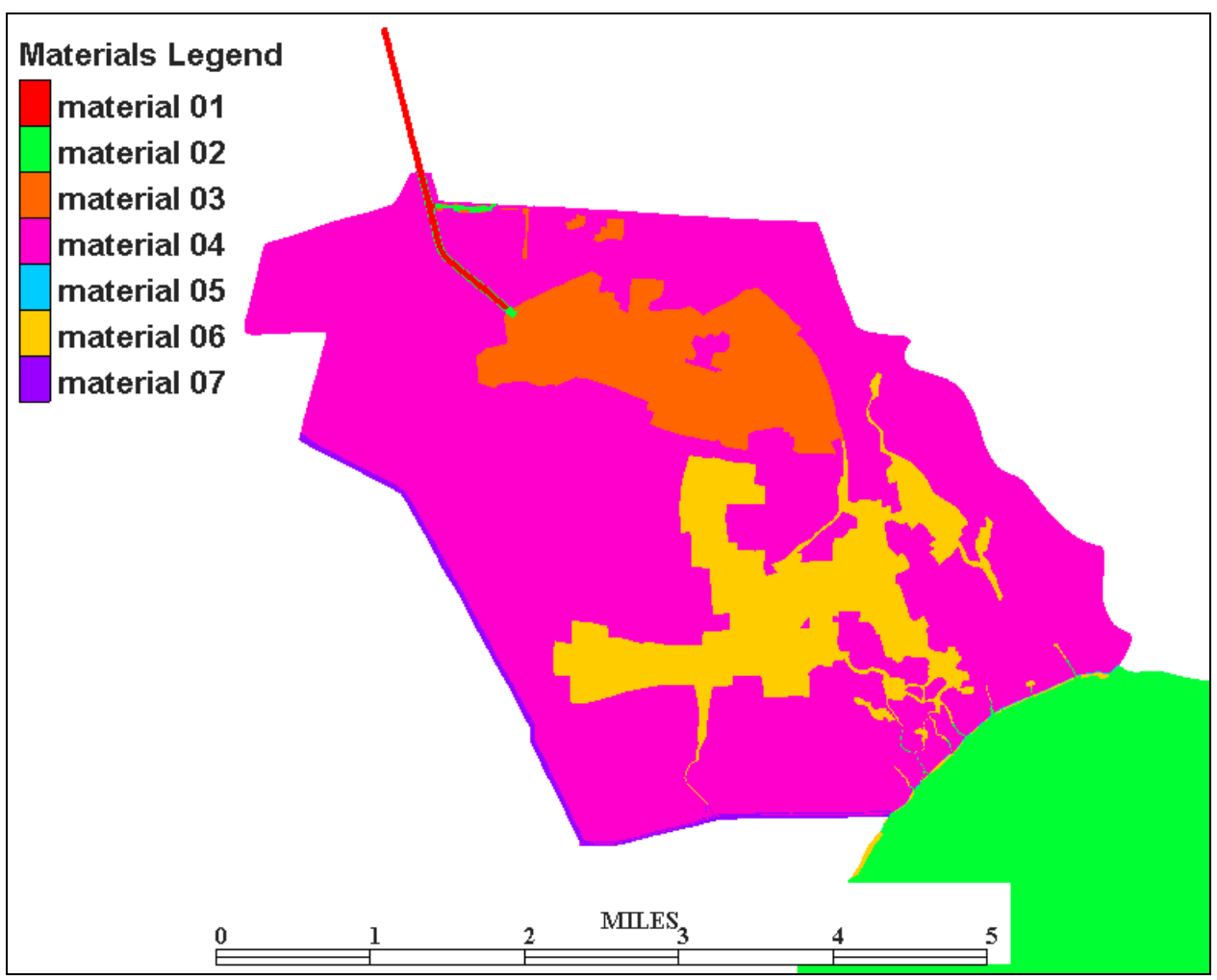

Figure 8. Frictional material types.

Table 2. Frictional values.

\begin{tabular}{|l|l|l|l|l|}
\hline Material Type & $n_{0}$ & $d_{0}$ & $n_{v}$ & $\alpha$ \\
\hline 1 & 0.06 & 1.00 & 0.10 & 0.05 \\
\hline 2 & 0.06 & 1.25 & 0.40 & 0.20 \\
\hline 3 & 0.06 & 1.00 & 0.40 & 0.20 \\
\hline 4 & 0.12 & 2.00 & 0.82 & 0.41 \\
\hline 5 & 0.12 & 2.50 & 0.82 & 0.41 \\
\hline 6 & 0.06 & 1.25 & 0.40 & 0.20 \\
\hline 7 & 0.12 & 2.25 & 0.82 & 0.41 \\
\hline
\end{tabular}




\section{Eddy viscosity specification}

The eddy viscosity was specified using the Péclet method. The equation for eddy viscosity using the Péclet method is

$$
P=\frac{\rho u d x}{E}
$$

where:

$$
\begin{aligned}
P & =\text { Péclet number } \\
\rho & =\text { fluid density } \\
u & =\text { average elemental velocity } \\
d x & =\text { length of element in streamwise direction } \\
E & =\text { eddy viscosity. }
\end{aligned}
$$

A global value of 15 was used for the Péclet number everywhere in the model domain.

\section{Boundary conditions development}

The boundary conditions for the model consisted of a tidal boundary at the lower end of Lake Cataouatche and an inflow at the Davis Pond freshwater diversion. Both of these boundaries were updated at the start of every halfhour time step. The data used at these boundaries were obtained from USGS gage measurements. The inflow applied was the observed flow at a USGS gage located in the diversion canal near Highway 90. The Lake Cataouatche tidal gage was located on the eastern shore of Lake Cataouatche. The locations of these gages are shown in Figure 9. A plot of the inflow and tidal boundary conditions applied to the model is shown in Figure 10. The Lake Cataouatche gage data plotted in Figure 10 were obtained by shifting the raw Lake Cataouatche data up by $0.9 \mathrm{ft}$. (See Appendix B for an indepth explanation of the reasoning behind this shift.) A Hamming filter was also applied to the data to remove any noise in the observed signal. 


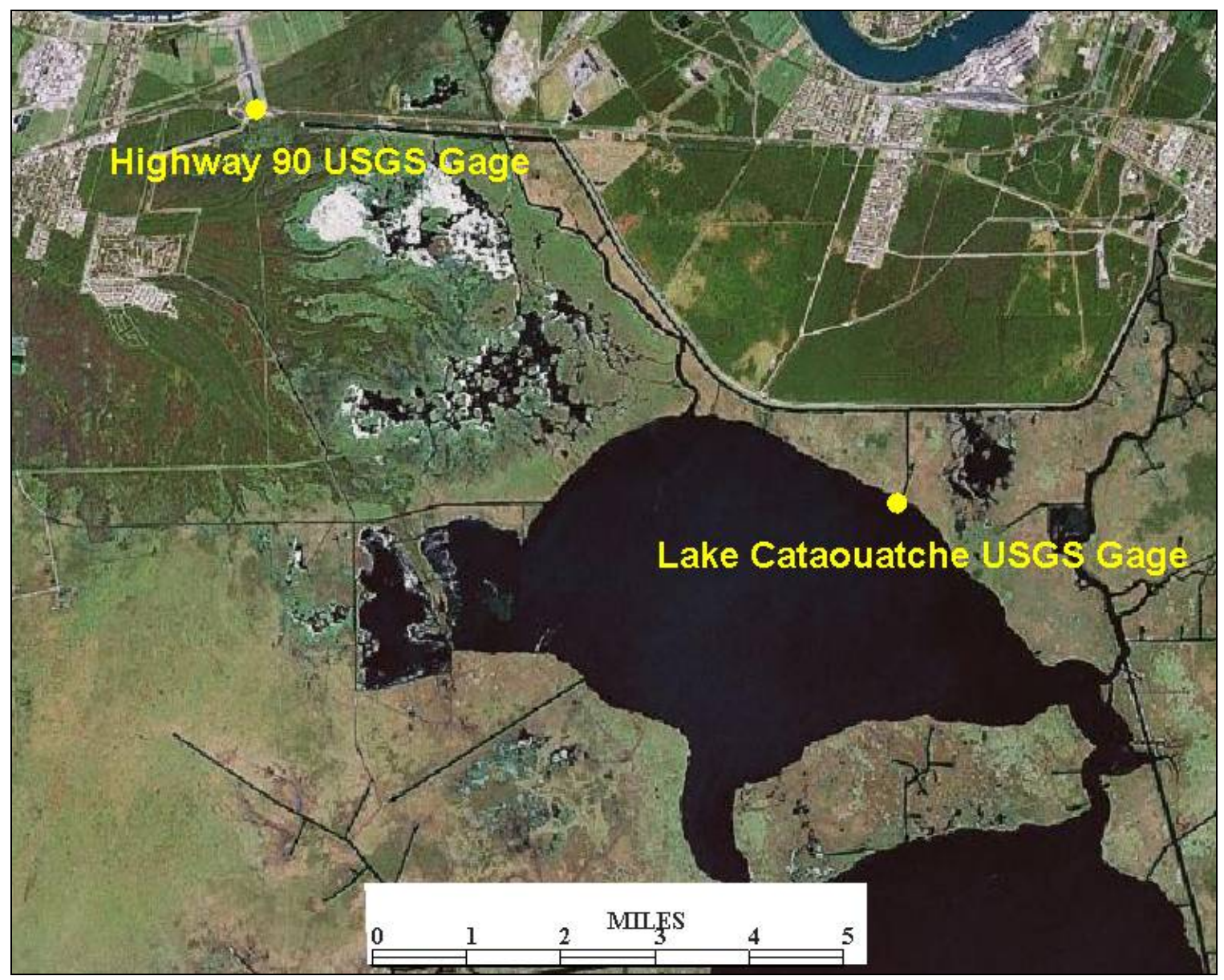

Figure 9. Location of USGS gages.

A comparison was made to ensure the validity of applying the Lake Cataouatche observed gage values at the southern boundary of the model domain. The plot in Figure 11 is a comparison plot of the Lake Cataouatche observed data (applied at the boundary) and the model results at the location of the Lake Cataouatche USGS gage. The plot shows little tidal variation between the boundary and the USGS gage location. Therefore, it was assumed that no significant error was introduced by applying the Lake Cataouatche gage data at the model boundary. The boundary conditions for the alternative runs consisted of a steady-state inflow with a constant water level in Lake Cataouatche of 1.3 ft NAVD88 and the design inflow of 10,650 cfs. 


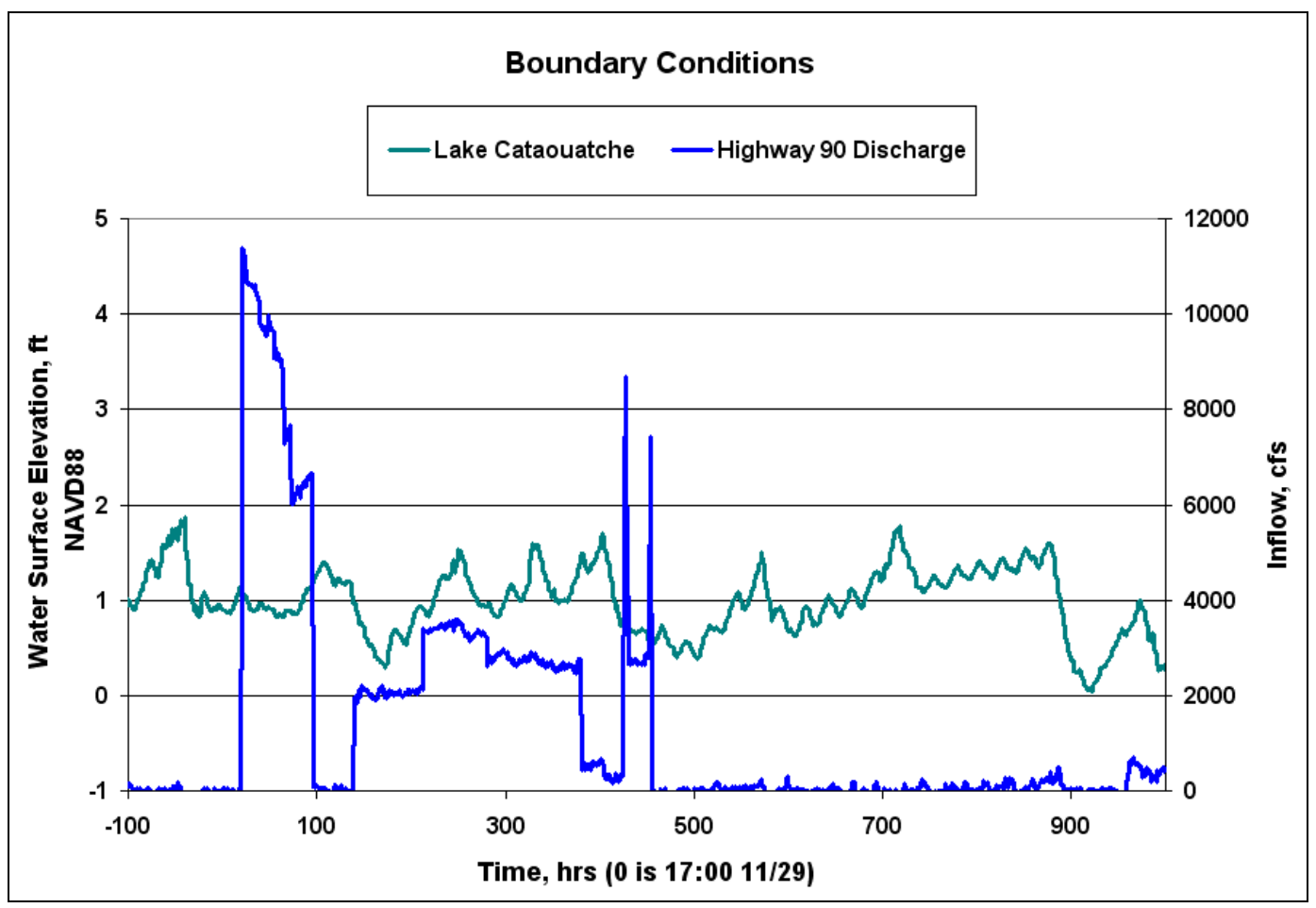

Figure 10. Plot of the boundary conditions.

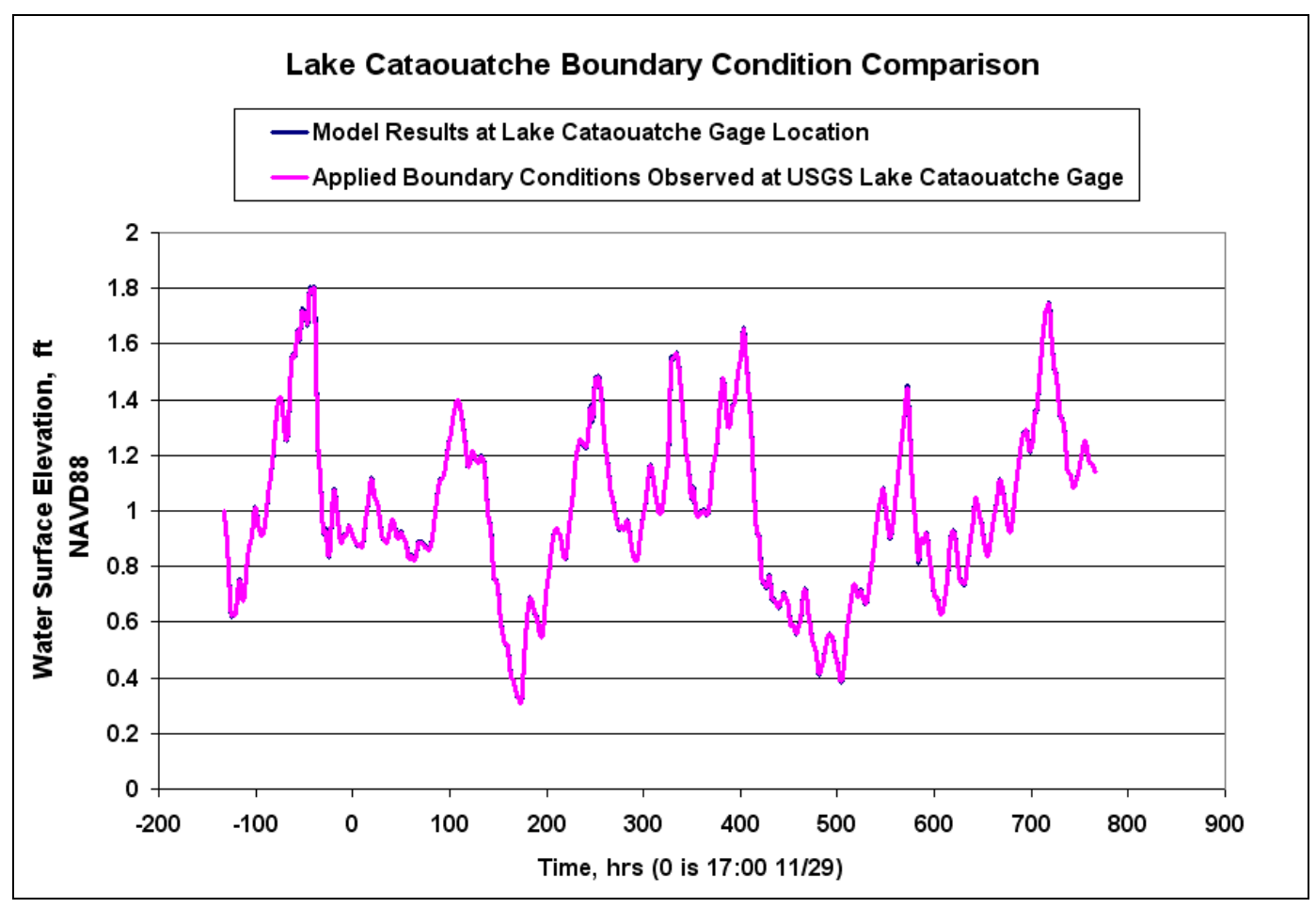

Figure 11. Comparison to ensure no significant effects due to applying the Lake Cataouatche gage data at the tidal boundary. 


\section{Hydrodynamic model validation}

Comparisons between the observed gage measurements and the model results are shown in Figures 12-22. The pink lines are the adjusted field data. The grey haze above and below the field data line represents the uncertainty ( $\pm 0.2 \mathrm{ft})$ in the vertical datums (see Appendix B). The purple lines are the model results. The model results are in good agreement with the observed gage data, with the model results rarely extending beyond the uncertainty bounds. The gage locations were shown previously in Figure 3 .

The comparisons for the Highway 90 gage and Gage 23 (Figures 12 and 16, respectively) are the only ones that are not consistently inside the error bounds. It is believed that the Highway 90 gage's close proximity to the model inflow boundary, along with the crudeness of the outflow canal's geometry (a trapezoidal channel approximated as a square channel), is the reason for this unfavorable comparison. Because Gage 20 (Figure 13) compares very well, it is assumed that this error at Highway 90 does not propagate very far into the system and, therefore, is of little concern to the overall behavior of the system. Gage 23 is located close to the gabion weir, where the water level has a greater slope. Therefore, any slight uncertainty in the gage location can have a significant effect in the measured water levels. Also, because the gage is near to the gabion weir, it is possible that supercritical flow is occurring. RMA2 is unable to model supercritical flow, so it would create a higher water level to compensate. Since Gages 27 and 28 (Figures 17 and 18, respectively) compare well, it is believed that if there is an error in the model results, it is localized at the gabion weir and does not affect the results farther into the system. 


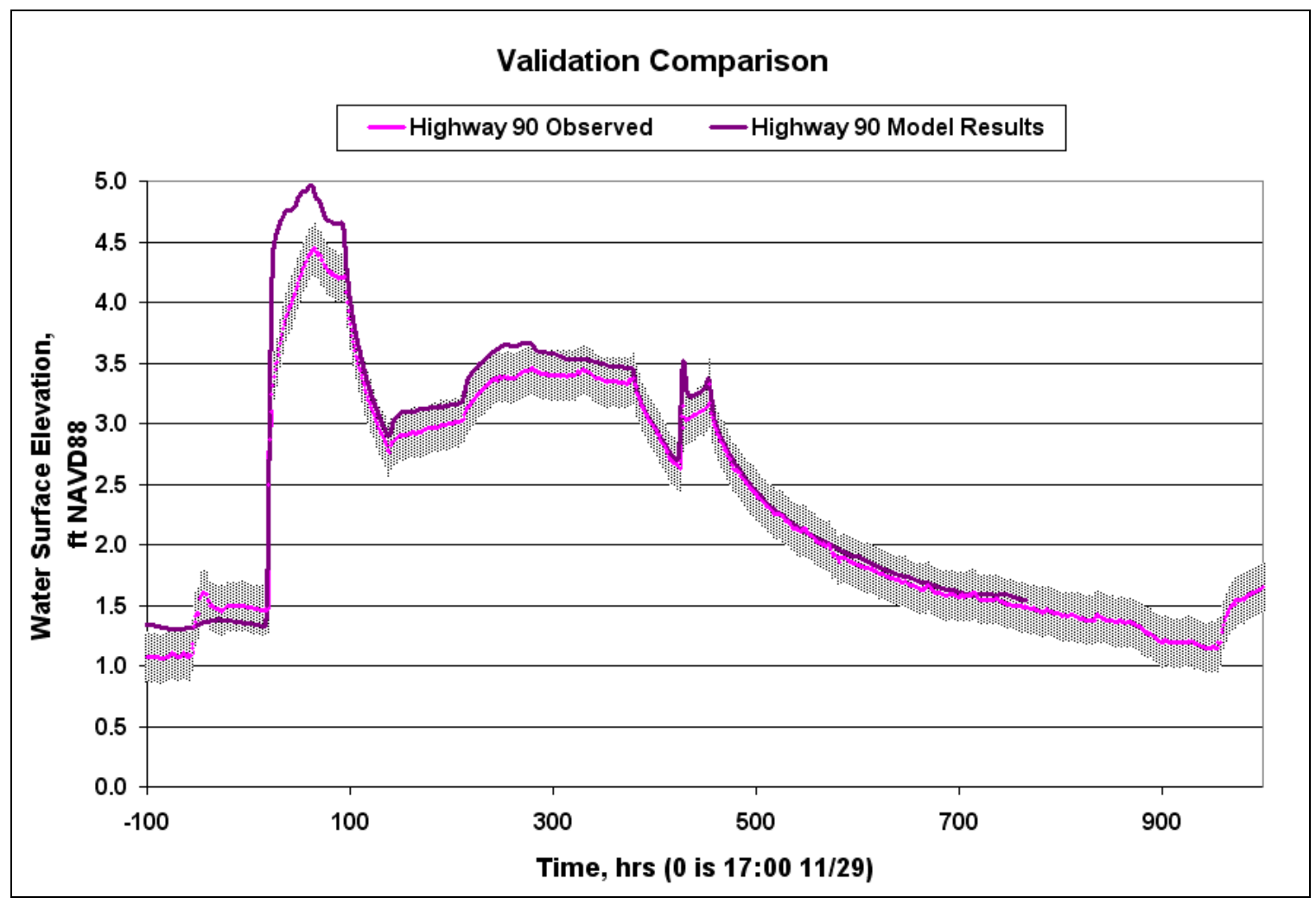

Figure 12. Plot of the validation comparison at the Highway 90 gage.

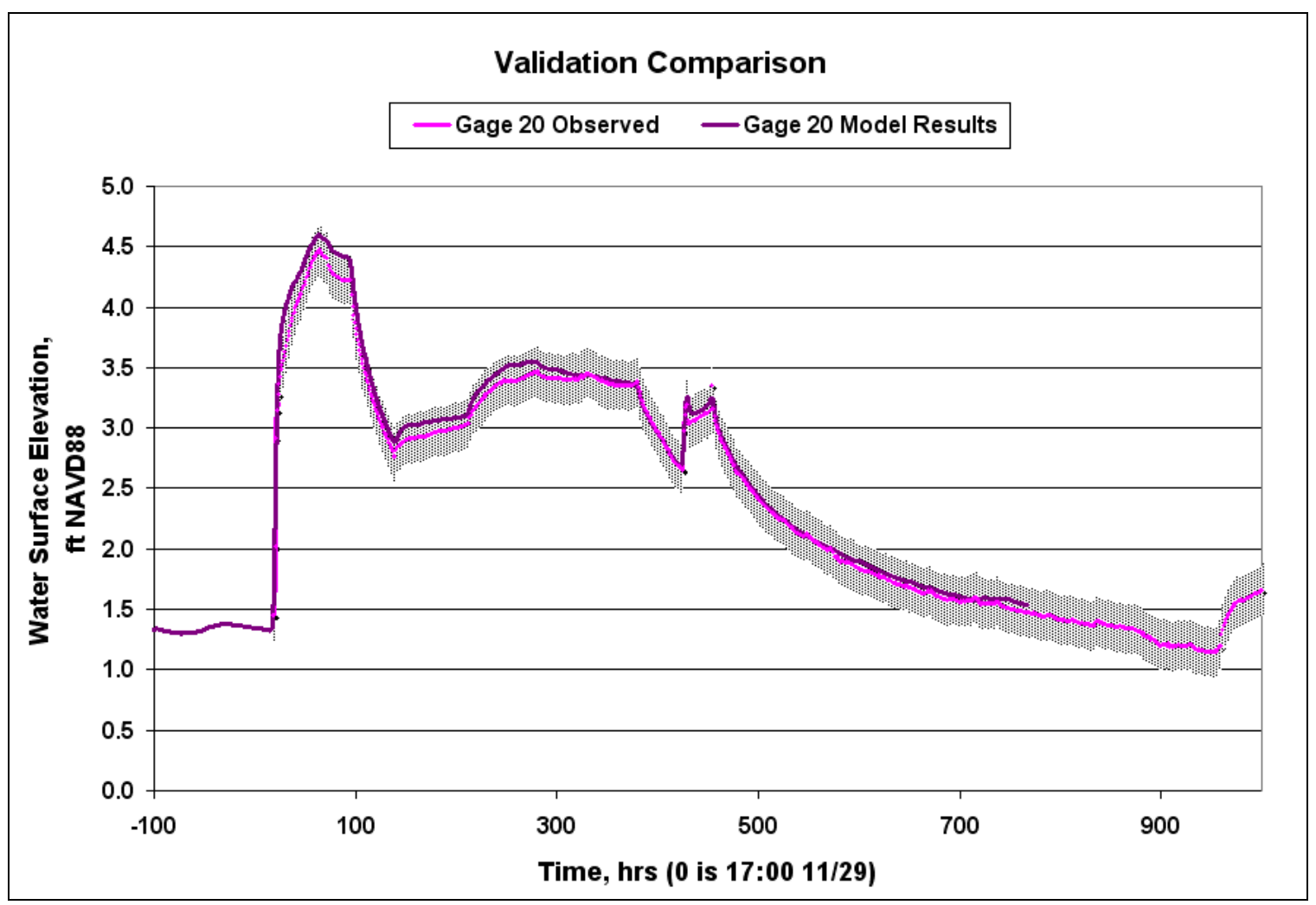

Figure 13. Plot of the validation comparison at Gage 20. 


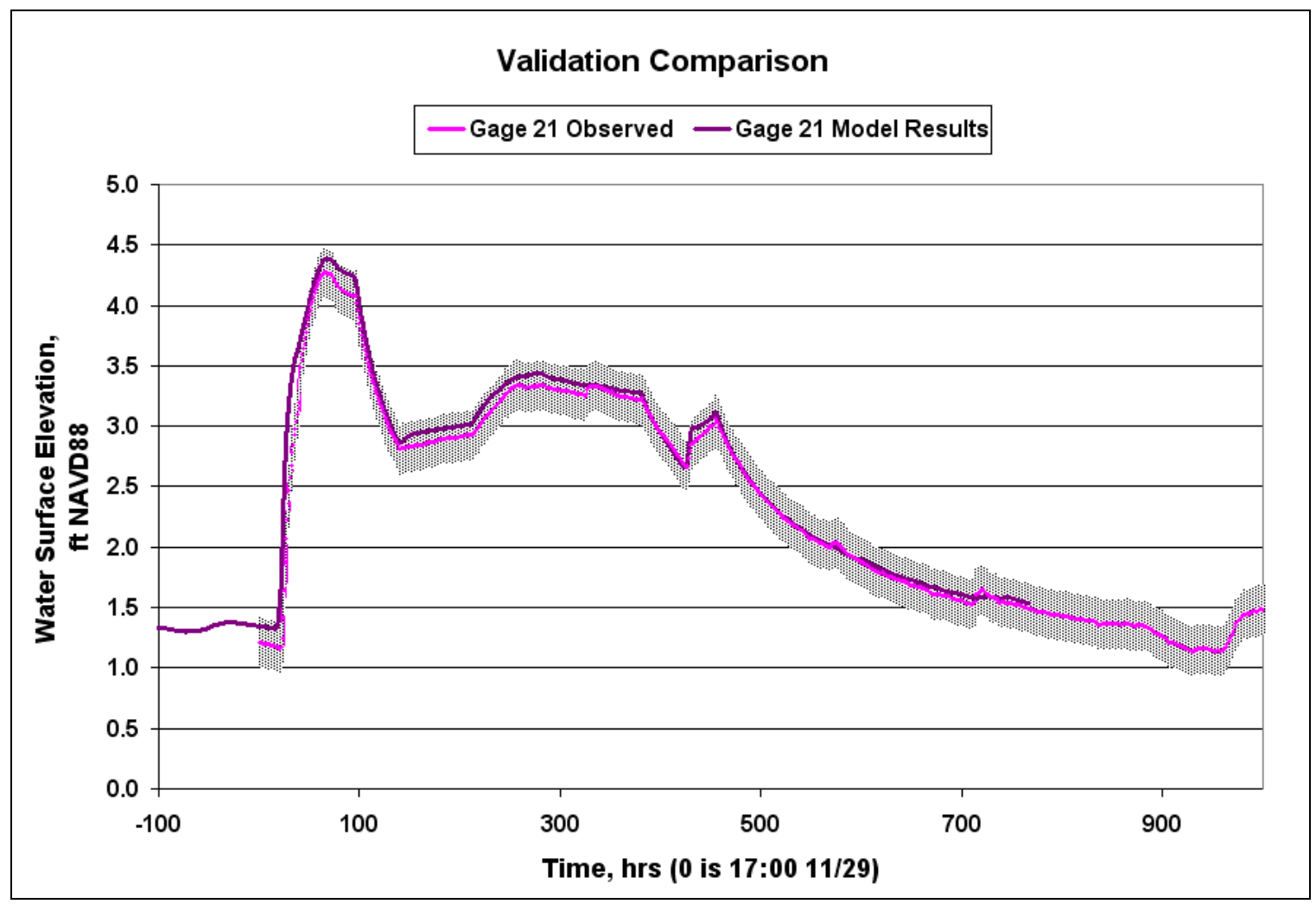

Figure 14. Plot of the validation comparison at Gage 21.

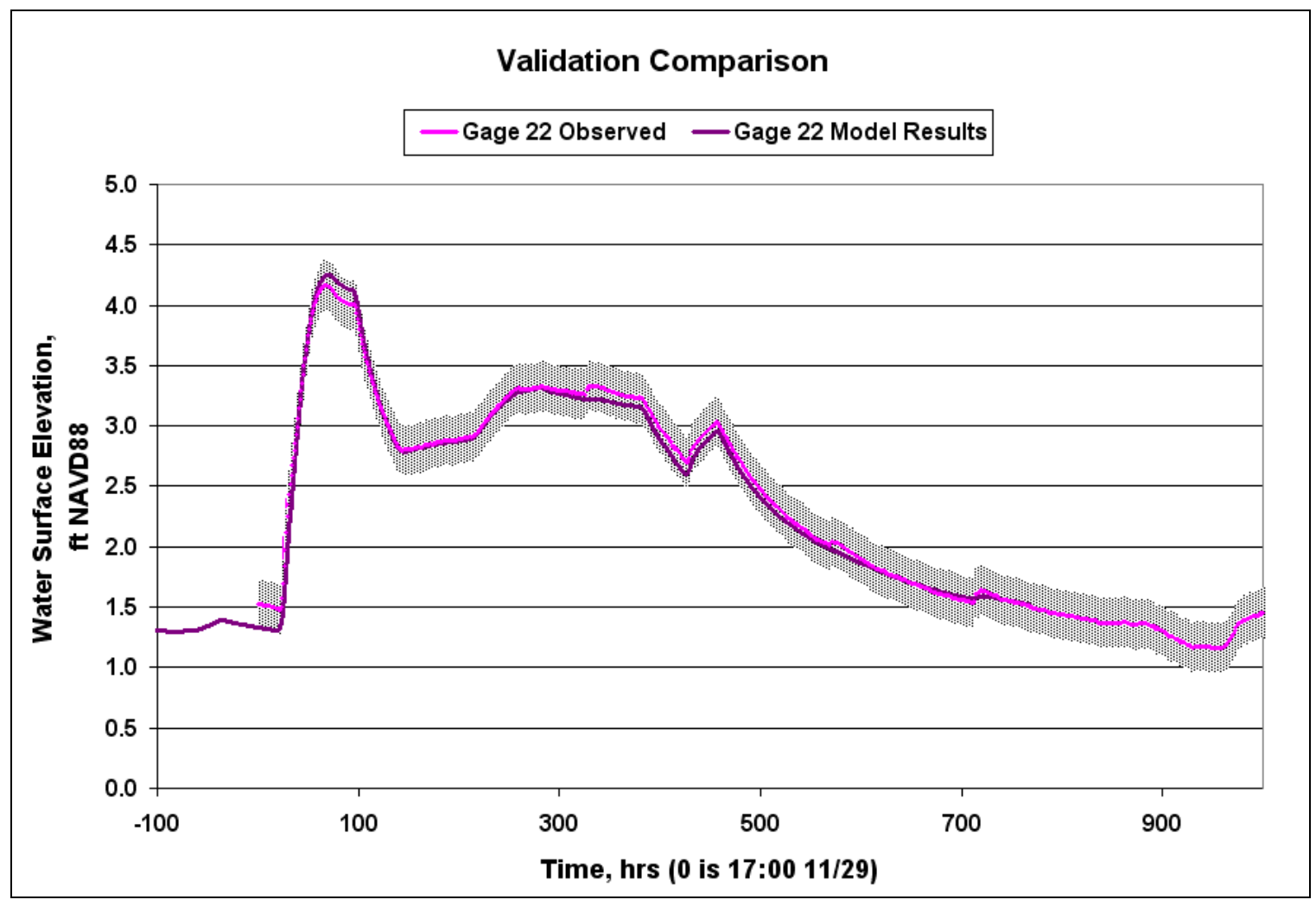

Figure 15. Plot of the validation comparison at Gage 22. 


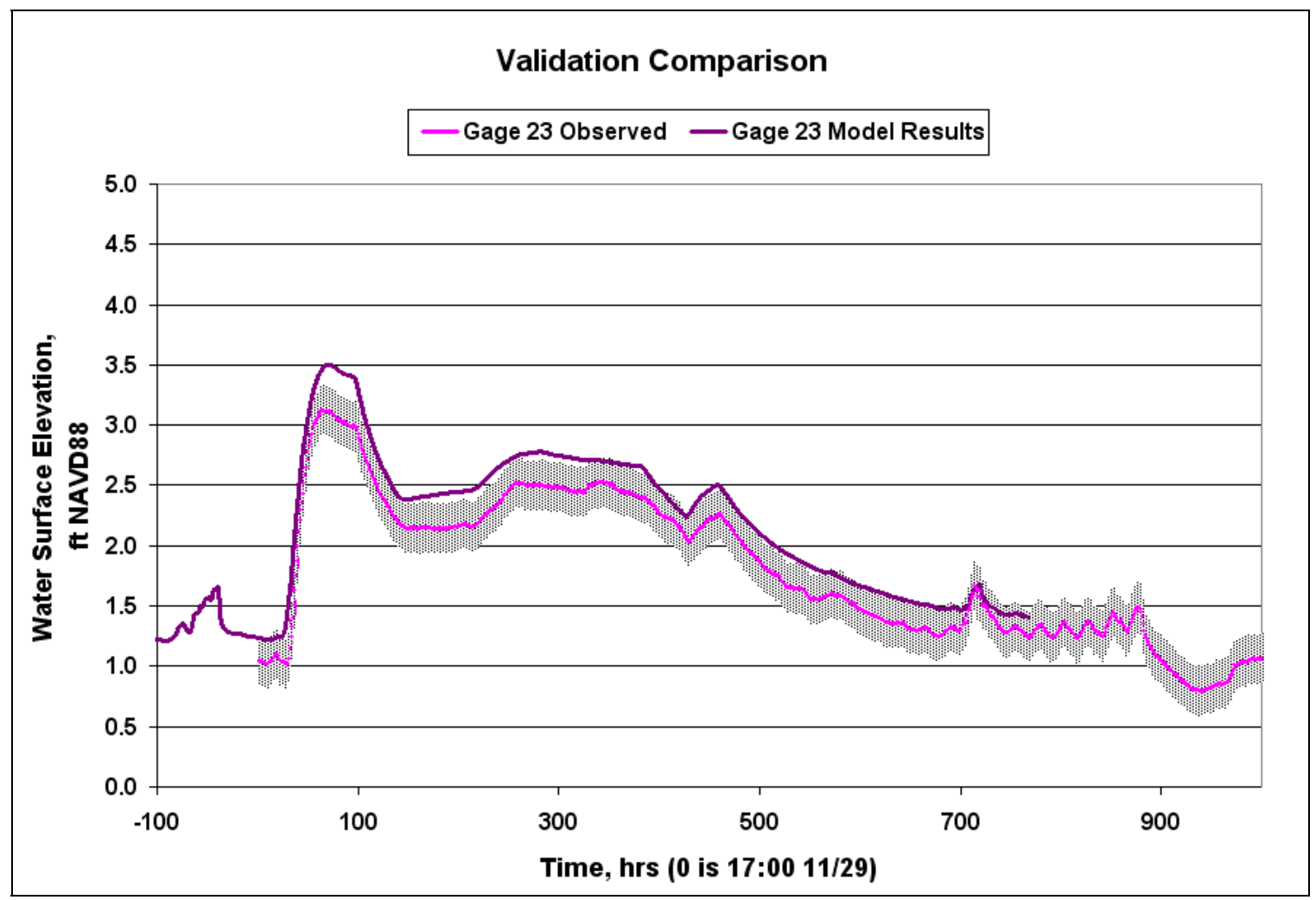

Figure 16. Plot of the validation comparison at Gage 23.

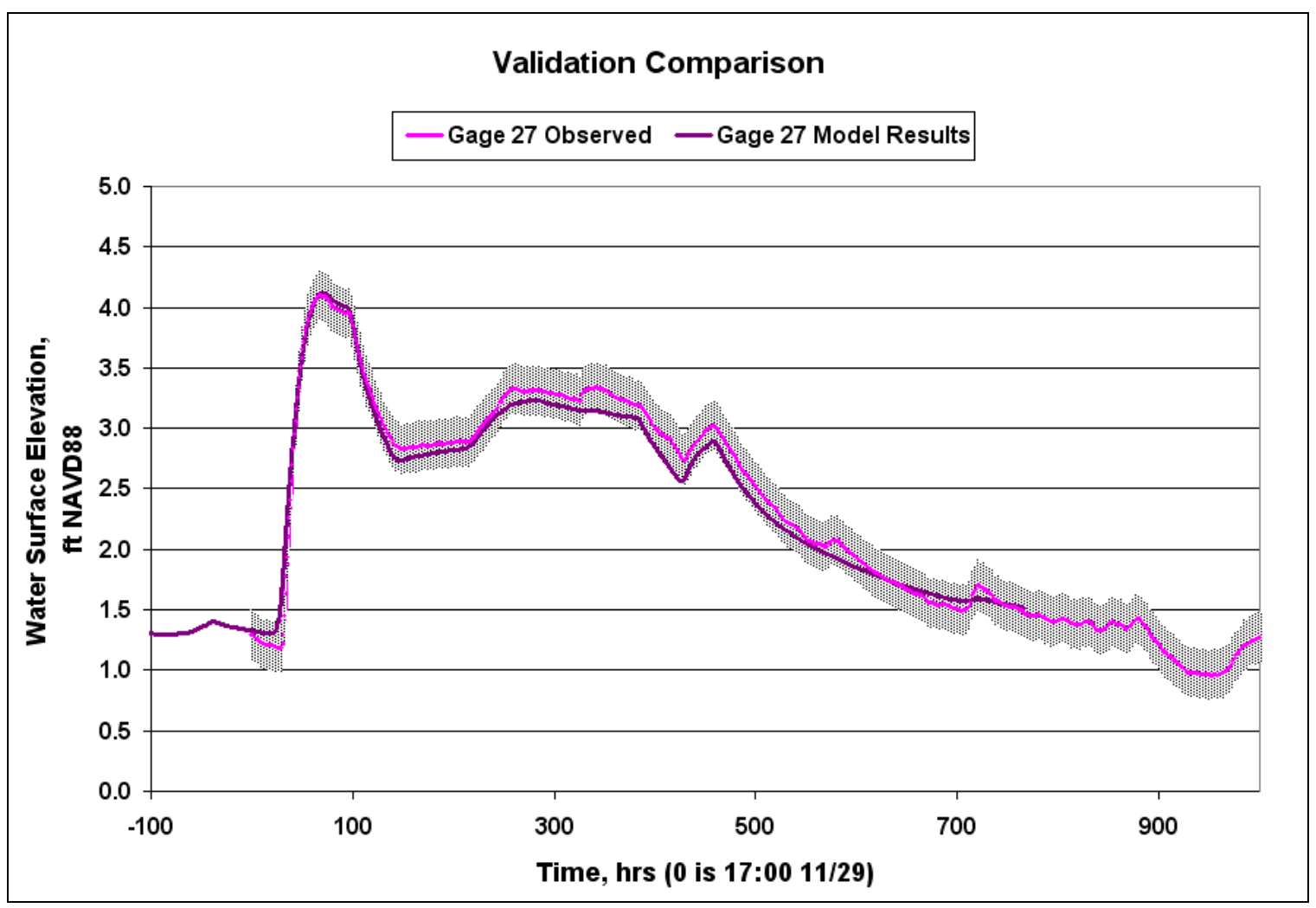

Figure 17. Plot of the validation comparison at Gage 27. 


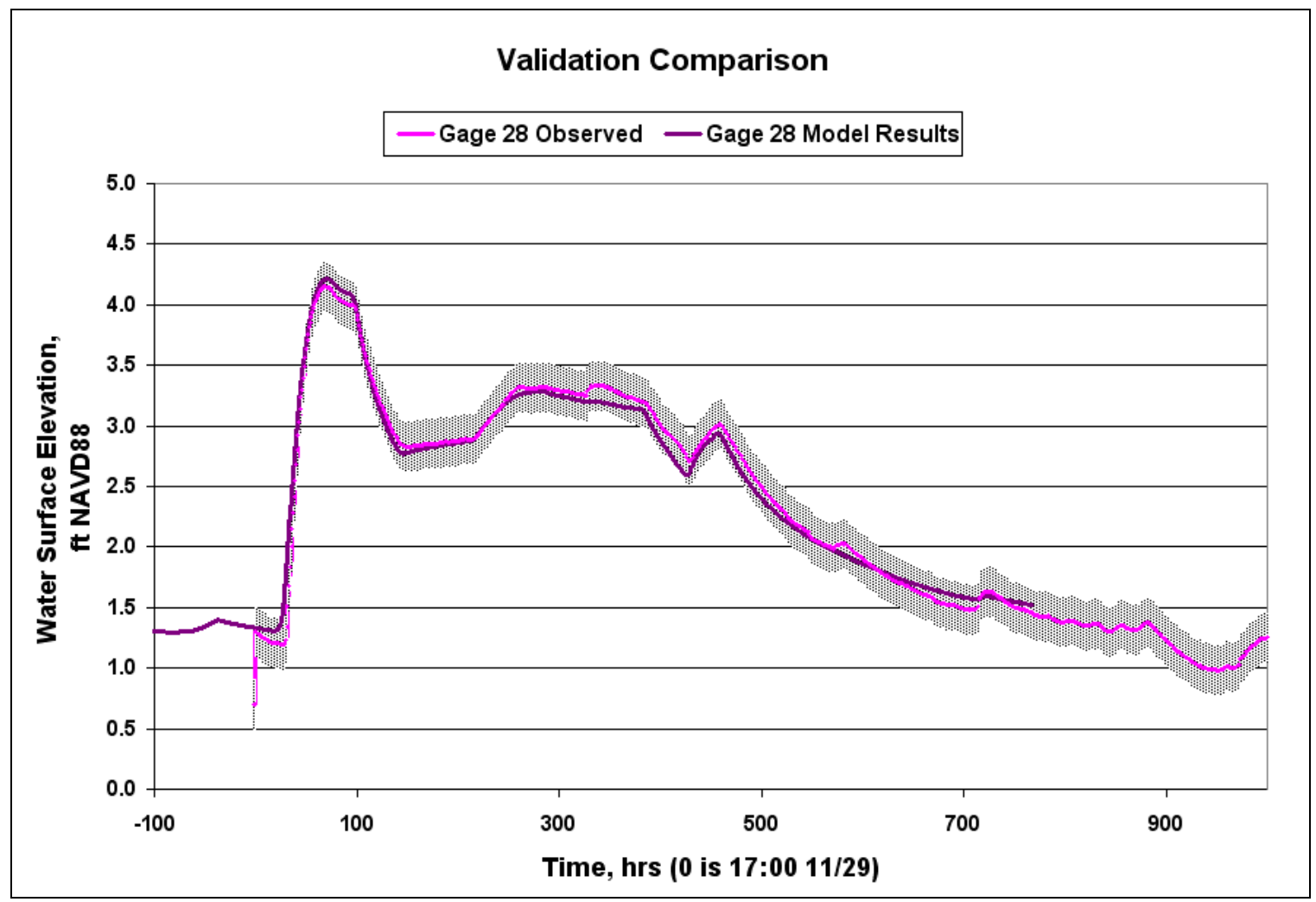

Figure 18. Plot of the validation comparison at Gage 28.

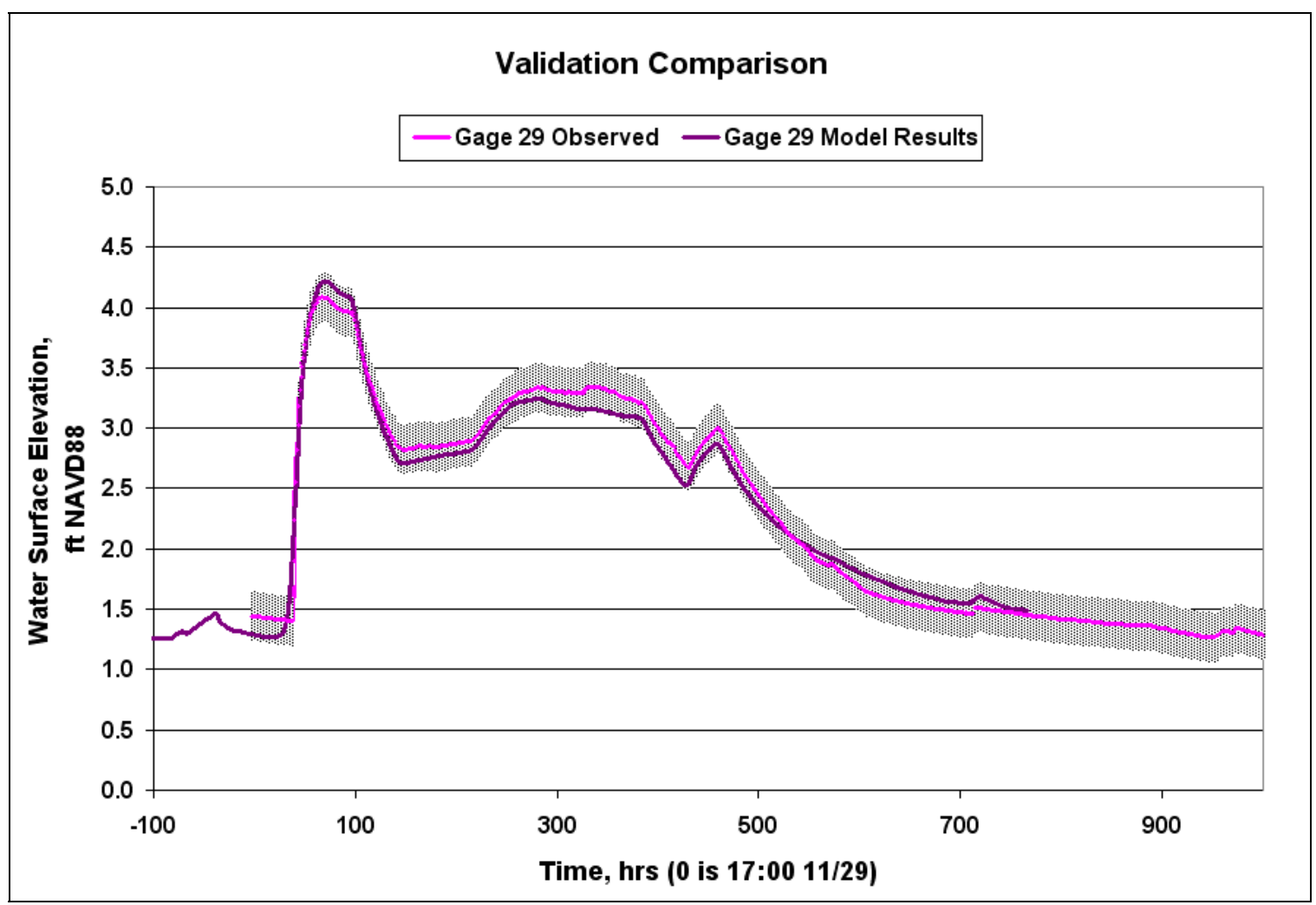

Figure 19. Plot of the validation comparison at Gage 29. 


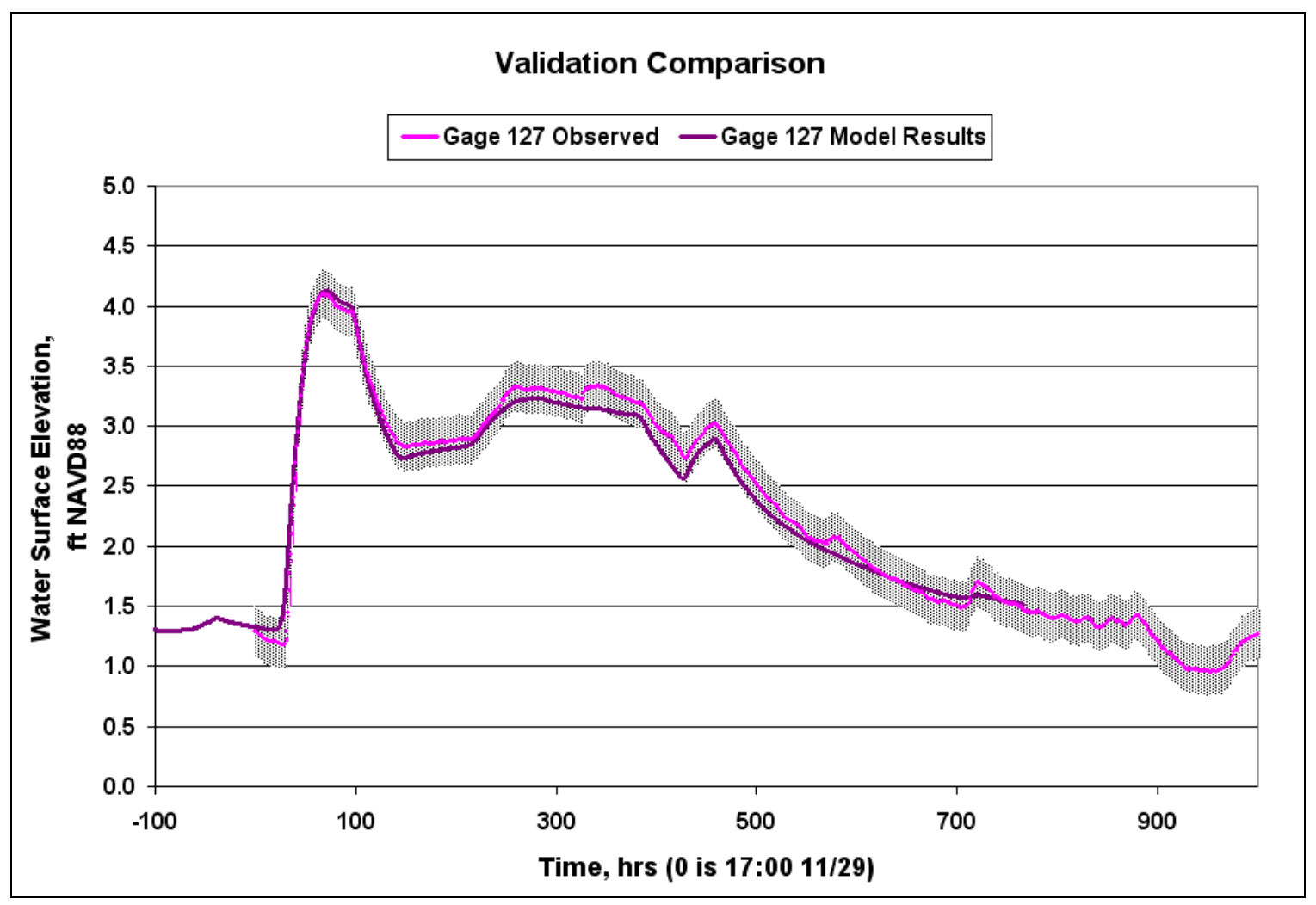

Figure 20. Plot of the validation comparison at Gage 127.

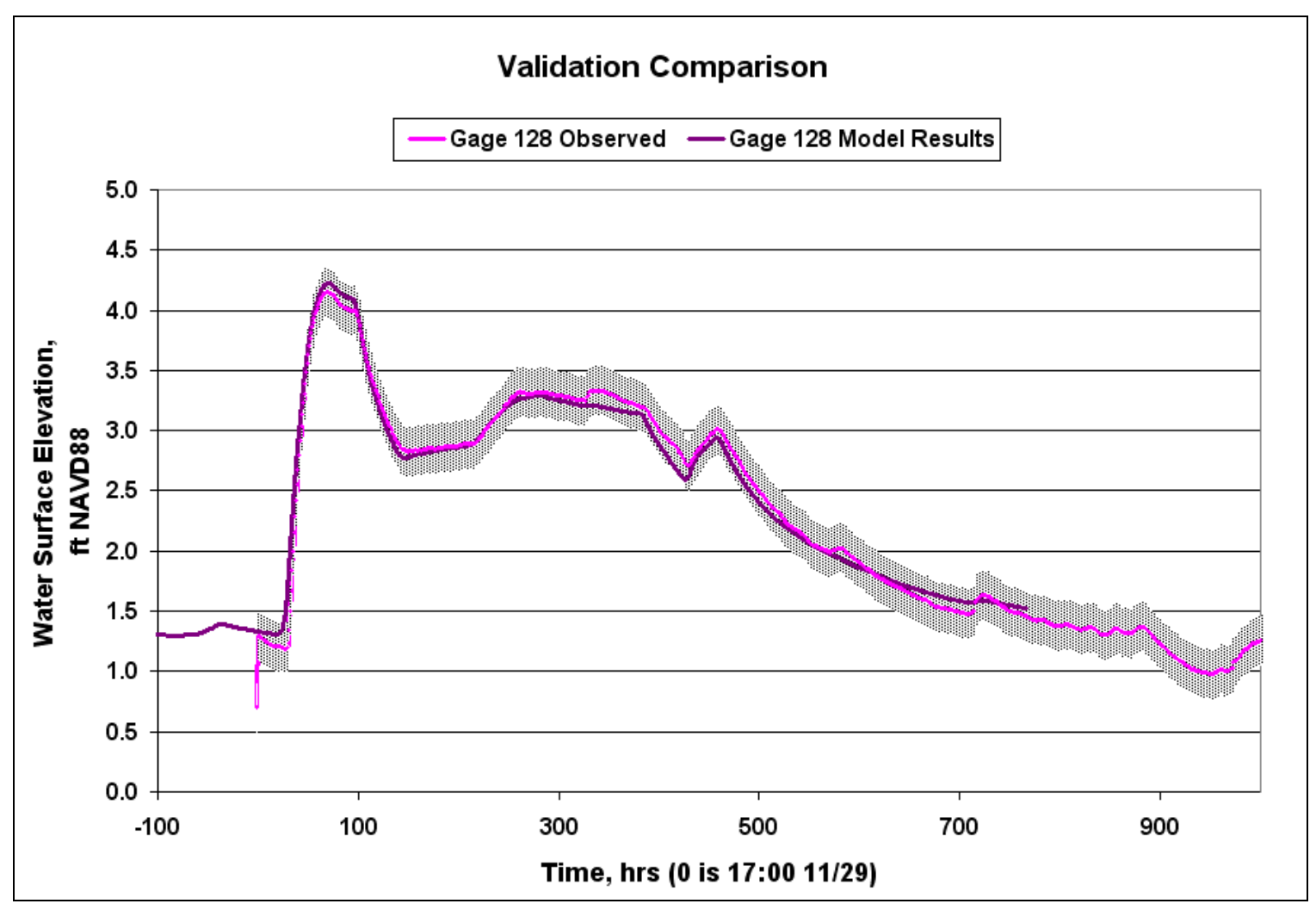

Figure 21. Plot of the validation comparison at Gage 128. 


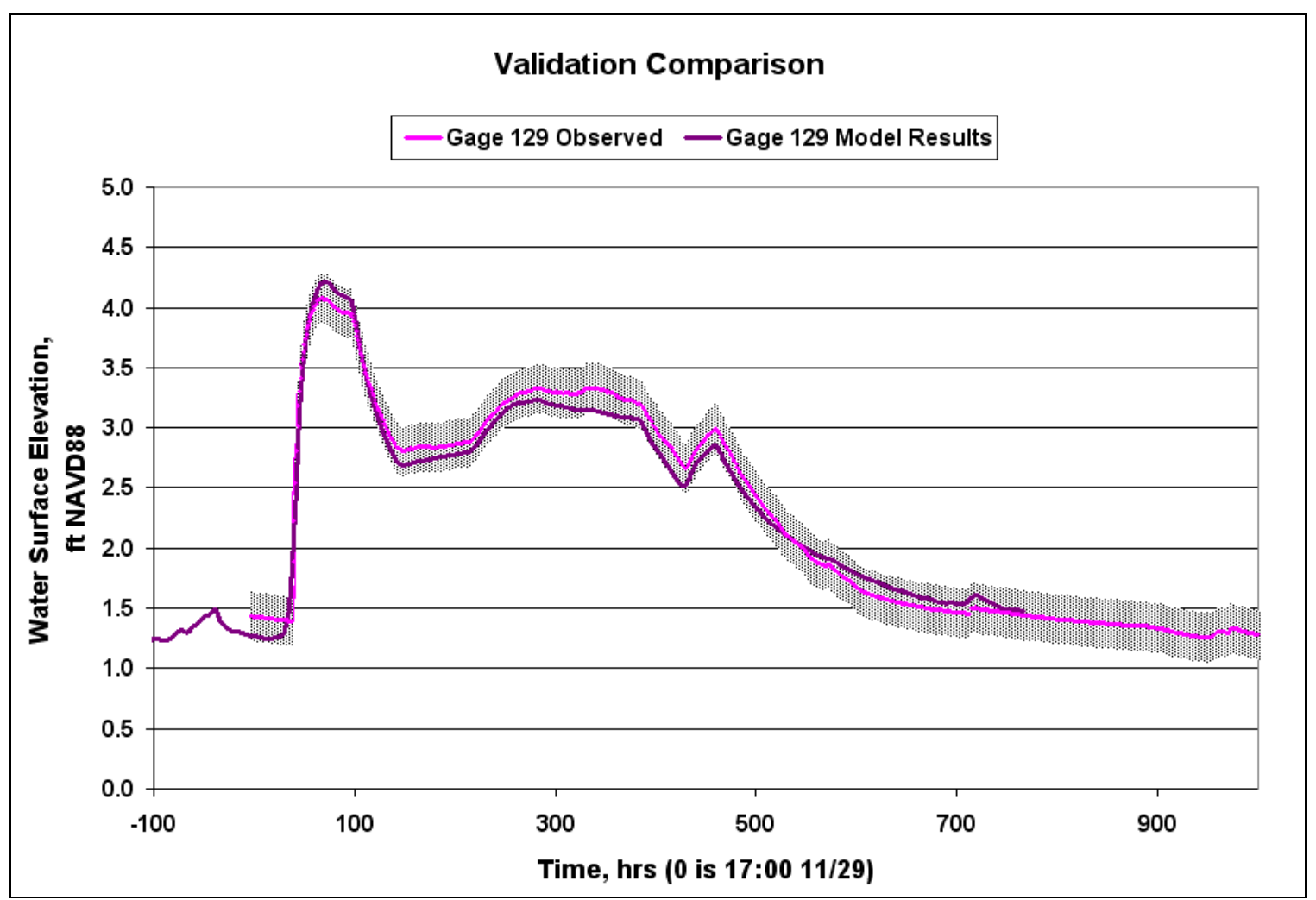

Figure 22. Plot of the validation comparison at Gage 129.

\section{Design alternatives}

Alternatives 1-3 consisted of extending the diversion channel toward the gabion weir using different channel paths. Alternatives 4-6 consisted of modifications to the outflow channels and the gabion weir to allow for more flow into Lake Cataouatche. Alternatives 7-8 consisted of testing the benefits of breaches in the Cypress Lumber Canal. The first eight alternatives were used to test the effects of different modifications individually. From the results of the eight initial alternatives, four additional alternatives were created to determine cumulative effects. Contour plots of the bathymetry of the different alternatives are shown in Figures 23-34. 
Alternative 1 (Figure 23) is the base/existing case (Figure 6) with the diversion canal extended down to a location approximately 2,000 ft upstream of the natural ridge. This channel configuration was chosen in a way that utilizes existing channels as much as possible. The channel has a bottom width of $120 \mathrm{ft}$ with 1 on 3 side slopes. The initial channel invert is $-17 \mathrm{ft}$ NAVD88, with a gradual sloping to $-18 \mathrm{ft}$ NAVD88 at its termination $2,000 \mathrm{ft}$ upstream of the natural ridge.

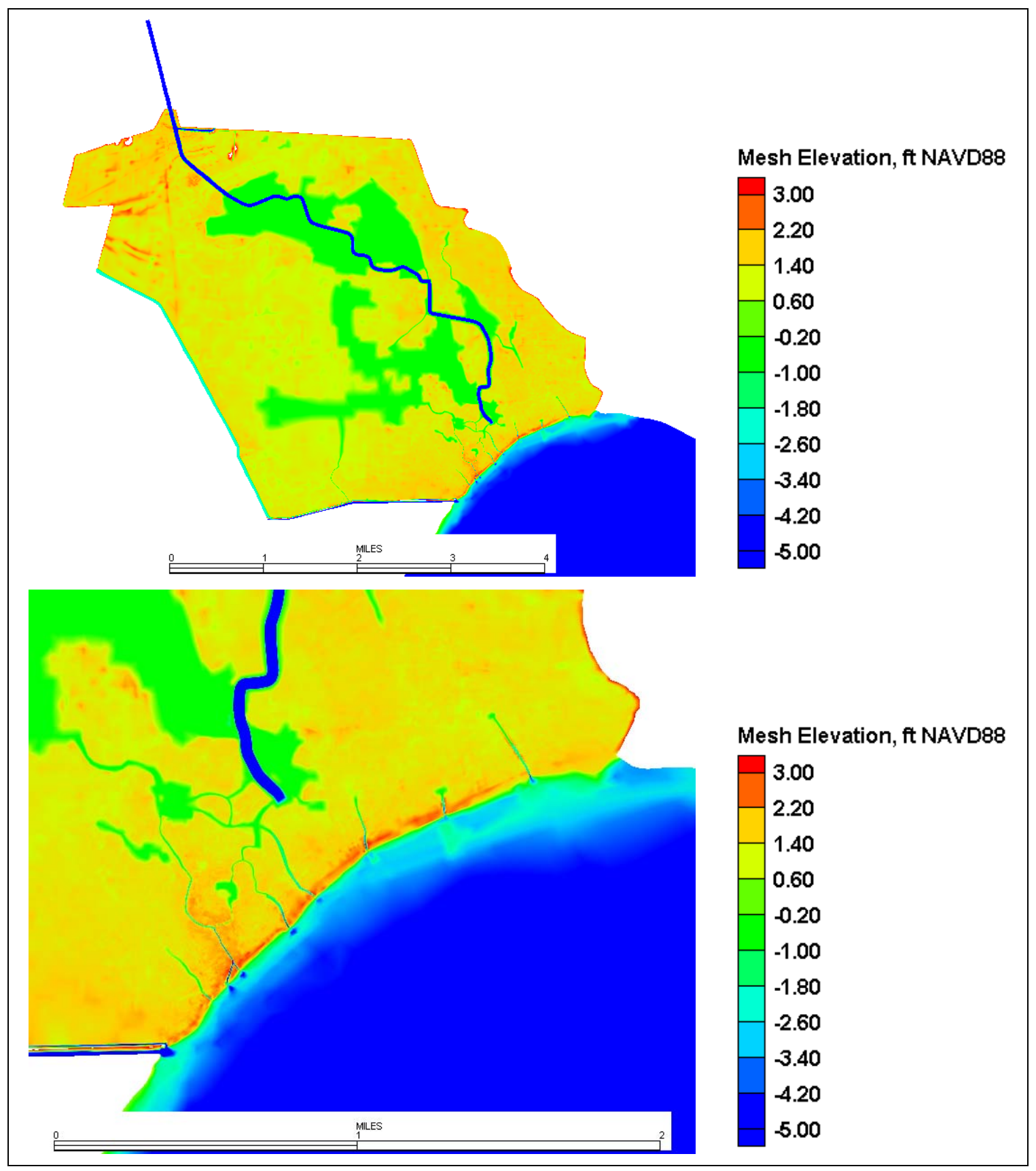

Figure 23. Contour plots of Alternative 1. 
Alternative 2 (Figure 24) is the base case with the diversion canal extended down to a location approximately 4,000 $\mathrm{ft}$ upstream of the natural ridge. This channel configuration was chosen in a way that utilizes existing channels as much as possible. The channel has a bottom width of $120 \mathrm{ft}$ with 1 on 3 side slopes. The initial channel invert is $-17 \mathrm{ft} \mathrm{NAVD88,} \mathrm{with} \mathrm{a}$ gradual sloping to $-18 \mathrm{ft}$ NAVD88 at its termination 4,000 $\mathrm{ft}$ upstream of the natural ridge. Alternative 2 is Alternative 1 with the diversion canal terminating $2,000 \mathrm{ft}$ farther upstream of the gabion weir.

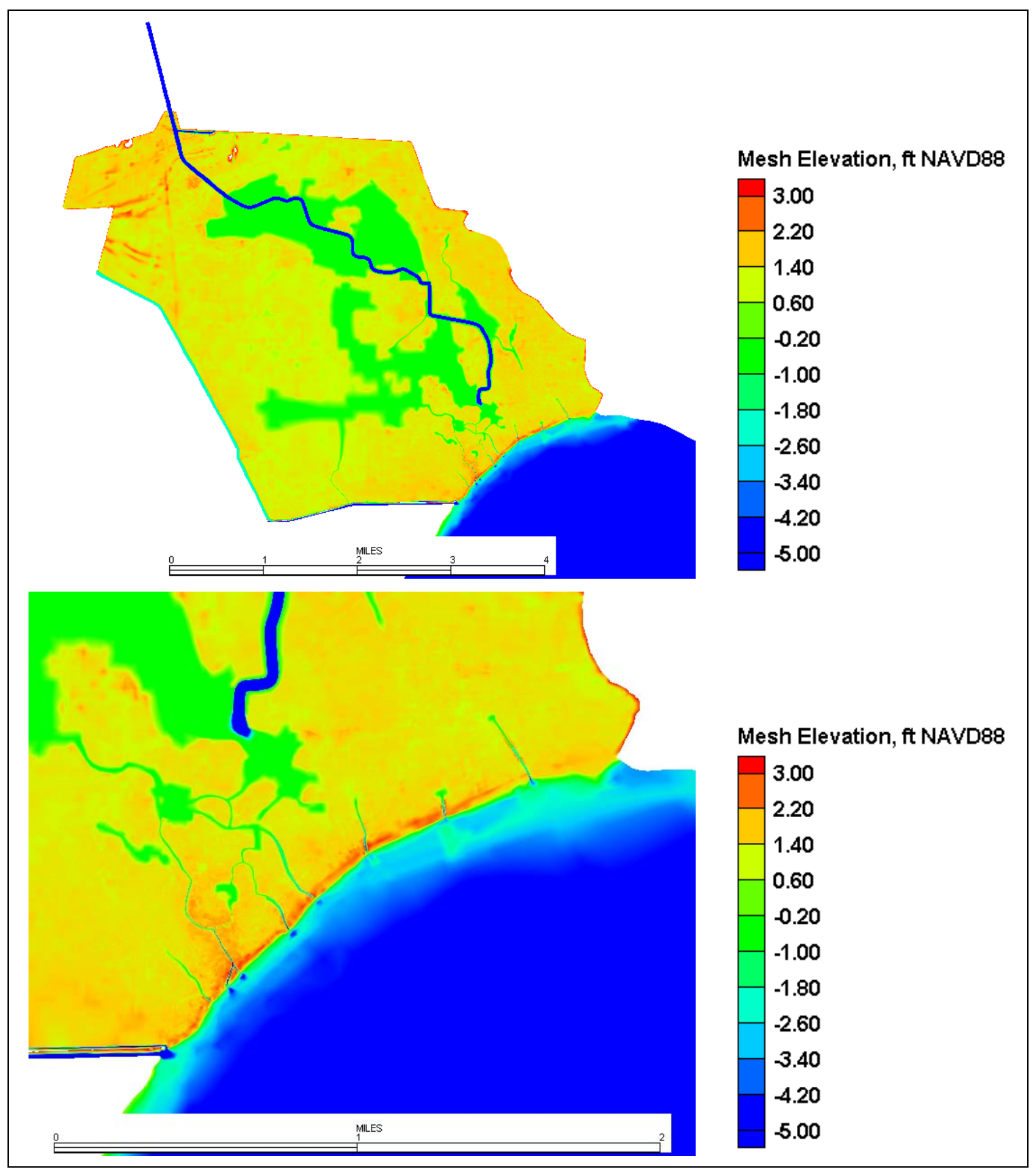

Figure 24. Contour plots of Alternative 2. 
Alternative 3 (Figure 25) is the base case with the diversion canal extended down to a location approximately 4,000 $\mathrm{ft}$ upstream of the natural ridge. This channel configuration is a straight line from the termination of the existing diversion channel to a point 4,000 $\mathrm{ft}$ upstream of the natural ridge. The termination point for Alternatives 2 and 3 are identical, with only the channel paths being different.

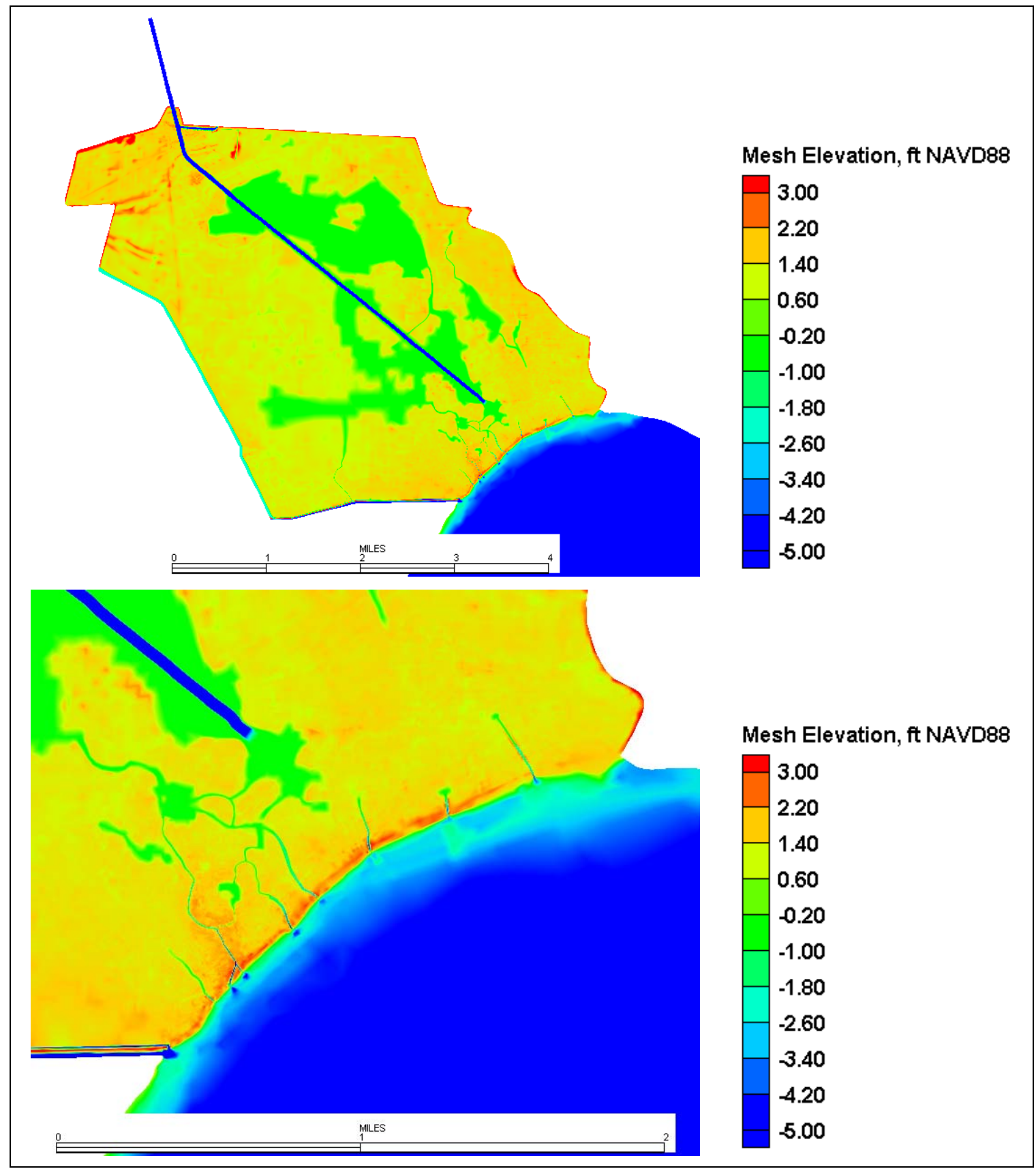

Figure 25. Contour plots of Alternative 3. 
Alternative 4 (Figure 26) is the base case with nine 85-ft-wide cuts in the natural ridge and gabion weir. The cuts were made to an elevation of $-1.5 \mathrm{ft}$ NAVD88 ( $-6 \mathrm{ft}$ for the Cypress Lumber Canal Cut). The approach channels for these cuts were also deepened to $\mathbf{- 1 . 5} \mathrm{ft}$ for a distance of approximately $2,000 \mathrm{ft}$ upstream of the gabion weir. The side slopes for the channels were 1 on 3 .

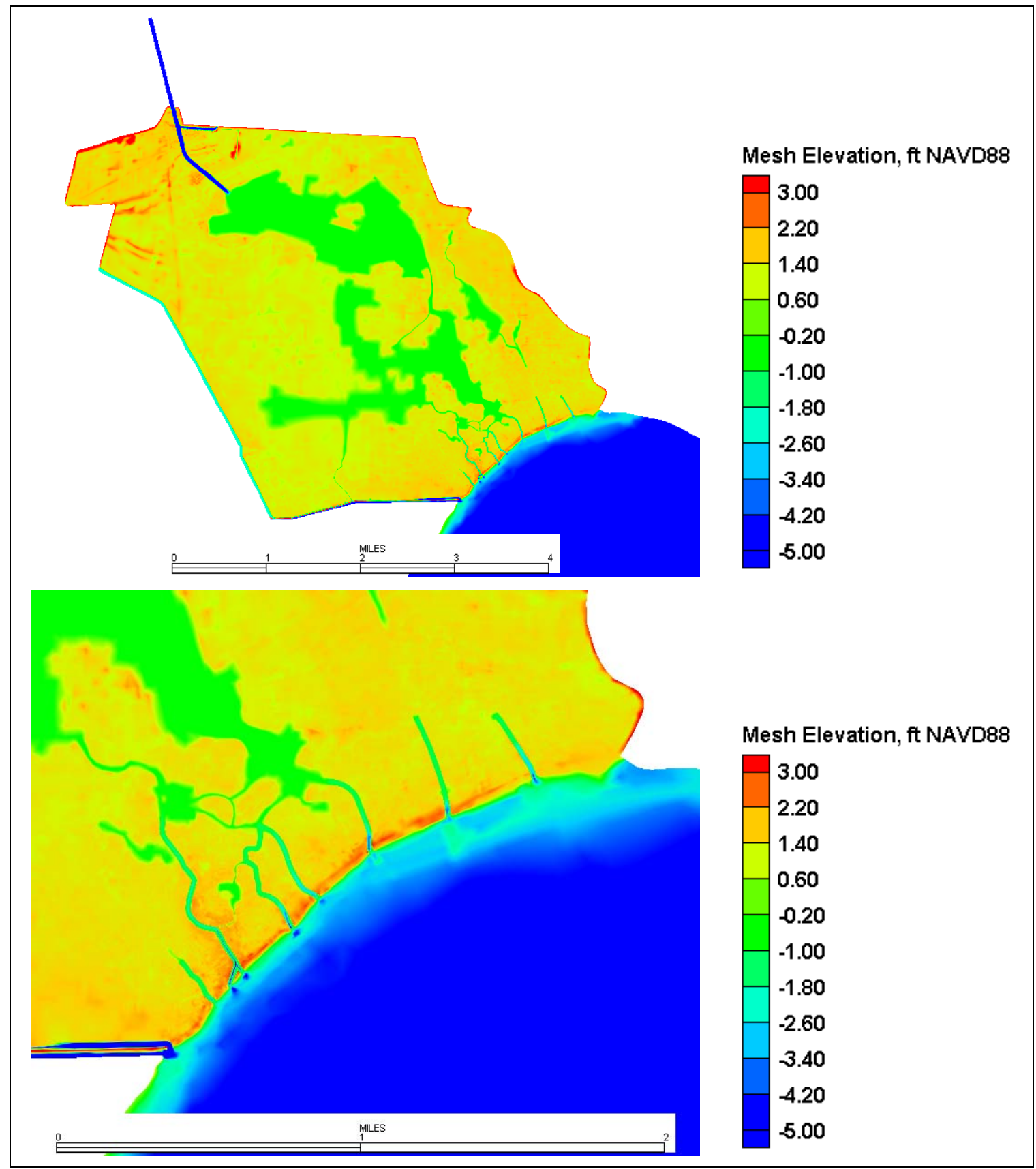

Figure 26. Contour plots of Alternative 4. 
Alternative 5 (Figure 27) is the base case with nine 85-ft-wide cuts in the natural ridge and gabion weir. The cuts were made to an elevation of -3.o $\mathrm{ft}$ NAVD88 ( $-6 \mathrm{ft}$ for the Cypress Lumber Canal cut). The approach channels for these cuts were also deepened to $-3.0 \mathrm{ft}$ for a distance of approximately 2,000 $\mathrm{ft}$ upstream of the gabion weir. The side slopes for the channels were 1 on 3 . Alternative 5 is Alternative 4 with the cuts and channels being deepened from -1.5 to $-3.0 \mathrm{ft}$.

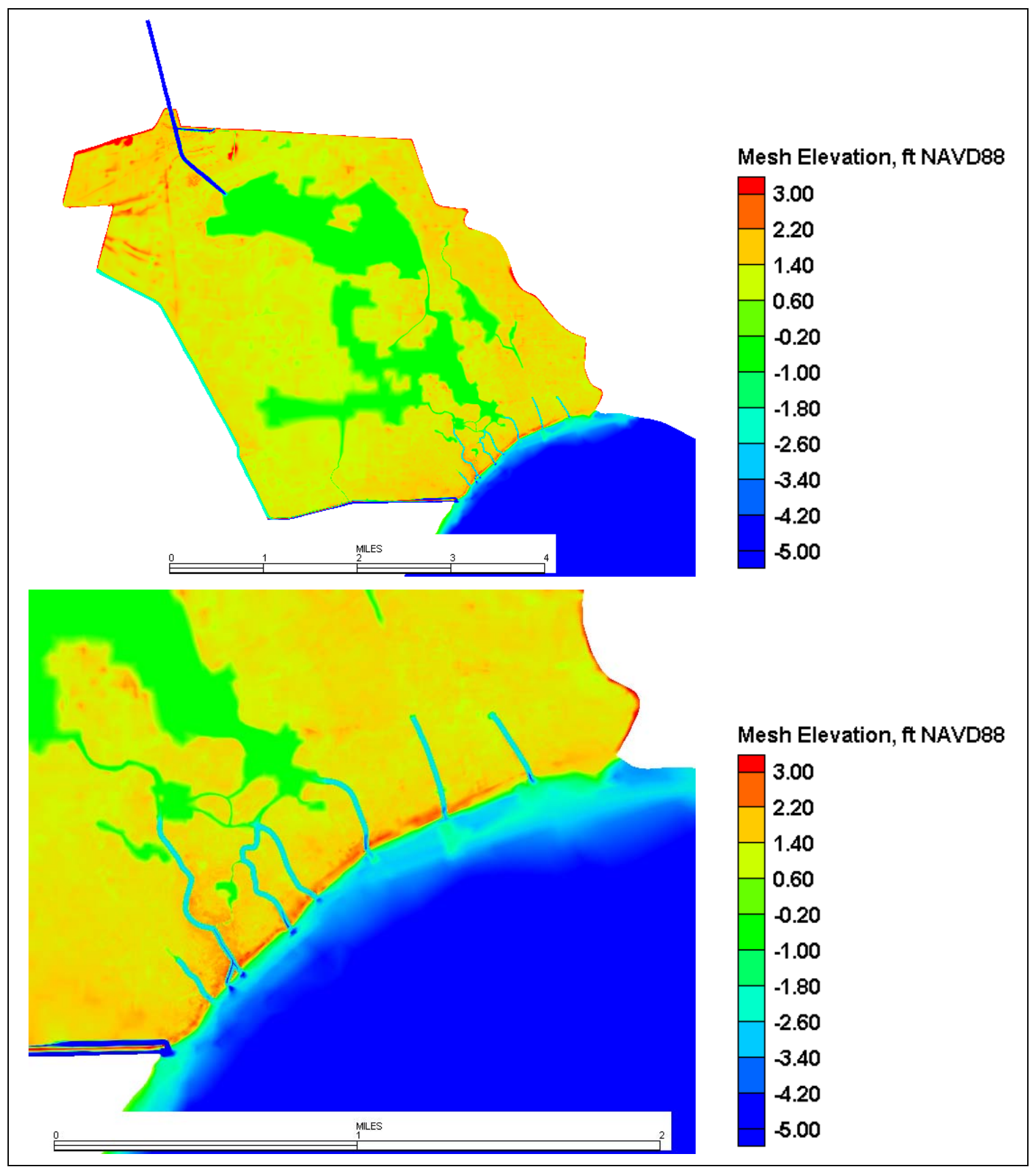

Figure 27. Contour plots of Alternative 5. 
Alternative 6 (Figure 28) is the base case with nine 85-ft-wide cuts in the natural ridge and gabion weir. The cuts were made to an elevation of $-3.0 \mathrm{ft} \mathrm{NAVD88} \mathrm{(}-6 \mathrm{ft}$ for the Cypress Lumber Canal cut). Five of the approach channels for these cuts were deepened to -3.o ft for a distance of approximately 2,000 ft upstream of the gabion weir. The remaining four channels were extended even farther into the ponding area. The side slopes for the channels were 1 on 3. Alternative 6 is Alternative 5 with three of the approach channels extended farther into the ponding area.

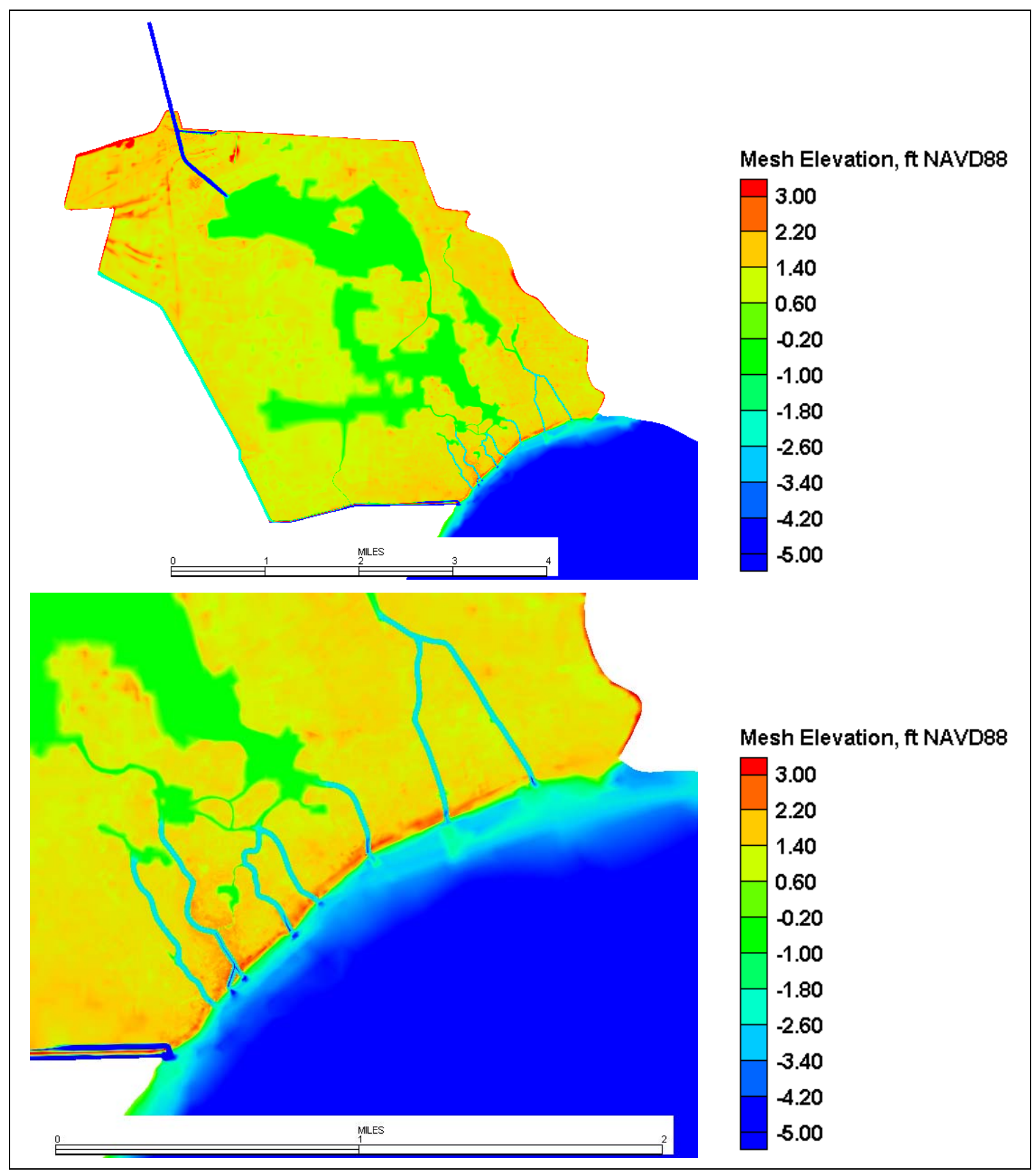

Figure 28. Contour plots of Alternative 6. 
Alternative 7 (Figure 29) is the base case with one breach in the Cypress Lumber Canal Levee. The breach was $85 \mathrm{ft}$ wide, with a bottom elevation of $-3 \mathrm{ft}$ NAVD88.

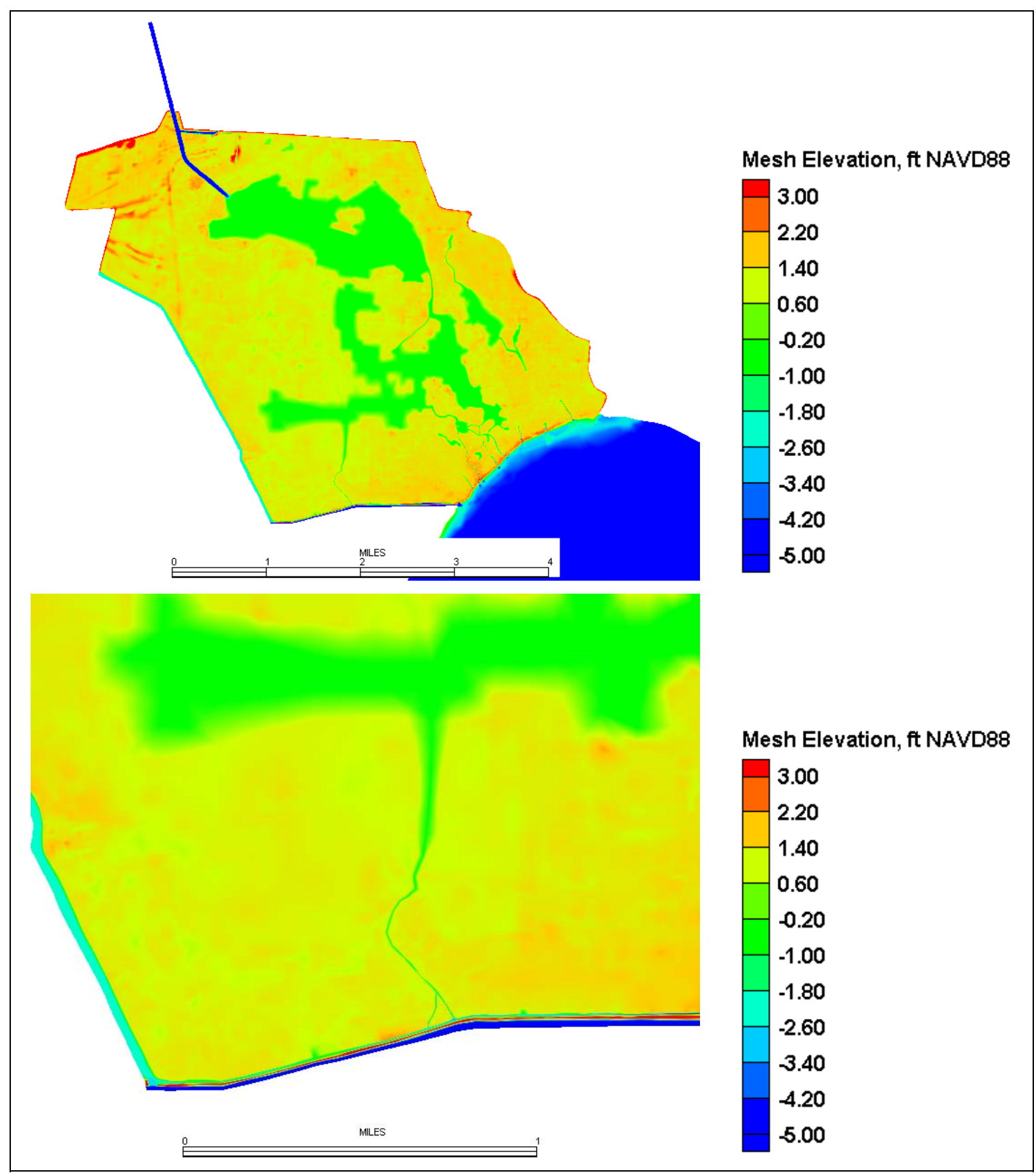

Figure 29. Contour plots of Alternative 7. 
Alternative 8 (Figure 30) is the base case with three breaches in the Cypress Lumber Canal Levee. The breaches were $85 \mathrm{ft}$ wide, with a bottom elevation of $-3 \mathrm{ft}$ NAVD88. Alternative 8 is Alternative 7 with two additional breaches in the Cypress Lumber Canal Levee.

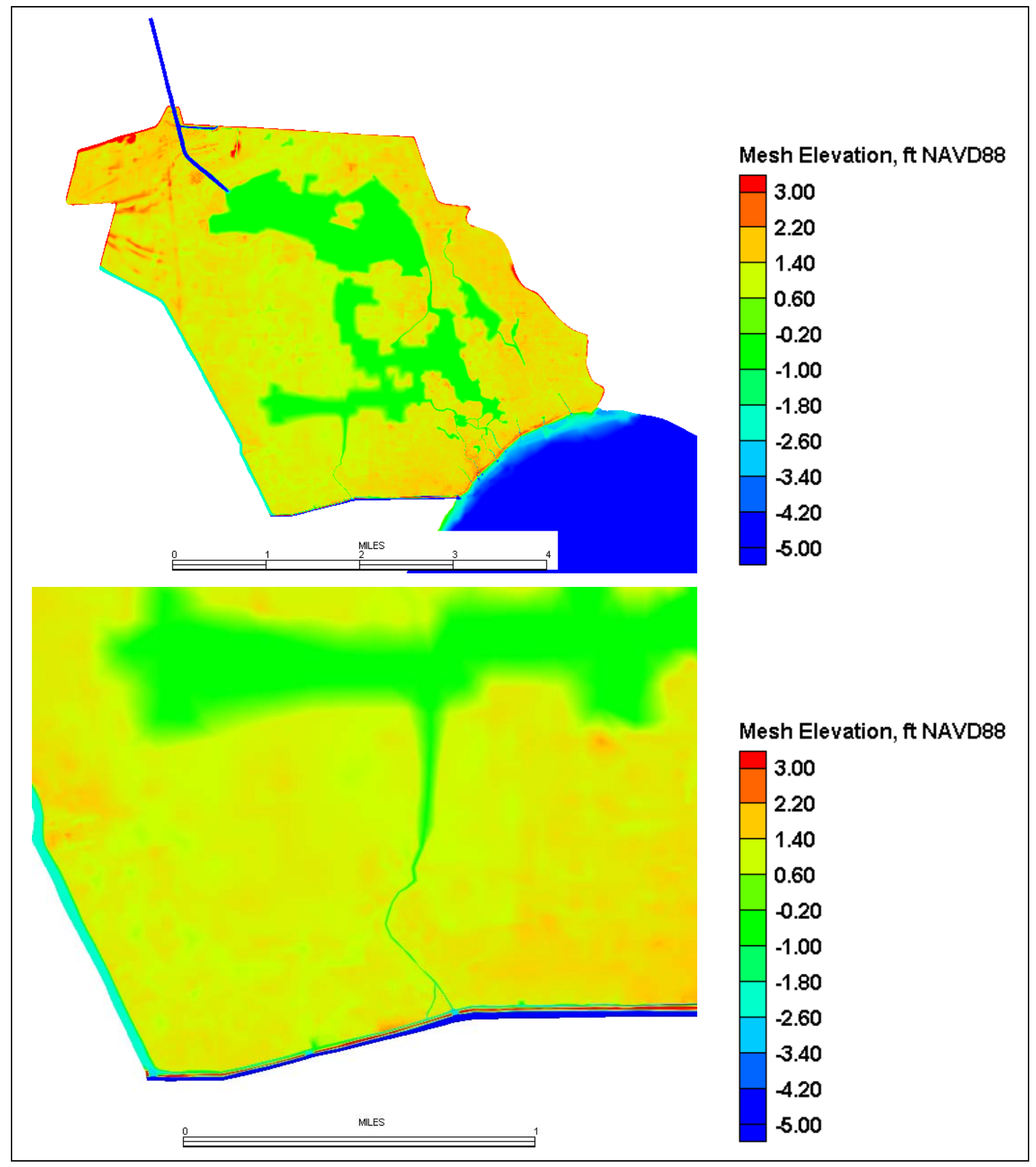

Figure 30. Contour plots of Alternative 8. 
Alternative 9 (Figure 31) is the base case with nine 85 -ft-wide cuts in the natural ridge and gabion weir. The cuts were made to an elevation of -3.o ft NAVD88 ( -6 for the Cypress Lumber Canal Cut) with 1 on 3 side slopes. The approach channels for these cuts were also deepened to $-3.0 \mathrm{ft}$ for a distance of approximately 2,000 $\mathrm{ft}$ upstream of the gabion weir for five of the channels. The remaining four channels were extended even farther into the ponding area. There are also three breaches in the Cypress

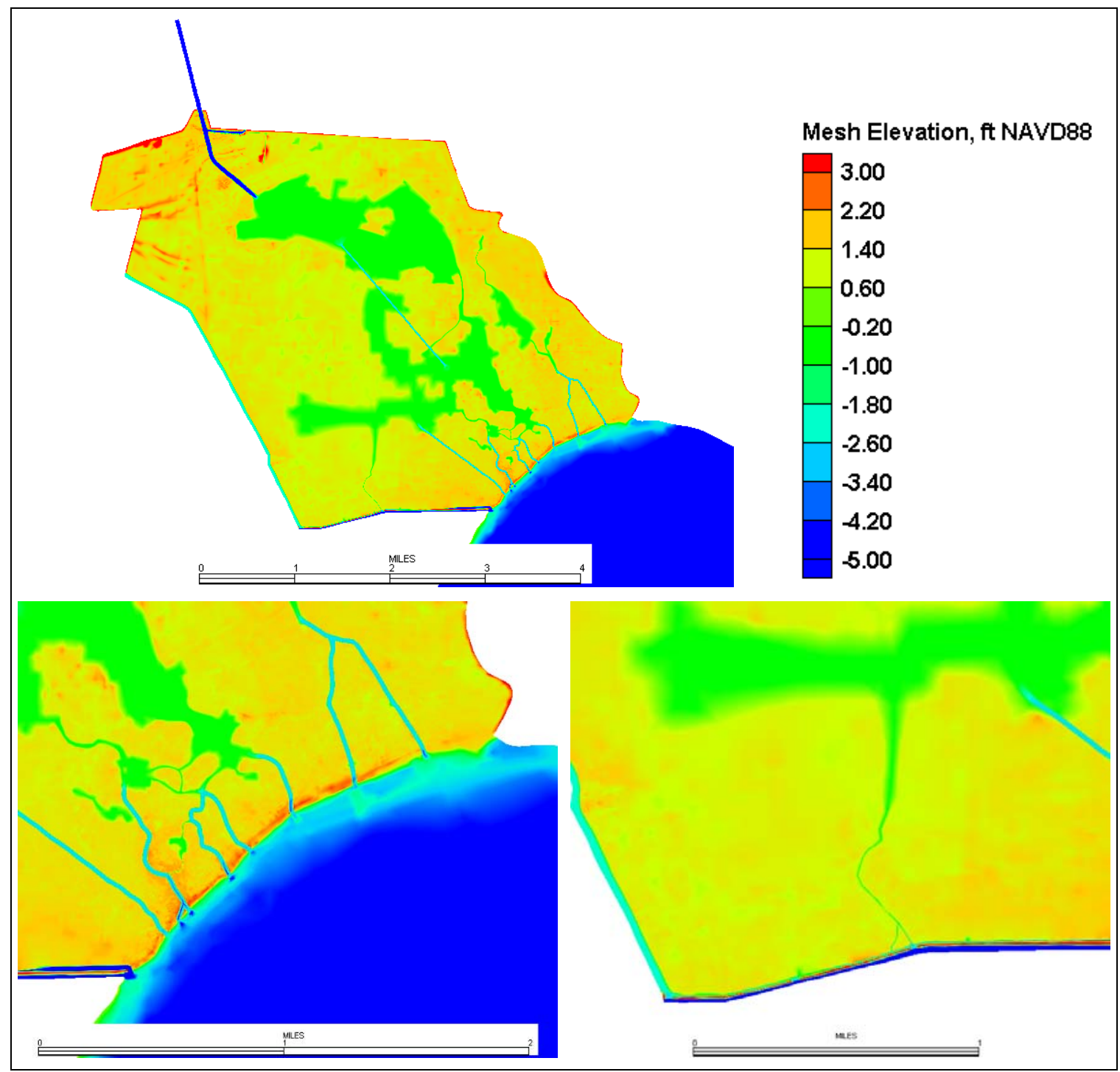

Figure 31. Contour plots of Alternative 9.

Lumber Canal Levee in the same locations as previously identified with Alternative 8. This alternative also includes a channel connecting the upper and lower ponding areas. This channel has a -3.0 ft NAVD88 elevation with a bottom width of $85 \mathrm{ft}$ and 1 on 3 side slopes. Alternative 9 is a 
combination of Alternative 6 (with a slightly different channel alignment for one of the approach channels) and Alternative 8 with an additional channel cut to connect the upper and lower ponding areas.

Alternative 10 (Figure 32) is the base case with eleven 85 -ft-wide cuts in the natural ridge and gabion weir. The cuts were made to an elevation of -3.0 $\mathrm{ft} \mathrm{NAVD88} \mathrm{(}-6$ for the Cypress Lumber Canal Cut) with 1 on 3 side slopes. The approach channels for these cuts were also deepened to $-3.0 \mathrm{ft}$ for a distance of approximately 2,000 ft upstream of the gabion weir for six of the channels. The remaining five channels were extended even farther into the ponding area. There are three breaches in the Cypress Lumber Canal Levee in the same locations as previously identified with

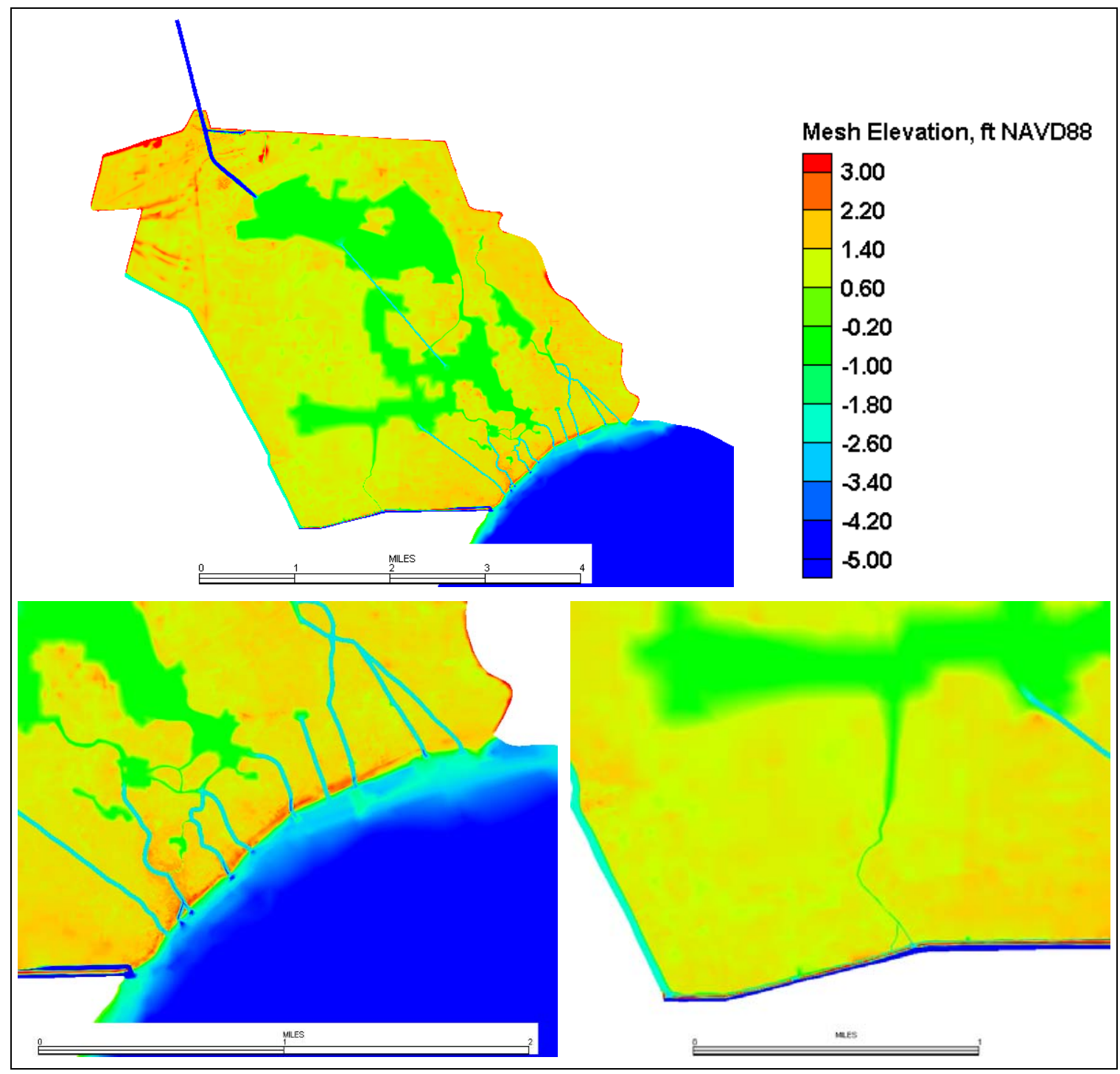

Figure 32. Contour plots of Alternative 10. 
Alternative 8. This alternative also includes a channel connecting the upper and lower ponding areas. That channel has a -3.0 ft NAVD88 elevation with a bottom width of $85 \mathrm{ft}$ and 1 on 3 side slopes. Alternative 10 is a combination of Alternative 6 (with two additional cuts and slightly different channel alignments) and Alternative 8 with an additional channel cut to connect the upper and lower ponding areas.

Alternative 11 (Figure 33) is the base case with nine 85- $\mathrm{ft}$-wide cuts in the natural ridge and gabion weir. The cuts were made to an elevation of -3.0 ft NAVD88 (-6 for the Cypress Lumber Canal Cut) with 1 on 3 slopes. The approach channels for these cuts were also deepened to $-3.0 \mathrm{ft}$ for

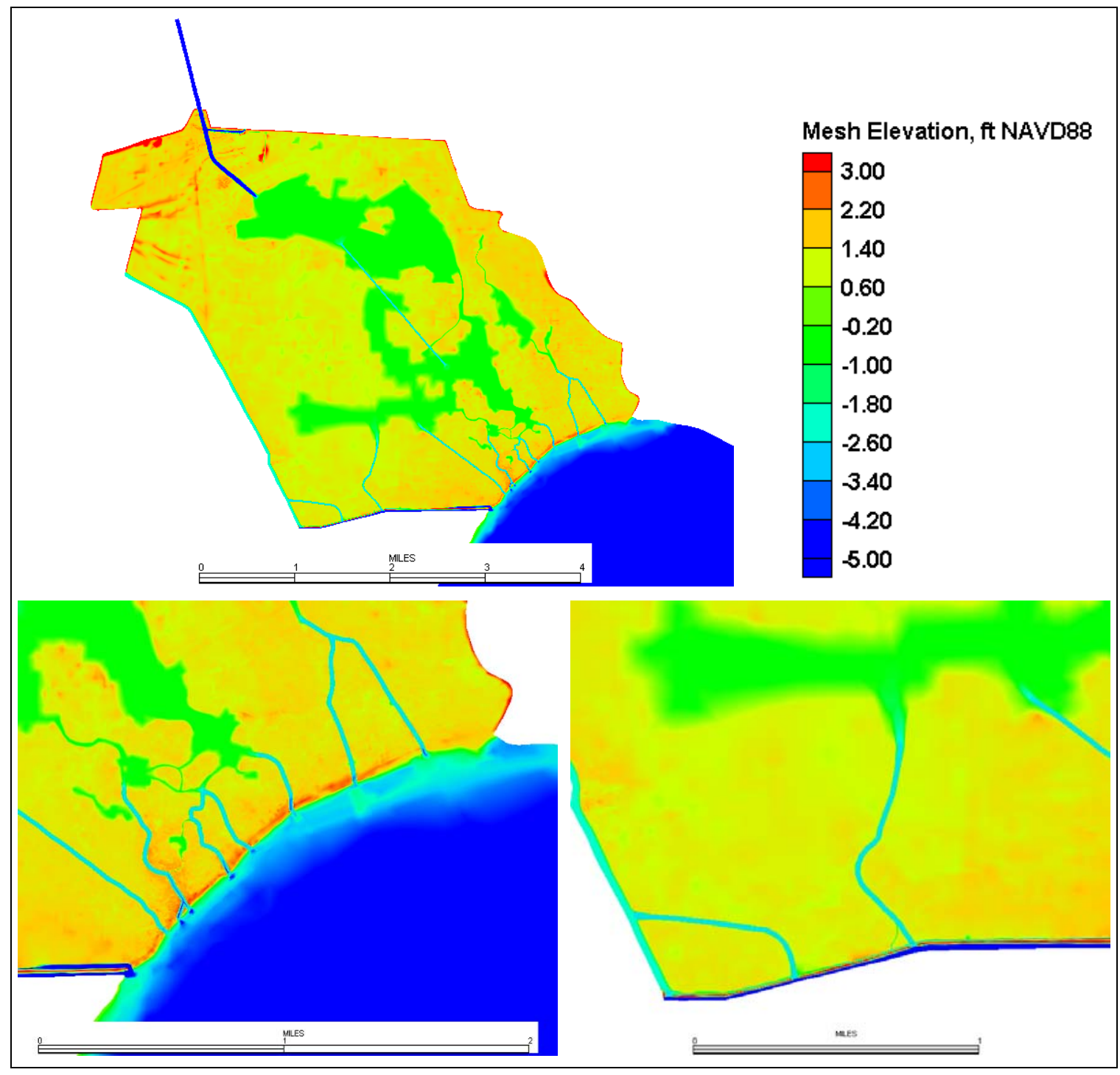

Figure 33. Contour plots of Alternative 11. 
approximately 2,000 $\mathrm{ft}$ upstream of the gabion weir for five of the channels. The remaining four channels were extended even farther into the ponding area. There are three breaches in the Cypress Lumber Canal Levee in the same locations as previously identified with Alternative 8. Alternative 11 also includes a channel connecting the upper and lower ponding areas. This channel has a -3.o ft NAVD88 elevation with a bottom width of $85 \mathrm{ft}$ and 1 on 3 side slopes. This alternative also consists of two additional channels that were cut from the locations of the two breaches in the Cypress Lumber Canal. These two additional channels are shown in Figure 33. They have bottom elevations of $-3 \mathrm{ft}$ NAVD88 with side slopes of 1 on 3 . Alternative 11 is Alternative 9 with the two additional channels.

Alternative 12 (Figure 34) is the base case with eleven 85-ft-wide cuts in the natural ridge and gabion weir. The cuts were made to an elevation of -3.0 $\mathrm{ft} \mathrm{NAVD88} \mathrm{(}-6$ for the Cypress Lumber Canal Cut) with 1 on 3 side

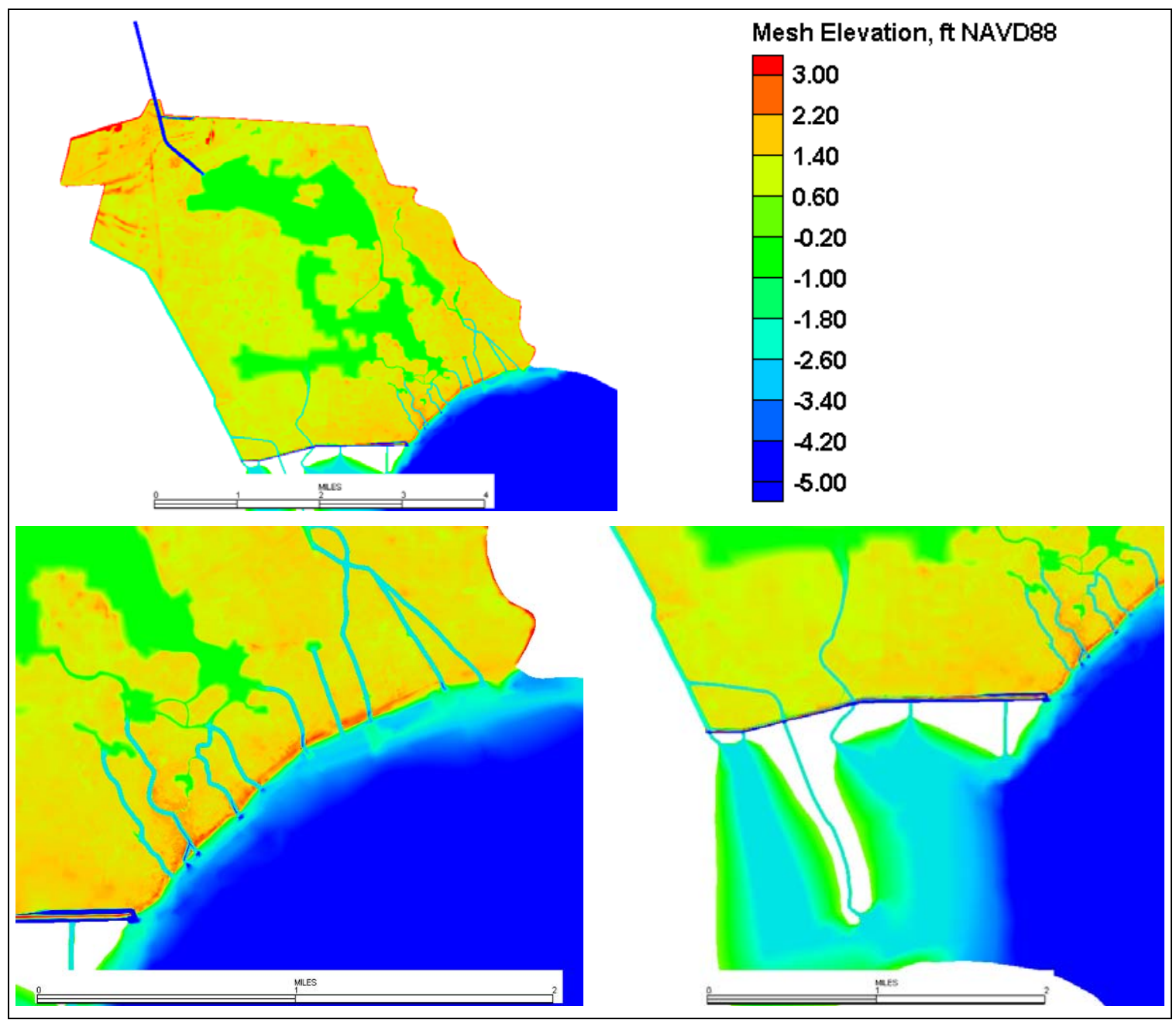

Figure 34. Contour plots of Alternative 12. 
slopes. The approach channels for these cuts were also deepened to $-3.0 \mathrm{ft}$ for a distance of approximately 2,000 $\mathrm{ft}$ upstream of the gabion weir for six of the channels. The remaining five channels were extended even farther into the ponding area. There are three breaches in the Cypress Lumber Canal Levee in the same locations as previously identified with Alternative 8. This alternative also consists of two additional channels that were cut from the locations of the two breaches in the Cypress Lumber Canal. These two additional channels are shown in Figure 34. To better capture the true benefit of the breaches in the Cypress Lumber Canal, the model domain was extended south to include additional channels that branch from the Cypress Lumber Canal. These channels provide additional connections to Lake Cataouatche, allowing for additional outflow from the Davis Pond area. The channels extending south from the Cypress Lumber Canal were to a bottom elevation of $-3 \mathrm{ft}$ NAVD88 with bottom widths of $85 \mathrm{ft}$ and side slopes of 1 on 3 . Alternative 12 is similar to Alternative 9, but without the channel connecting the upper and lower ponding area, and with the additional domain added south of the Cypress Lumber Canal.

\section{Computational environment}

The hydrodynamic model runs were performed on the ERDC High Performance Computing (HPC) SGI Origin 3000 (Ruby) parallel-processing supercomputer. The base conditions model contains 49,836 nodes and 17,893 elements. The model was executed on 8 parallel processors and required approximately 20 hours of computational time to run the verification period of 37 days with a time step of 30 minutes. The production runs required a shorter duration to obtain the steady-state solutions. Version 5.0 of RMA2 was used. 


\section{Hydrodynamic Model Results}

The plot in Figure 35 shows the model water surface profile for the Davis Pond study area for Alternatives 1-8. Figure 35 shows Alternatives 4-6 coming closest to the desired profile, while Alternatives 1-3 and 7-8 produce insignificant changes to the water levels (Note: some of the profiles are virtually identical.) The desired profile was provided by MVN. Therefore, it is reasonable to assume that the primary restriction to the passage of water out of the system is the gabion weir along the southern boundary of the Davis Pond marsh area. Additionally, around 10,000 ft upstream of the gabion weir there is a sudden increase to the water level profile (for Alternatives 4-6), which indicates a limit in the channel conveyance. This result corresponds to a constriction between the upper and lower ponding areas that limits the benefits obtained from Alternatives 4-6.

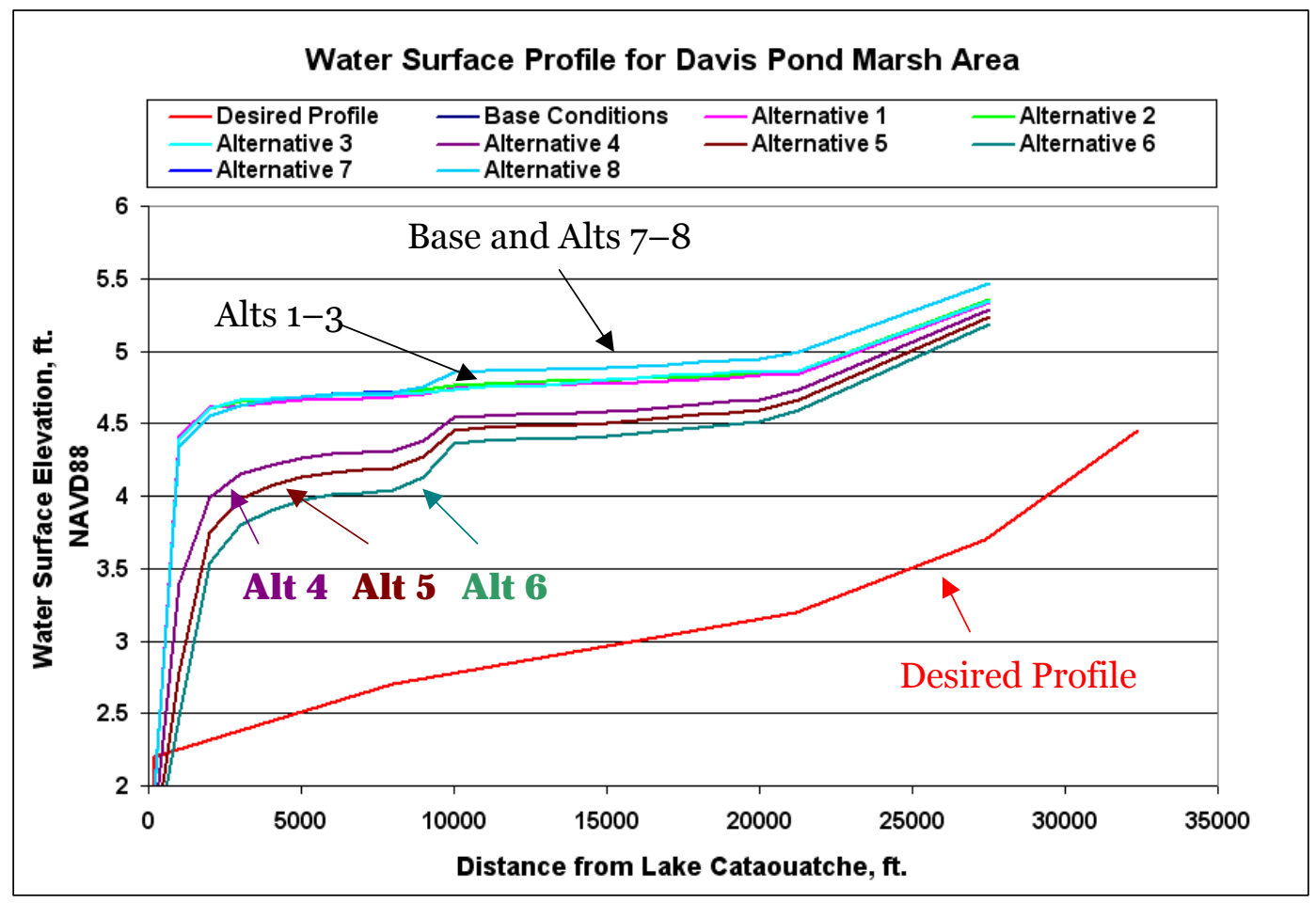

Figure 35. Water surface profile obtained from Alternatives 1-8.

These initial results were analyzed to create Alternatives 9-12. The model results for these three additional alternatives are shown in Figure 36 and Figure 37. While these alternatives result in significant reductions in water surface elevation, the water levels for all alternatives are still significantly higher than the desired water surface elevation profile. Since 
Alternative 12 was deemed the most desirable, additional runs were done with inflows of 7,500 and 5,000 cfs for this case.

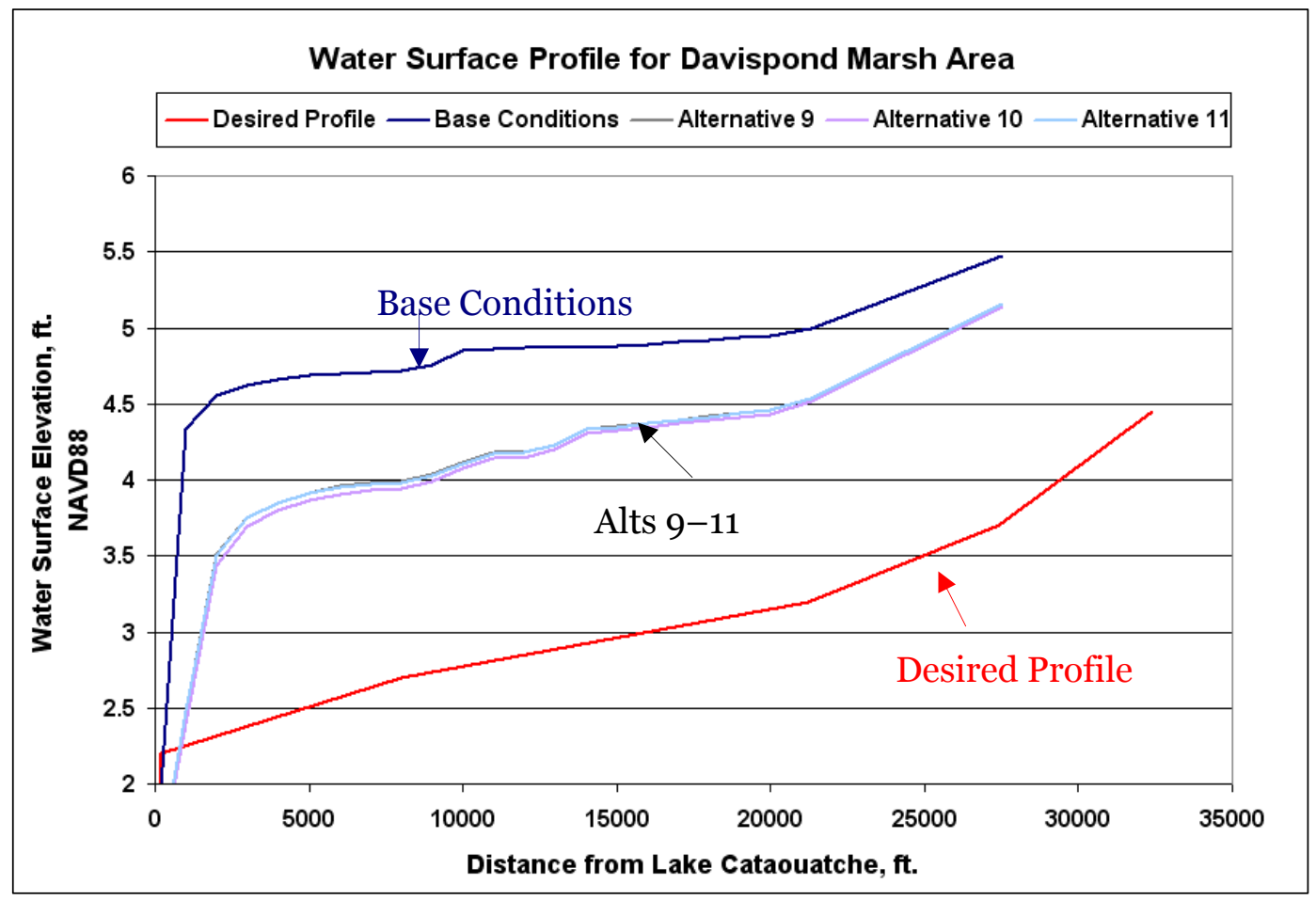

Figure 36. Water surface profile obtained from Alternatives 9-11.

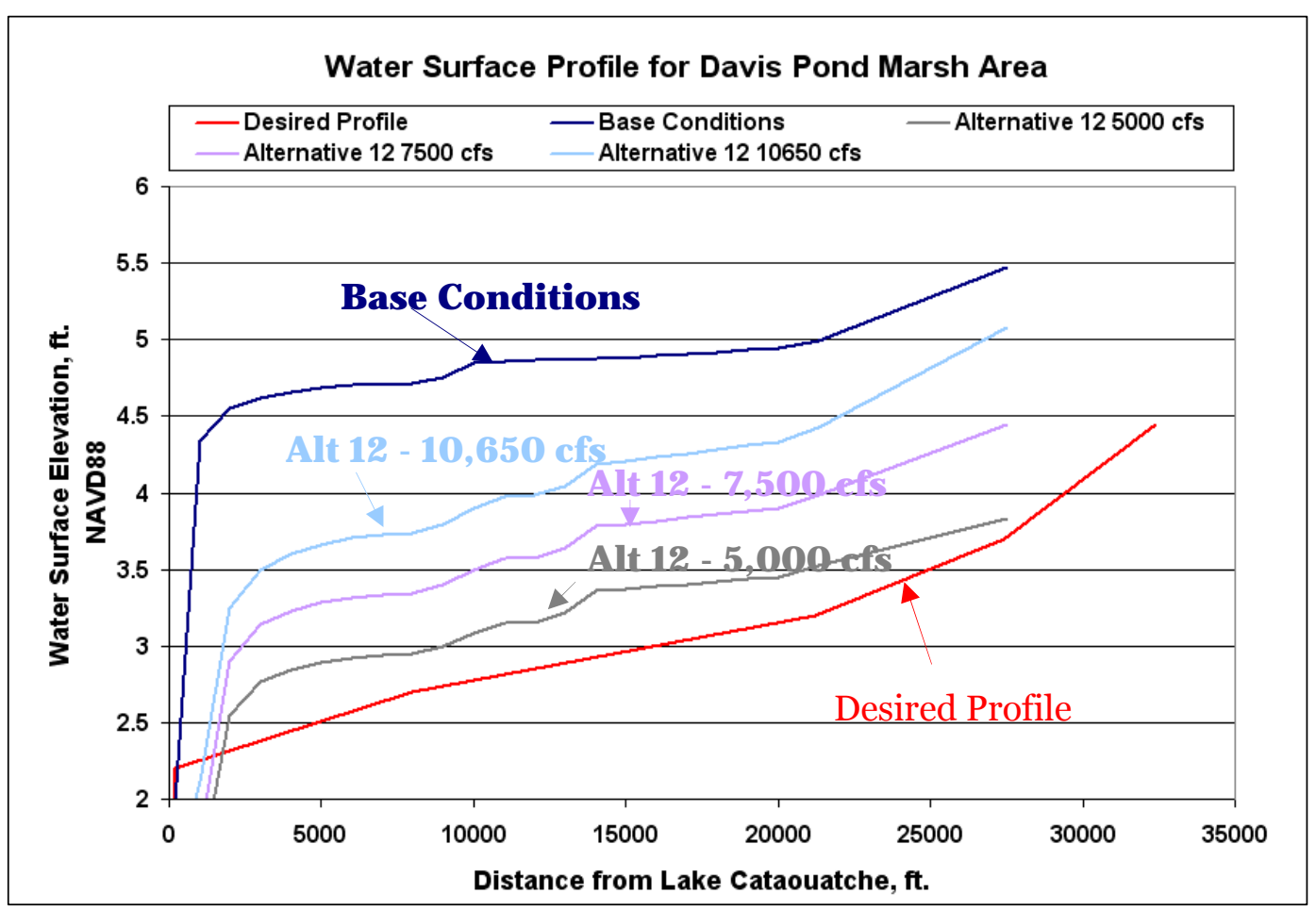

Figure 37. Water surface profile obtained from Alternative 12. 
The previous plots depict profiles along a specific path for each alternative. Figures 38-50 show contour plots of water surface elevations for the entire ponding area. These plots provide a more comprehensive idea of the total changes experienced by the system. Difference plots of the base conditions and Alternatives 9-12 are shown in Figures 51-52. These figures show the benefits that would be obtained by the implementation of Alternatives 9-12.

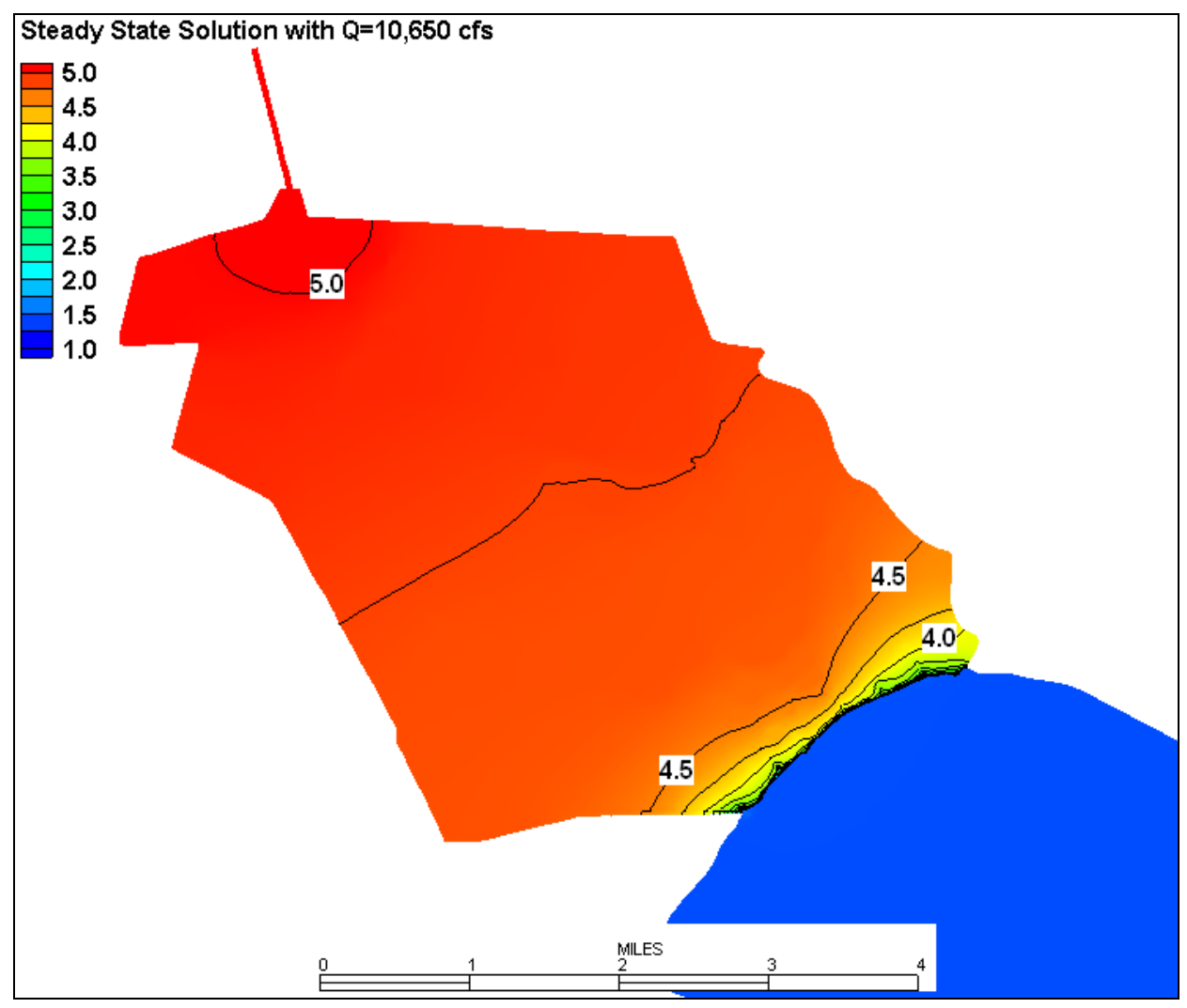

Figure 38. Water surface elevation for the base conditions in feet NAVD88. 


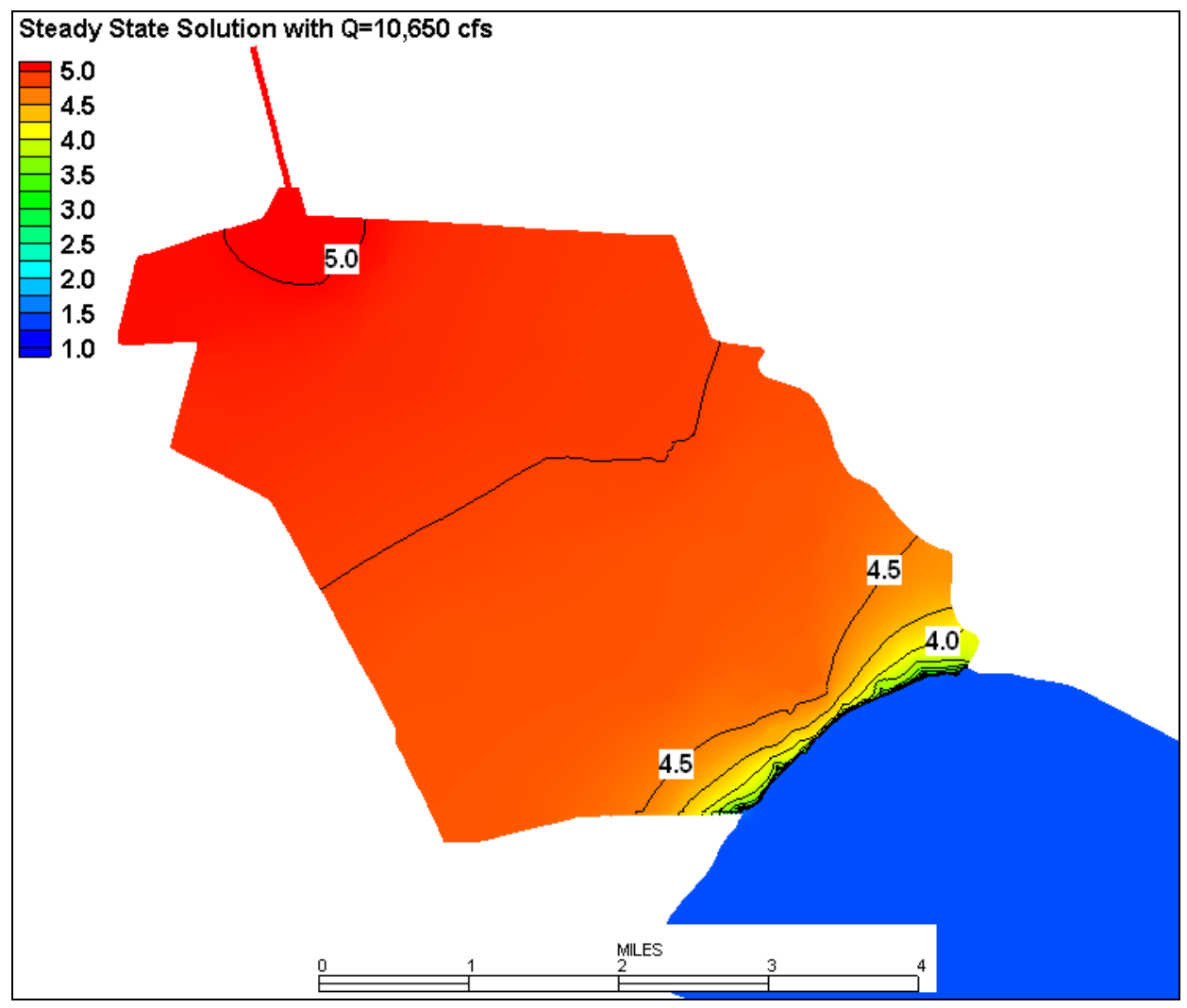

Figure 39. Water surface elevation for Alternative 1 in feet NAVD88.

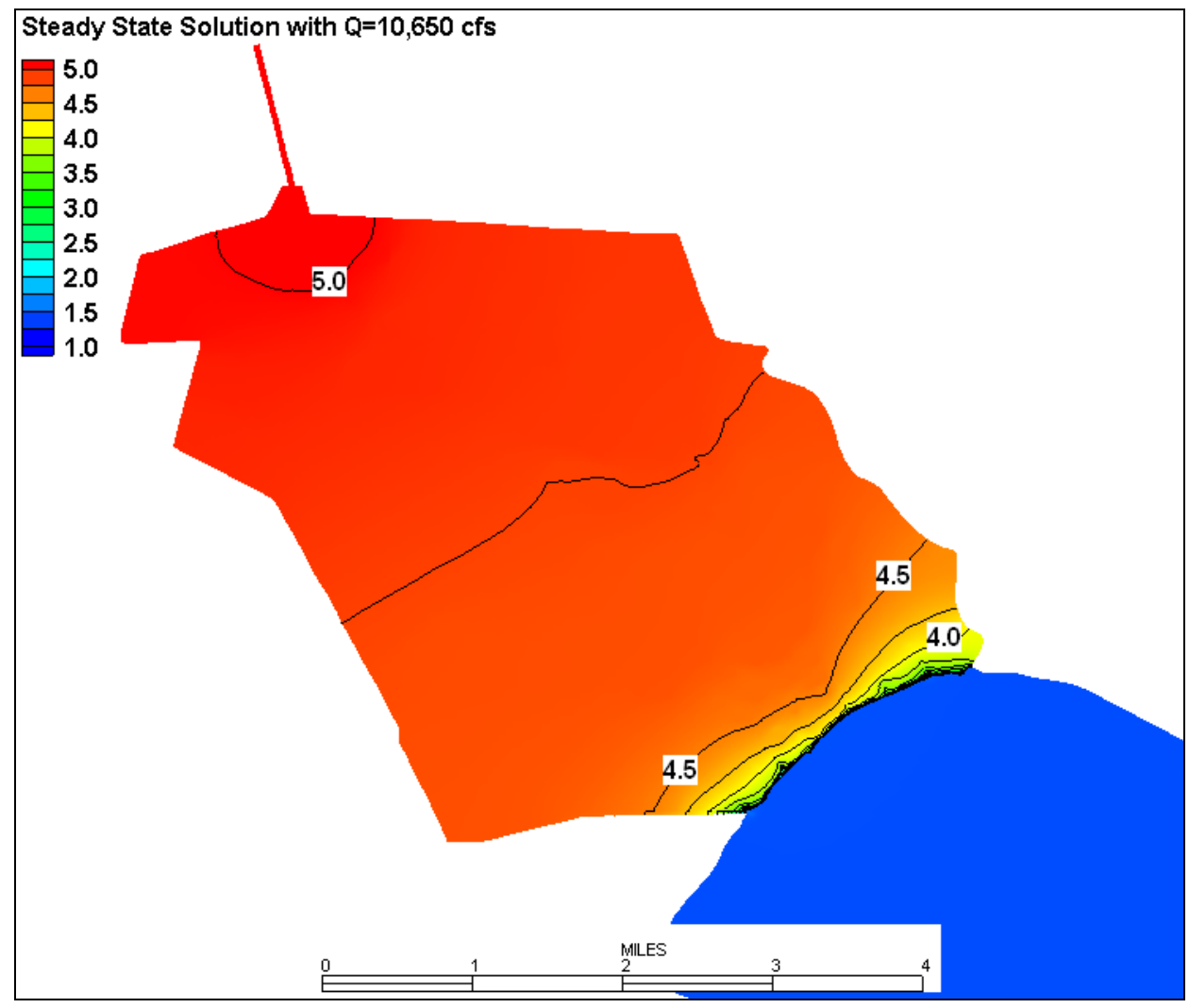

Figure 40. Water surface elevation for Alternative 2 in feet NAVD88. 


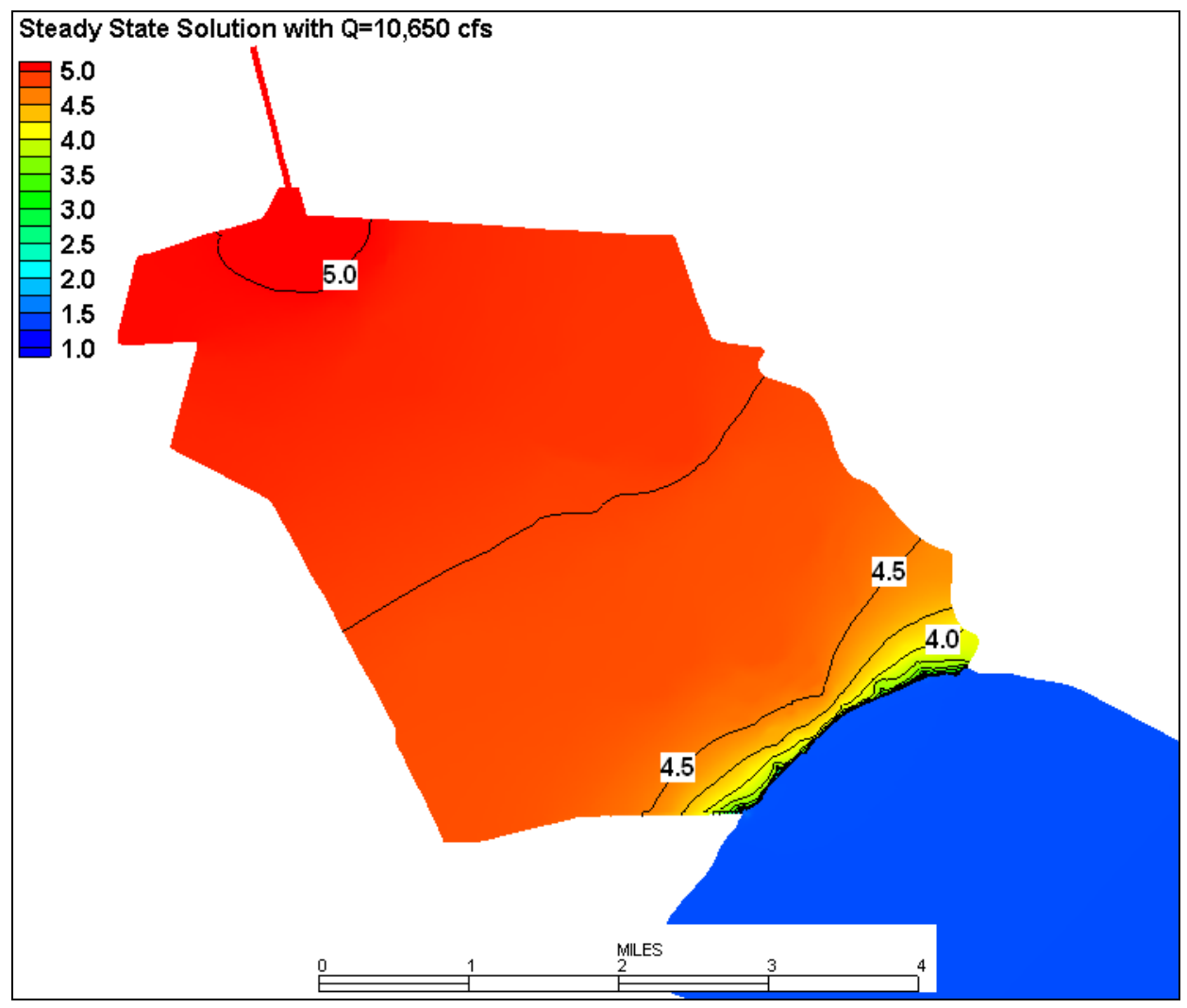

Figure 41. Water surface elevation for Alternative 3 in feet NAVD88.

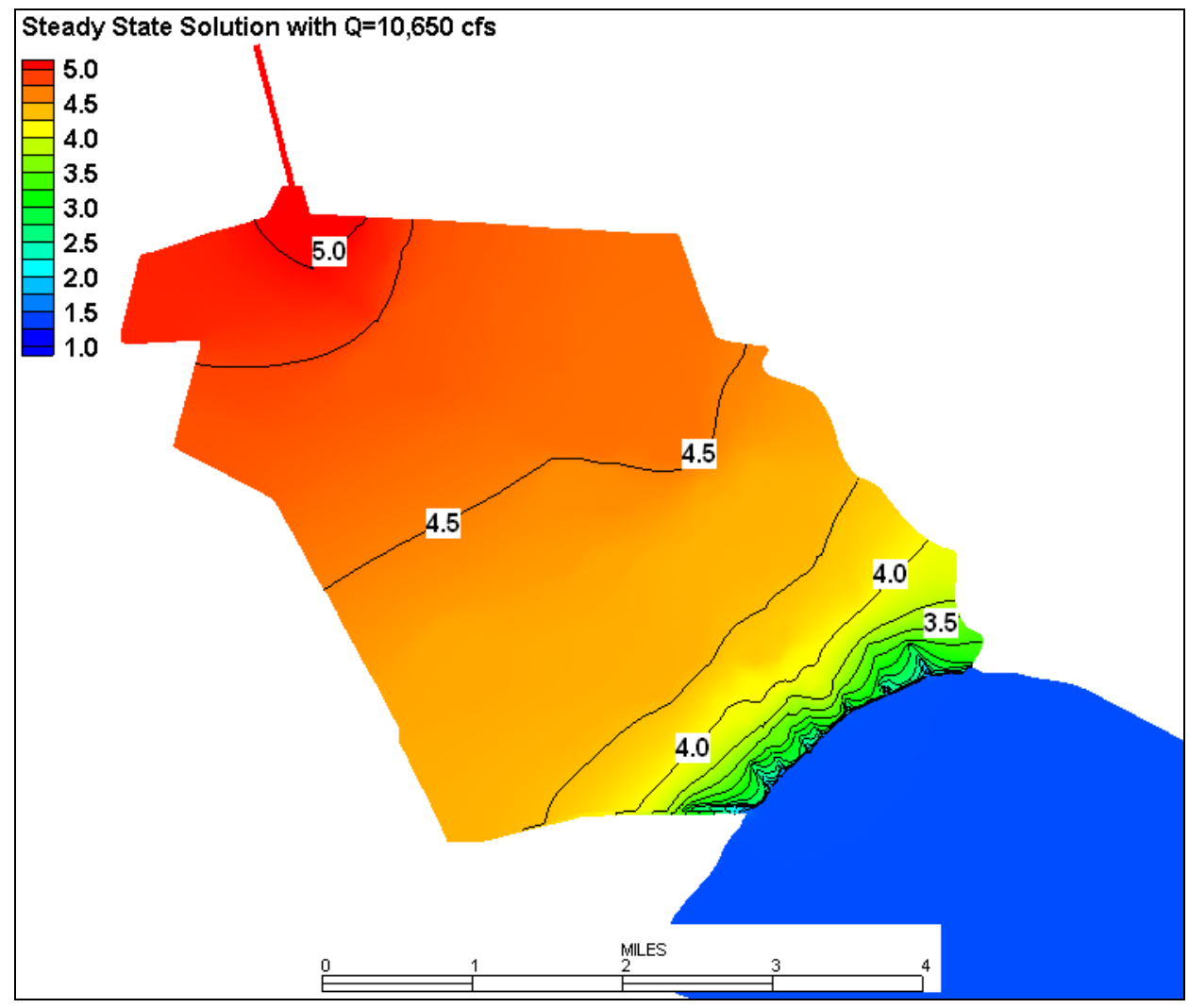

Figure 42. Water surface elevation for Alternative 4 in feet NAVD88. 


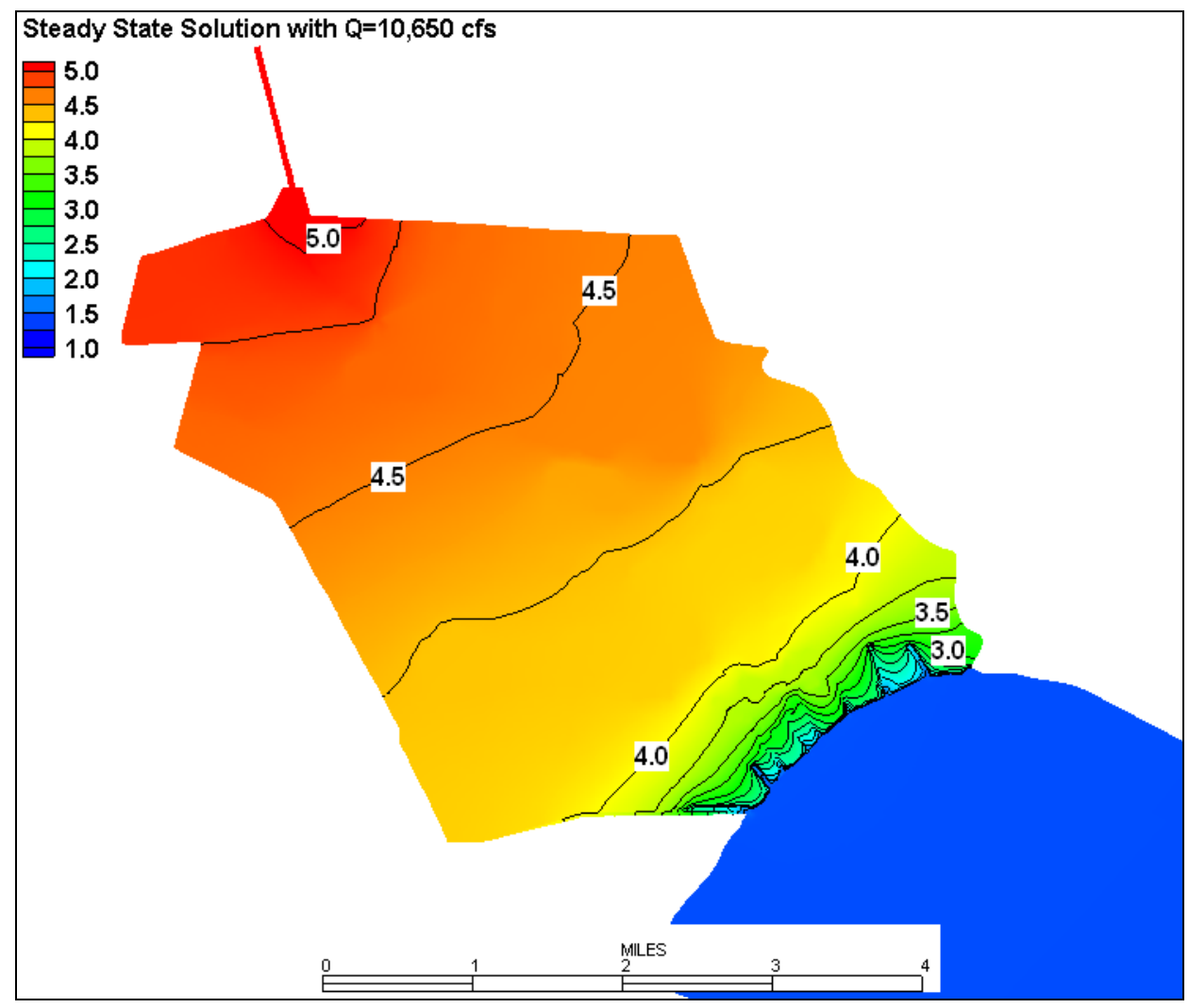

Figure 43. Water surface elevation for Alternative 5 in feet NAVD88.

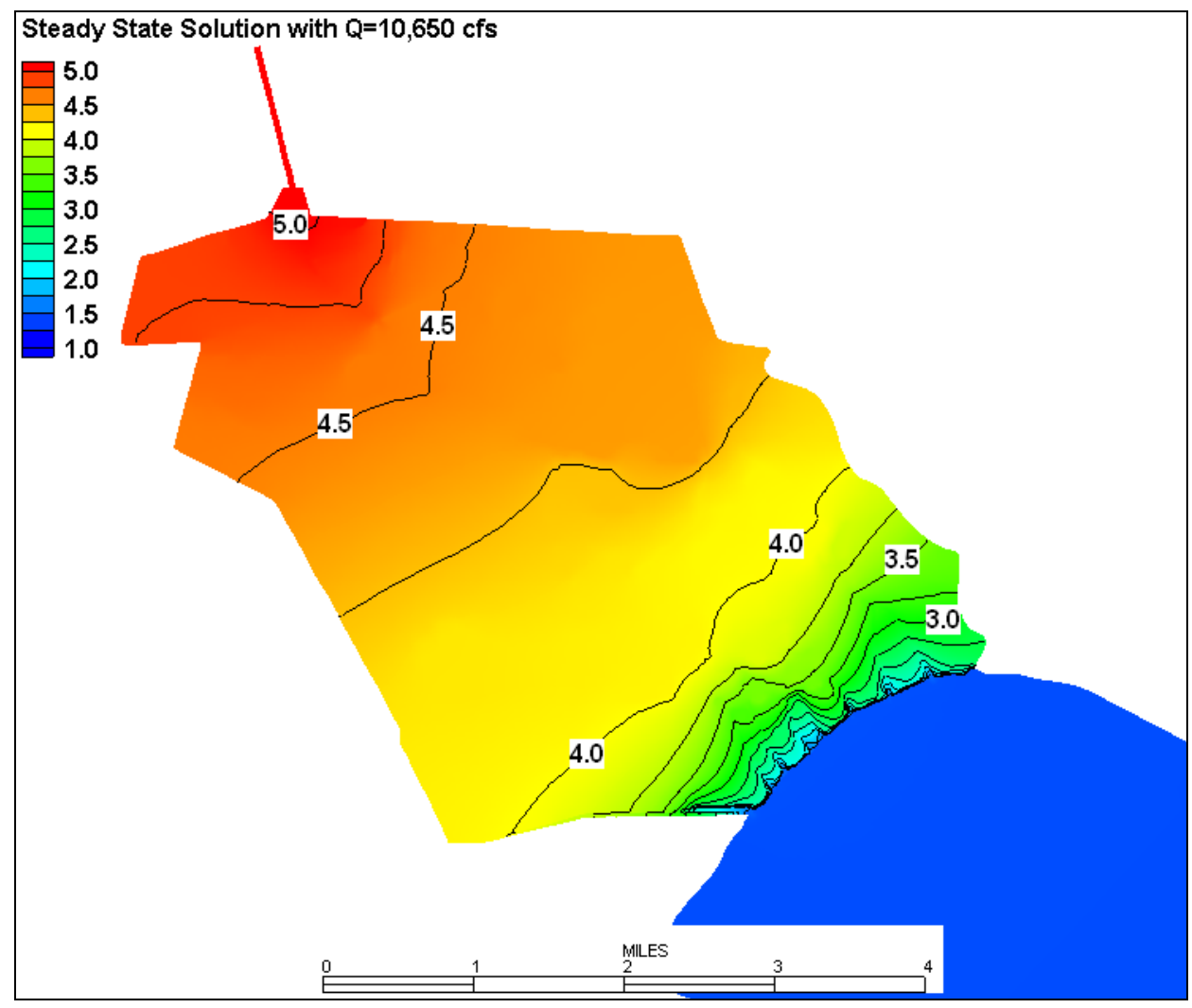

Figure 44. Water surface elevation for Alternative 6 in feet NAVD88. 


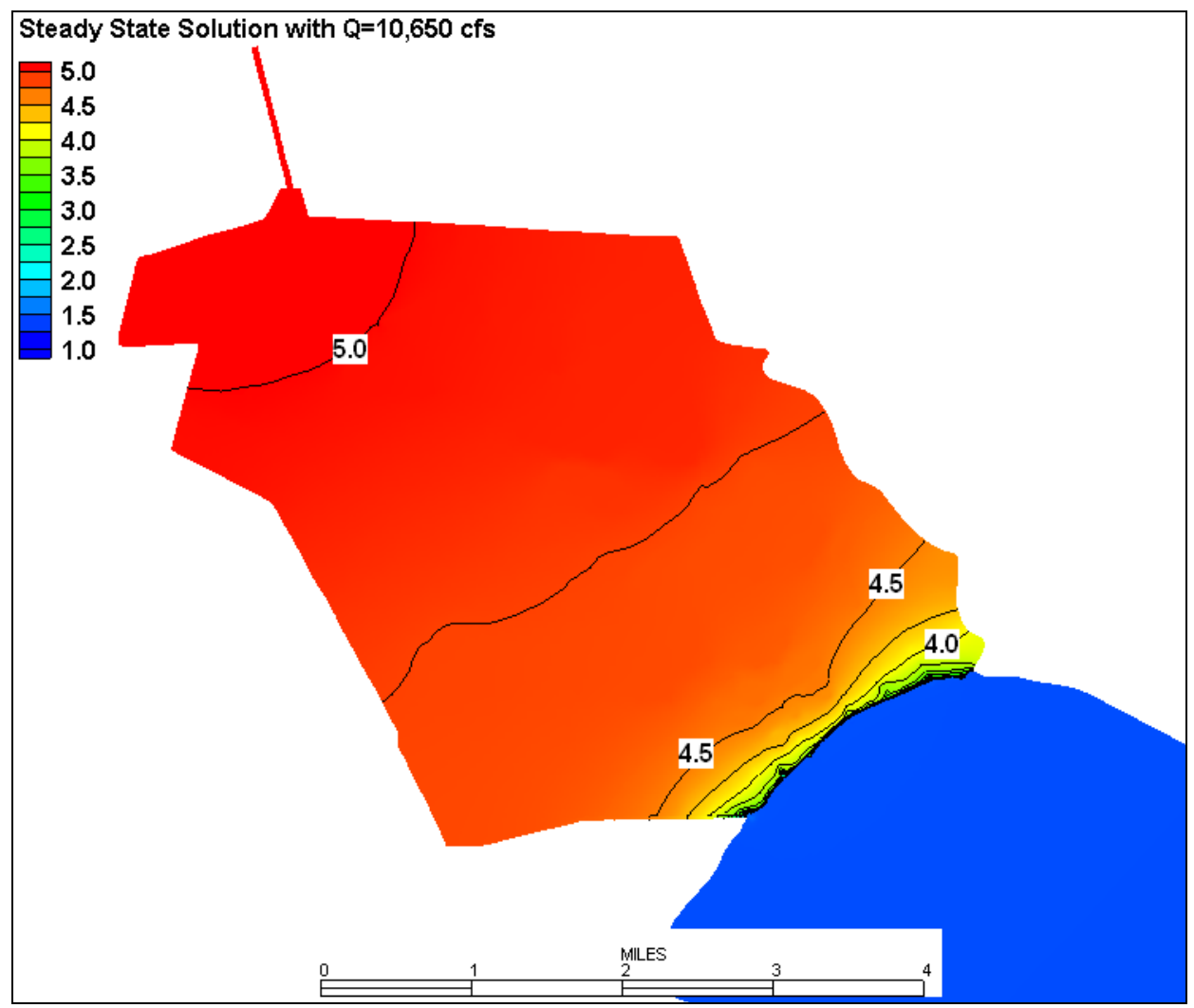

Figure 45. Water surface elevation for Alternative 7 in feet NAVD88.

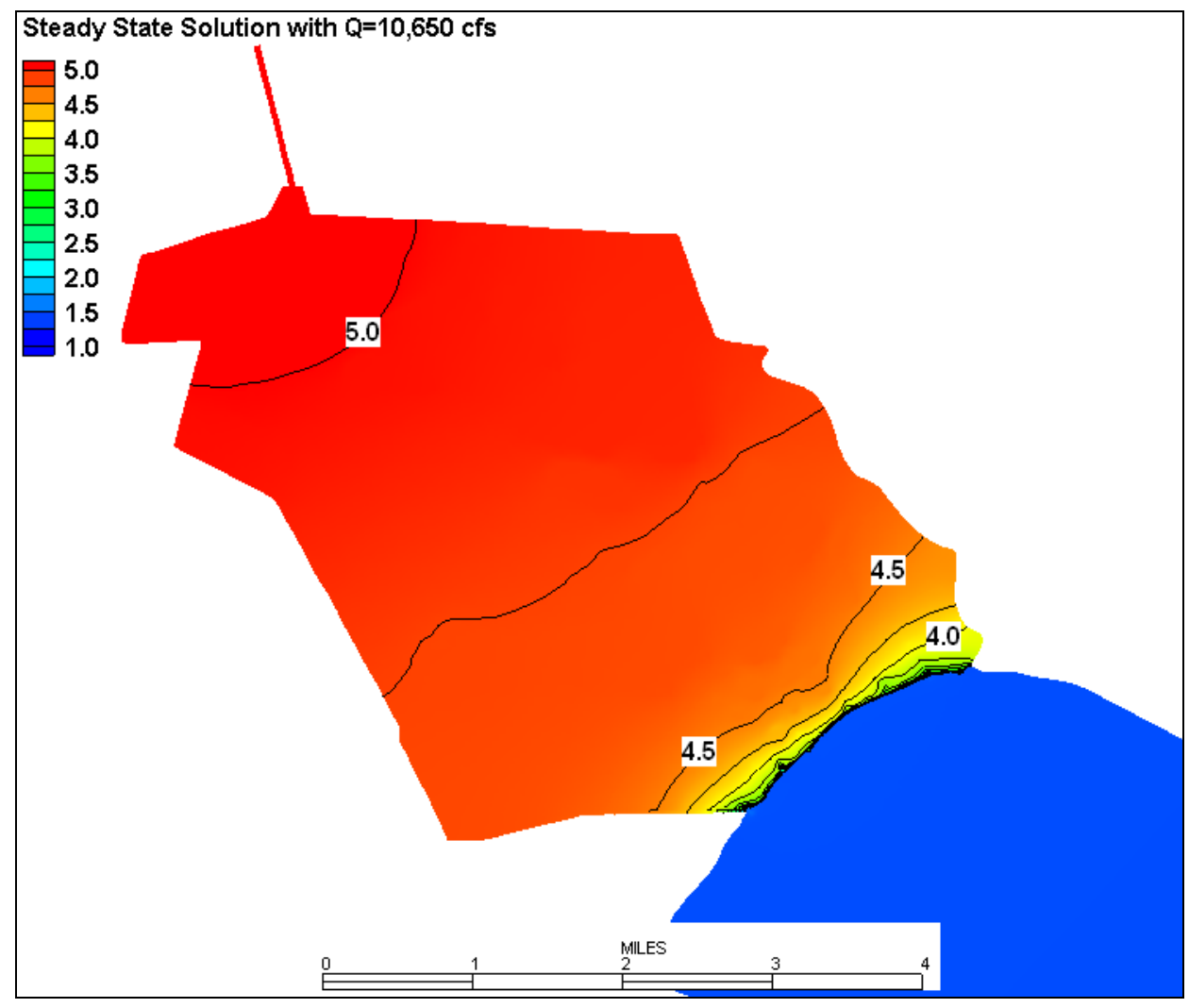

Figure 46. Water surface elevation for Alternative 8 in feet NAVD88. 


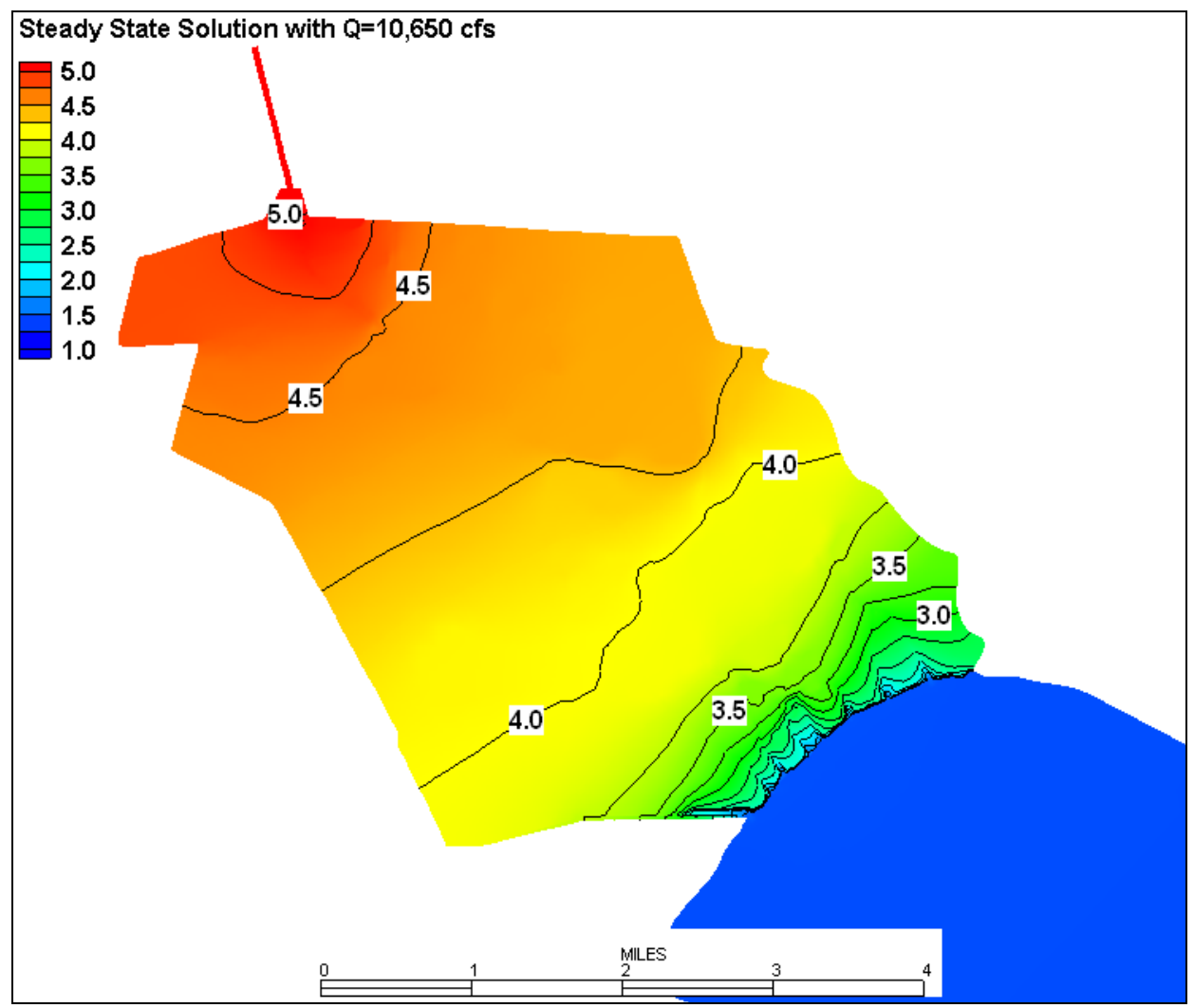

Figure 47. Water surface elevation for Alternative 9 in feet NAVD88.

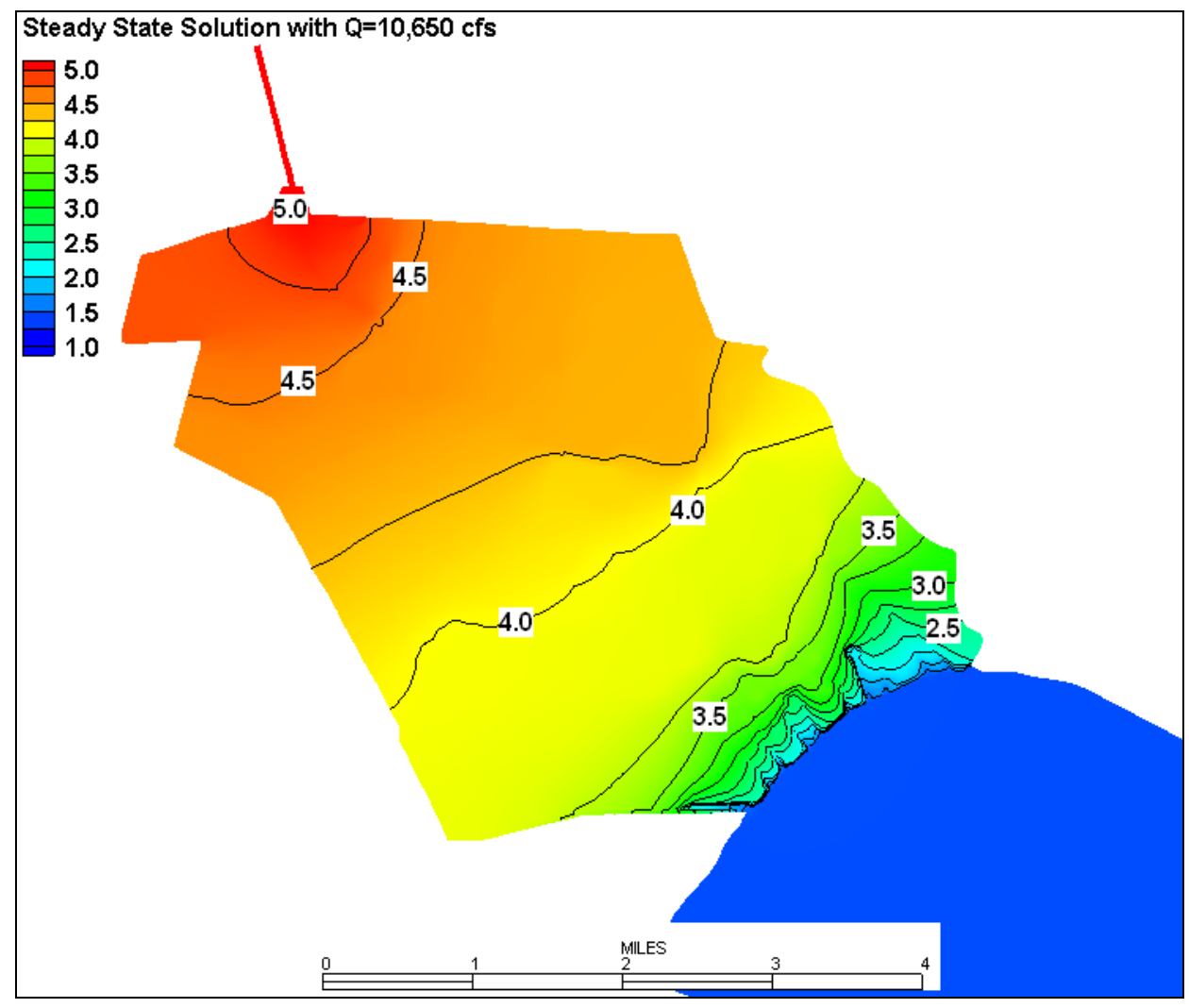

Figure 48. Water surface elevation for Alternative 10 in feet NAVD88. 


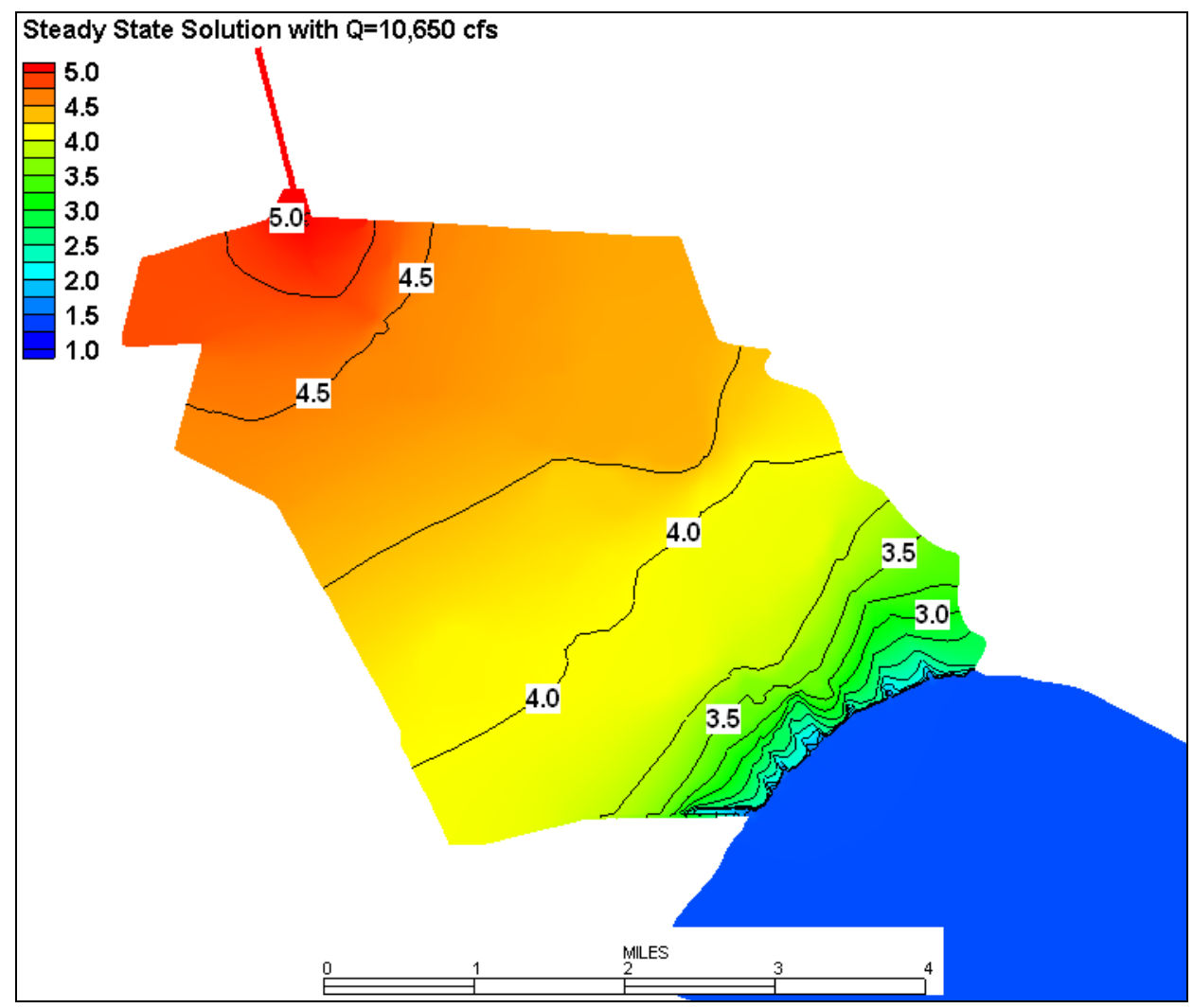

Figure 49. Water surface elevation for Alternative 11 in feet NAVD88.

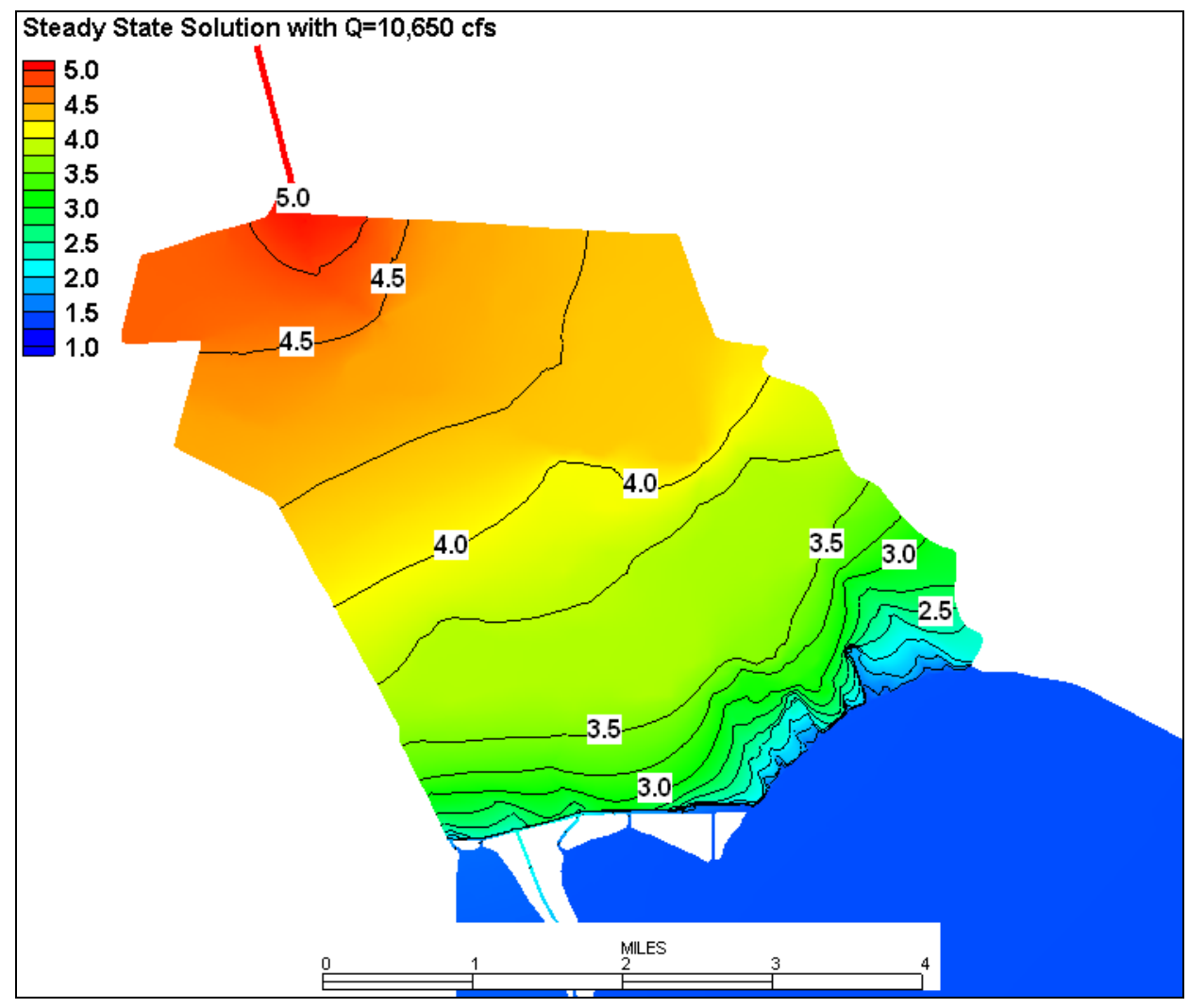

Figure 50. Water surface elevation for Alternative 12 in feet NAVD88. 


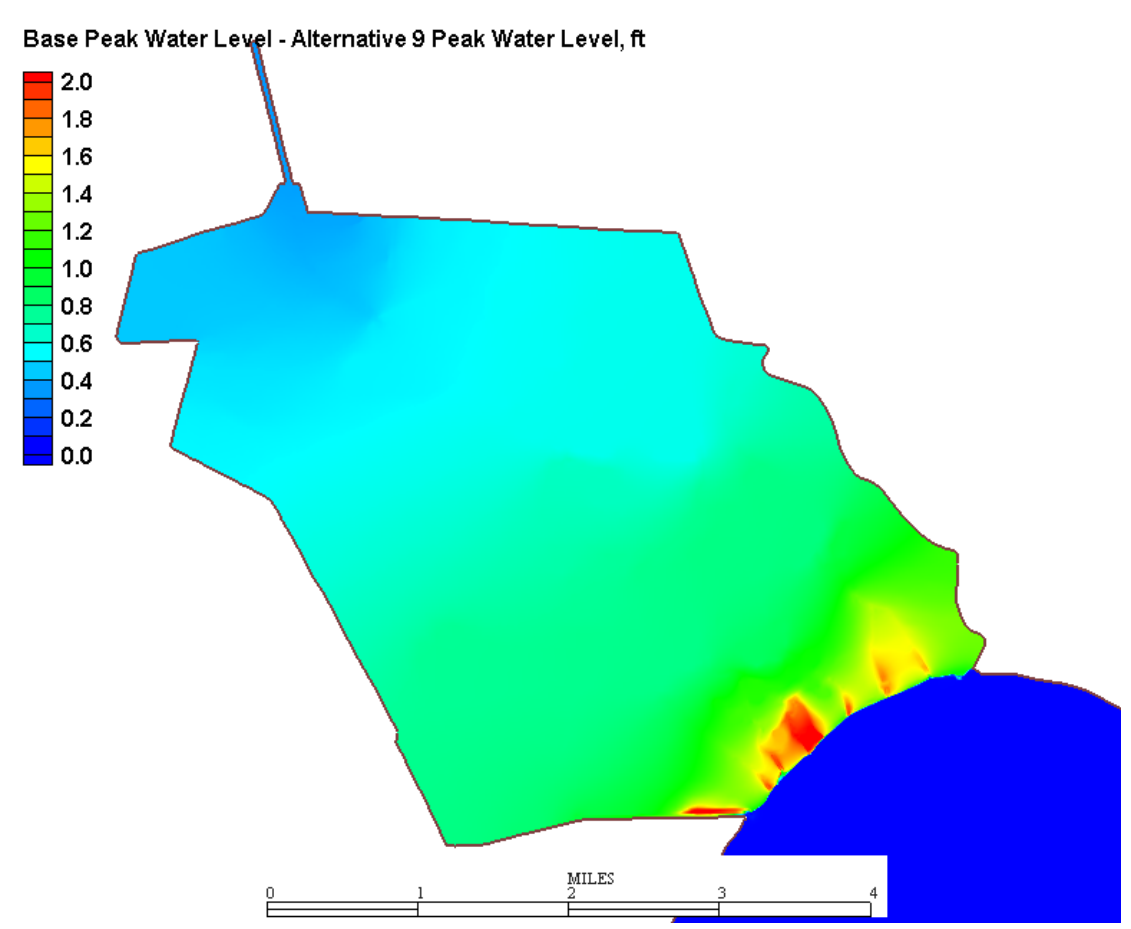

Base Solution - Alternative 9 Solution

Base Peak Water Level - Alternative 10 Peak Water Level, ft

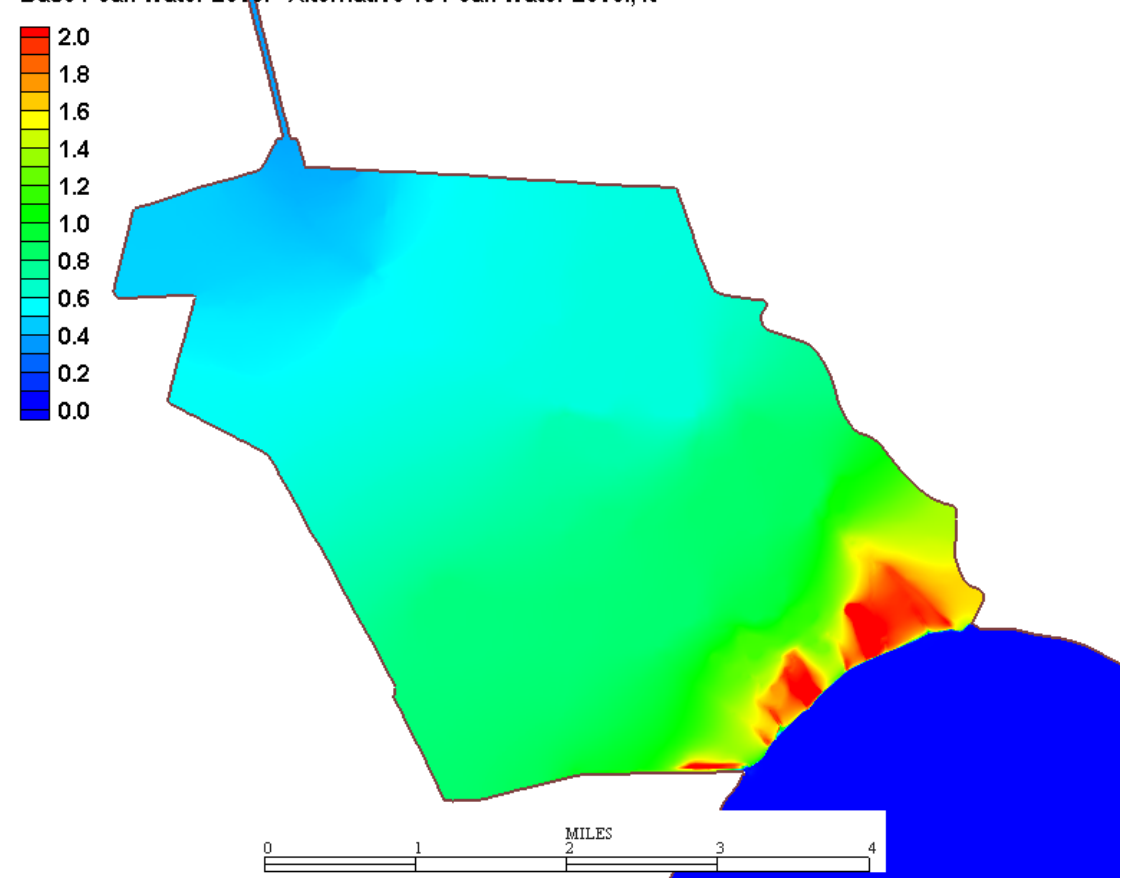

Base Solution - Alternative 10 Solution

Figure 51. Contour difference plots of the base conditions and Alternatives 9-10. 


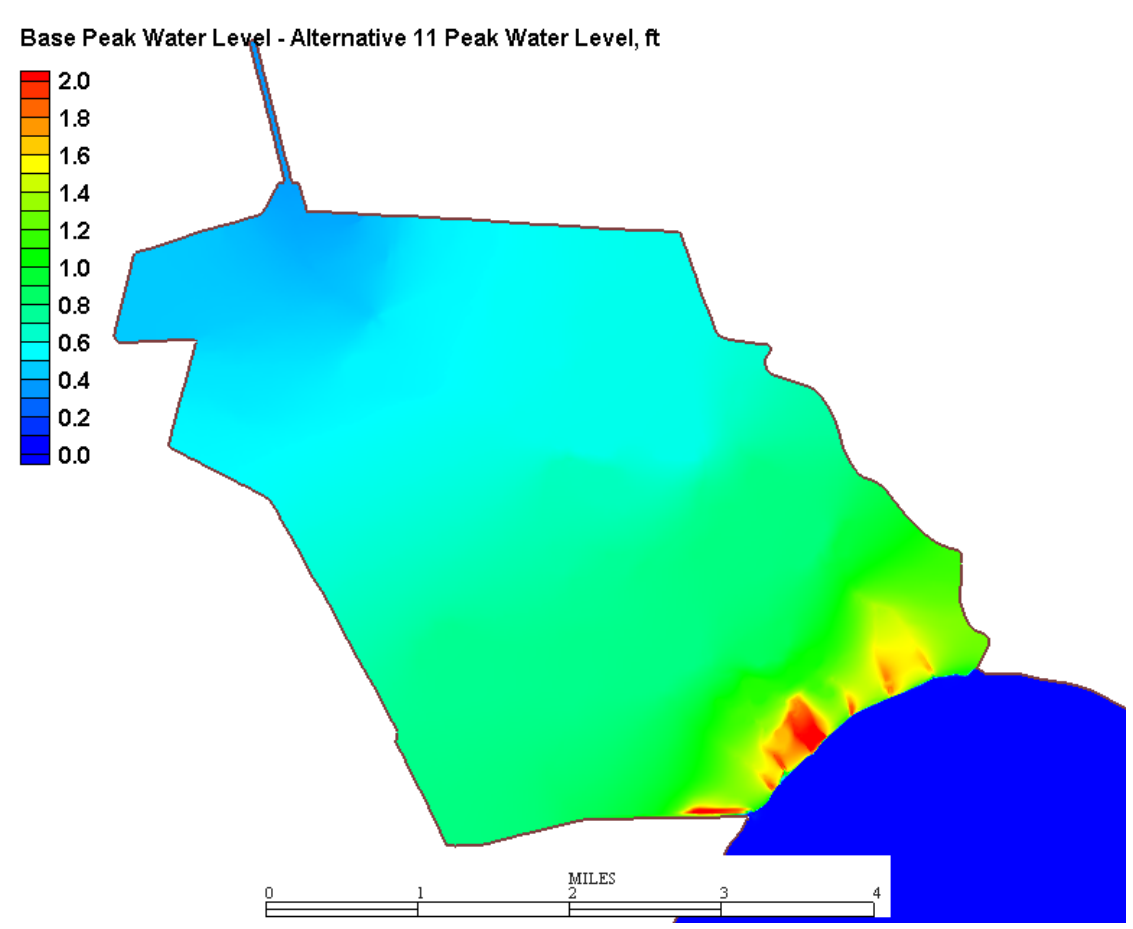

Base Solution - Alternative 11 Solution

Base Peak Water Level - Alternative 12 Peak Water Level, $\mathrm{ft}$

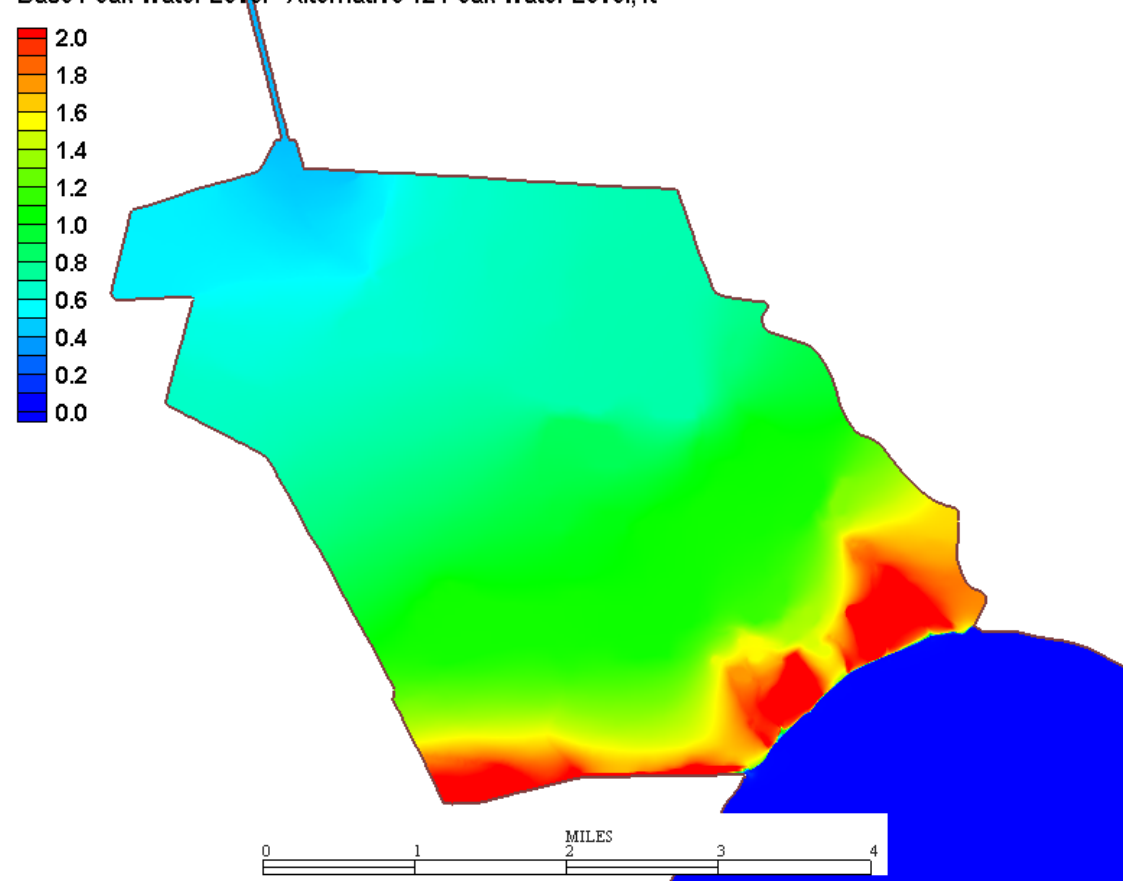

Base Solution - Alternative 12 Solution

Figure 52. Contour difference plots of the base conditions and Alternatives 11-12. 


\section{Conclusions}

From the initial set of alternatives, it was determined using the hydrodynamic model that the primary restriction to the passage of water through the system, and the concomitant excessive water levels, was the gabion weir in conjunction with the ridge just north of the weir located along the southern boundary of the Davis Pond marsh. The ridge and rock weir restricted the flow of water from the marsh area into Lake Cataouatche, creating perched water levels in the Davis Pond marsh. Alternatives 4-6 increased the size of the cuts in the ridge and weir, allowing more water to pass into Lake Cataouatche. It was noted that these increased connections to Lake Cataouatche revealed a channel conveyance restriction between the upper and lower ponding areas (see the water surface elevation profile plot, Figure 35, for Alternatives 4-6 at 10,000 ft upstream of Lake Cataouatche). Alternatives 7 and 8 produced little improvement, but that result could be due the model domain limitations. Alternative 12 was tested with areas added to the model domain to include channels to the south in order to allow for additional means of conveying water from the Cypress Lumber Canal into Lake Cataouatche. These additional areas allowing water to pass out of the ponding area made Alternative 12 the most beneficial alternative in terms of water level.

No alternative produced results at or below the desired water surface elevation profile. The most extreme alternatives produced water surface elevation profiles that were a foot or higher than the desired water surface elevation profiles. Alternative 12, with an inflow of 5,000 cfs, produced results that were still over $0.25 \mathrm{ft}$ above the desired profile. Additional lowering of the discharge could produce a water surface profile at or below the desired profile, but this lower inflow may not meet the habitat restoration goals for the entire Barataria Basin.

From these results, it can be concluded that the desired water surface elevation profile is an unrealistic goal for anything short of drastic modifications to the system or drastic lowering of the desired inflow. 


\section{References $^{2}$}

Ackers, P., and W. R. White. 1973. Sediment transport: New approach and analysis. Journal, Hydraulics Division, American Society of Civil Engineers, 99(HY-11):2041-2060.

Ariathurai, R., R. D. MacArthur, and R. C. Krone. 1977. Mathematical model of estuarial sediment transport. Technical Report D-77-12. Vicksburg, MS: U.S. Army Engineer Waterways Experiment Station.

Brigham Young University. 2002. SMS version 8.o reference manual for the Surface Water Modeling System. Provo, UT: Engineering Graphics Laboratory. http://chl.wes.army.mil/software/tabs/docs.htp.

Flather, R. A. 1988. A numerical model investigation of tides and diurnal-period continental shelf waves along Vancouver Island. Journal of Physical Oceanography 18:115-139.

Garratt, J. R. 1977. Review of drag coefficients over oceans and continents. Monthly Weather Review 105:915-929.

King, I. P., and R. Rachiele. 1989. Program documentation: A two dimensional water quality model; Version 3.o. Lafayette, CA: Resource Management Associates.

Krone, R. B. 1962. Flume studies of transport of sediment in estuarial shoaling processes. Final Report. Berkeley, CA: Hydraulics Engineering Research Laboratory, University of California.

Letter, J. V., Jr. 1993. Grand and White Lakes flood control project; Numerical model investigation. Technical Report HL-93-11. Vicksburg, MS: U.S. Army Engineer Waterways Experiment Station.

LeProvost, C., and A. Poncet. 1987. Finite element method for spectral modeling of tides. Int. J. Num. Methods Eng. 12:853-871.

New Orleans District. 2004. Davis Pond freshwater diversion structure. New Orleans, LA. http://www.mvn.usace.army.mil/pao/dpond/davispond.htm.

Norton, W. R., and I. P. King. 1977. Operating instructions for the computer program. Lafayette, CA: Resource Management Associates.

Partheniades, E. 1962. A study of erosion and deposition of cohesive soils in salt water. PhD diss., University of California, Berkeley, CA.

Raudkivi, A. J. 1990. Loose boundary hydraulics. Third ed. Pergamon Press.

\footnotetext{
2 An annotated Bibliography of selected TABS-MD applications is available at: http://chl.erdc.usace.army.mil/Media/3/3/5/TAB_2001_bib.pdf.
} 
Roig, L. C. 1995. Mathematical theory and numerical methods for the modeling of wetland hydraulics. In Water Resources Engineering, Proceedings of the 1995 First International Conference San Antonio, Texas, August 14-18, 1995. New York: ASCE, 249-253.

Swart, D. H. 1976. Coastal sediment transport, computation of longshore transport. R968, Part 1. The Netherlands: Delft Hydraulics Laboratory.

Thomas, W. A., and W. H. McAnally, Jr. 1985. User's manual for the generalized computer program system; Open-channel flow and sedimentation: main text and appendices A through O. Instruction Report. Vicksburg, MS: U.S. Army Engineer Waterways Experiment Station.

U.S. Army Engineer Research and Development Center. 2003. Users Guide to RMA2WES Version 4.5. Vicksburg, MS: Coastal and Hydraulics Laboratory.

White, W. R., H. Milli, and A. D. Crabbe. 1975. Sediment transport theories: An appraisal of available methods. Report Int 119, Vols 1 and 2. Wallingford, England: Hydraulics Research Station. 


\section{Appendix A: Description of Marsh Porosity and Its Application to Floatant Marsh}

\section{General overview}

The marsh porosity method was developed (Roig 1995) as a transition method between wet and dry states within RMA2. The partial motivation was to eliminate the severe shocks that occur with conventional wetting and drying, which must rather arbitrarily define elements as either wet or dry. Combine the binary wet/dry state decision with numerical oscillations, and the model often becomes unstable while attempting to resolve wet/dry boundaries within the nonlinear iterations for a time step for the conventional wetting and drying logic.

The basic philosophy of the marsh porosity method is that there is a gradual and continuous variation between the wet and dry states that is both more realistic and more stable numerically. The implementation of the method involves the definition of a fractional wetted area as a function of water surface elevation. The implementation of the method within RMA2 is limited to a four-phase variation (see Figure A1) for the case of a falling water surface elevation. In the first phase, at an extremely high relative water level, the node is viewed as completely wet, with a fractional wetted area of 1.0 (above an elevation of $4 \mathrm{ft}$ in Figure A1). As the water level falls, the node enters the second transition phase, where the fractional wetted area decreases linearly with falling water level (between elevations 1.2 and 3.0 in Figure A1). The third phase is the portion of the vertical distribution where the fractional wetted area takes on a minimum value $\left(\mathrm{AC}_{3}\right.$ in Figure A1 for elevations between 0.0 and 1.2). The final phase would be the dry phase when the water level falls below o.o. In the actual implementation in RMA2, the drying logic will dry the node when the local water depth falls below the drying threshold (DSETD on the DE card).

The marsh porosity method is implemented within RMA2 on a nodal basis. This has been the source of considerable confusion to users developing an understanding of the technique. The fractional wetted area is more easily conceptualized on an elemental basis but, in fact, it is actually representative of the local area associated with each node. Mathematically, 


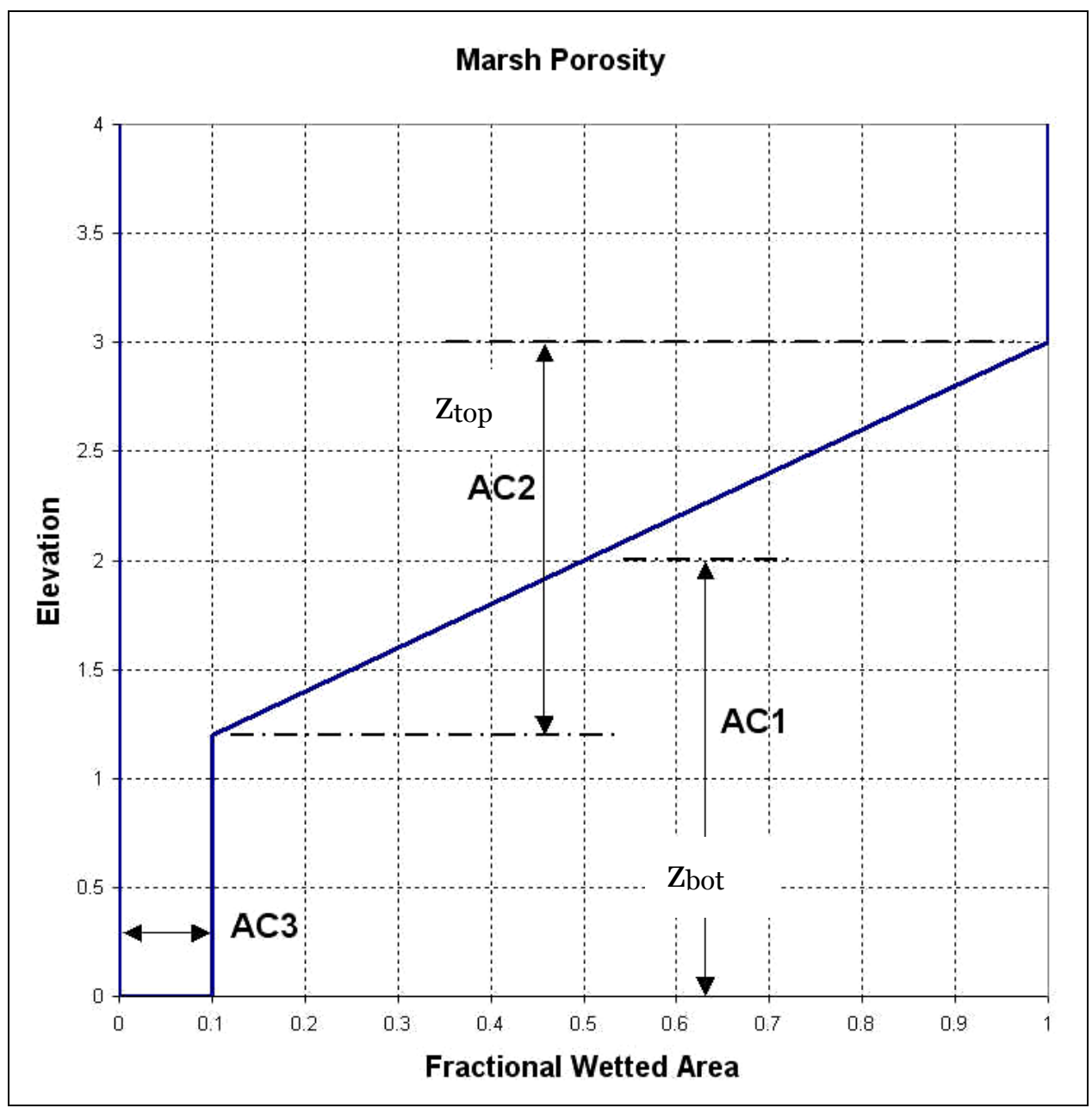

Figure A1. Basic marsh porosity specification in RMA2.

the influence of the marsh porosity of each node is distributed over each element based on the finite element nodal basis functions of the element. This means that the closer one is to the node, the more effective its nodal marsh porosity value is, and the farther away, the less influence it has.

Ultimately the decision of whether an element is wet or dry comes down to the status of the wet or dry state of each of the nodes in the element. In the conventional wetting and drying approach, without marsh porosity, an element is made dry if a single node within the element becomes dry. When marsh porosity is invoked, the element becomes dry only after every node in the element is "dry". This is logical in that if it were the same as the conventional method of wetting and drying, then it would not provide the desired transition. By deferring the drying process until all nodes are dry, the shock is removed. In the process of deferring drying, the remaining wet nodes within the element are passing less and less water due to the 
restricting effect of reducing the fractional wetted area. The flow-restricting effect is accentuated when the bottom roughness is prescribed as a function of water depth.

\section{Mathematical implementation}

The mathematics of the implementation are rather elegant. The basic governing equations for RMA2 are summarized below, as extracted from RMA2 users' guide (USACE 2003).

The generalized computer program RMA2 solves the depth-integrated equations of fluid mass and momentum conservation in two horizontal directions. The forms of the solved equations are

$$
\begin{gathered}
h \frac{\partial u}{\partial t}+h u \frac{\partial u}{\partial x}+h v \frac{\partial u}{\partial y}-\frac{h}{p}\left[\mathrm{E}_{x x} \frac{\partial^{2} u}{\partial x^{2}}+\mathrm{E}_{x y} \frac{\partial^{2} u}{\partial y^{2}}\right] \\
+g h\left[\frac{\partial a}{\partial x}+\frac{\partial h}{\partial x}\right]+\frac{g u n^{2}}{\left(1.486 h^{1 / 6}\right)^{2}}\left(u^{2}+v^{2}\right)^{1 / 2} \\
-\zeta V_{a}^{2} \cos \psi-2 h v \omega \sin \Phi=0 \\
h \frac{\partial v}{\partial t}+h u \frac{\partial v}{\partial x}+h v \frac{\partial v}{\partial y}-\frac{h}{p}\left[\mathrm{E}_{y x} \frac{\partial^{2} v}{\partial x^{2}}+\mathrm{E}_{y y} \frac{\partial^{2} v}{\partial y^{2}}\right] \\
+g h\left[\frac{\partial a}{\partial y}+\frac{\partial h}{\partial y}\right]+\frac{g v n^{2}}{\left(1.486 h^{1 / 6}\right)^{2}}\left(u^{2}+v^{2}\right)^{1 / 2} \\
-\zeta V_{a}^{2} \sin \psi+2 h u \omega \sin \Phi=0 \\
\frac{\partial h}{\partial t}+h\left(\frac{\partial u}{\partial x}+\frac{\partial v}{\partial y}\right)+u \frac{\partial h}{\partial x}+v \frac{\partial h}{\partial y}=0
\end{gathered}
$$

where:

$$
\begin{aligned}
h & =\text { depth } \\
u, v & =\mathrm{x} \text { and } \mathrm{y} \text { direction velocities, respectively } \\
x, y, t & =\text { Cartesian coordinates and time } \\
\rho & =\text { density of fluid }
\end{aligned}
$$


$\varepsilon=$ eddy viscosity coefficient, for $\mathrm{xx}=$ normal direction on $\mathrm{x}$-axis surface; $\mathrm{yy}=$ normal direction on $\mathrm{y}$-axis surface;

$\mathrm{xy}$ and $\mathrm{yx}=$ shear direction on each surface

$g=$ acceleration due to gravity

$a=$ elevation of bottom

$n=$ Manning's n value

1.486 = conversion from SI (metric) to non-SI units

$\zeta=$ empirical wind shear coefficient

$V_{a}=$ wind speed

$\psi=$ wind direction

$\omega=$ rate of earth's angular rotation

$\Phi=$ local latitude.

The application of the marsh porosity method is accomplished by defining an effective marsh porosity depth. This is defined as the integral of the fractional wetted area from the relative zero elevation in Figure A1 (bottom of the offset channelized area) to the water surface elevation:

$$
h_{\sigma}=\int_{0}^{h} K d z
$$

where $K$ is the fractional wetted area presented in Figure A1. The specification of $K$ is as follows for the special case that $h>z_{\text {top }}$ :

$$
K\left\{\begin{array}{lr}
=A C 3 & \text { for } z<z_{b o t} \\
=A C 3+\frac{(1-A C 3)\left(z-z_{b o t}\right)}{A C 2} & \text { for } z_{b o t}<z<z_{\text {top }} \\
=1 & \text { for } z_{\text {top }}<z<h
\end{array}\right.
$$

For this special case $\left(h>z_{\text {top }}\right)$ the effective depth can be evaluated.

$$
\begin{aligned}
h_{\sigma} & =\int_{0}^{h} K d z=\int_{0}^{z_{b o t}} A C 3 d z+\int_{z_{b o t}}^{z_{\text {top }}}\left[A C 3+\frac{(1-A C 3)\left(z-z_{b o t}\right)}{A C 2}\right] d z \\
& +\int_{z_{t o p}}^{h} d z \\
& =h-\frac{(1-A C 3)\left(z_{\text {top }}+z_{b o t}\right)}{2}
\end{aligned}
$$


In the application of this to the governing equations, there are two steps that should be mentioned. First, the depth $\mathrm{h}$ defined above is a modified depth from the depth displayed within the Surface-water Modeling System (SMS) (Brigham Young University [BYU] 2002) for the nodal elevation. The first thing that is done when marsh porosity is used is to "offset" the bottom elevation by the distance $\mathrm{AC} 1\left(h=h_{S M S}-\mathrm{AC} 1\right)$. The next step is to develop an effective depth factor based on the integrated value above.

$$
\sigma=\frac{h_{\sigma}}{h}
$$

If the governing equations above are multiplied through by $\sigma$, the equations are converted to the same equations as above, but with $h_{\sigma}$ substituted for $h$. The wind stress and friction terms will be appropriately reduced by $\sigma$, which varies between 0 and 1 , corresponding to the reduced surface area over which these terms act. When the nonlinear equations are solved via Newton-Raphson iteration, the Jacobian matrix has additional terms involving $\frac{\partial h_{\sigma}}{\partial h}$. When the water surface is well above $z_{\text {top }}$ these corrections are not significant. Equation A4 shows that the marsh porosity results in a reduction in the actual water depth. If the coefficients $\mathrm{AC} 1, \mathrm{AC}_{2}$ and $\mathrm{AC}_{3}$ are zero, then $z_{b o t}=z_{t o p}=A_{0}$, the elevation from the SMS geometry file, and $h_{\sigma}=h$.

The usefulness of the marsh porosity method has been extending beyond its original intent. It was recognized that the vertical variation in the marsh porosity factor is directly analogous to the statistical distribution of bottom elevation. With this analogy complex, sub-mesh scale geometric variations can be represented on various spatial scales using marsh porosity. This approach was first applied to wetlands on the coast of Louisiana on spatial scales of miles to represent canals and levees along with natural wetland topography (Letter 1993). It has been routinely applied to other estuarine systems.

The use of marsh porosity as a statistical representation of sub-grid scale features makes the use of conventional wetting and drying less of a necessity. Because the method now represents the statistical variation, physically removing the element from the computational domain has less meaning. This leads to an additional alternative in the application of marsh porosity, where the offset elevation (AC1) is set such that the statistical 
minimum elevation is always wet and no wetting and drying is performed. This approach is very stable numerically.

\section{Floatant marsh}

The study area, Davis Pond, is covered extensively by floatant marsh, where water is able to flow through and underneath a floating mat of vegetation. The effect of this on the routing of flow through the system was evaluated by considering the analogy to marsh porosity.

The floatant marsh is considered in the context of marsh porosity in two ways. First the analogy of the presence of the floatant marsh on a uniform horizontal mineral bottom is considered. Then the presence of the floatant marsh in addition to the variable bottom elevation with a description via mash porosity is evaluated.

Assume for consideration a thickness of the floating marsh, $D$, of which a thickness $d$ is submerged. The water depth is $h$ above the mineral bottom. The porosity of the floating mat is $P_{m}$ as shown in Figure A2.

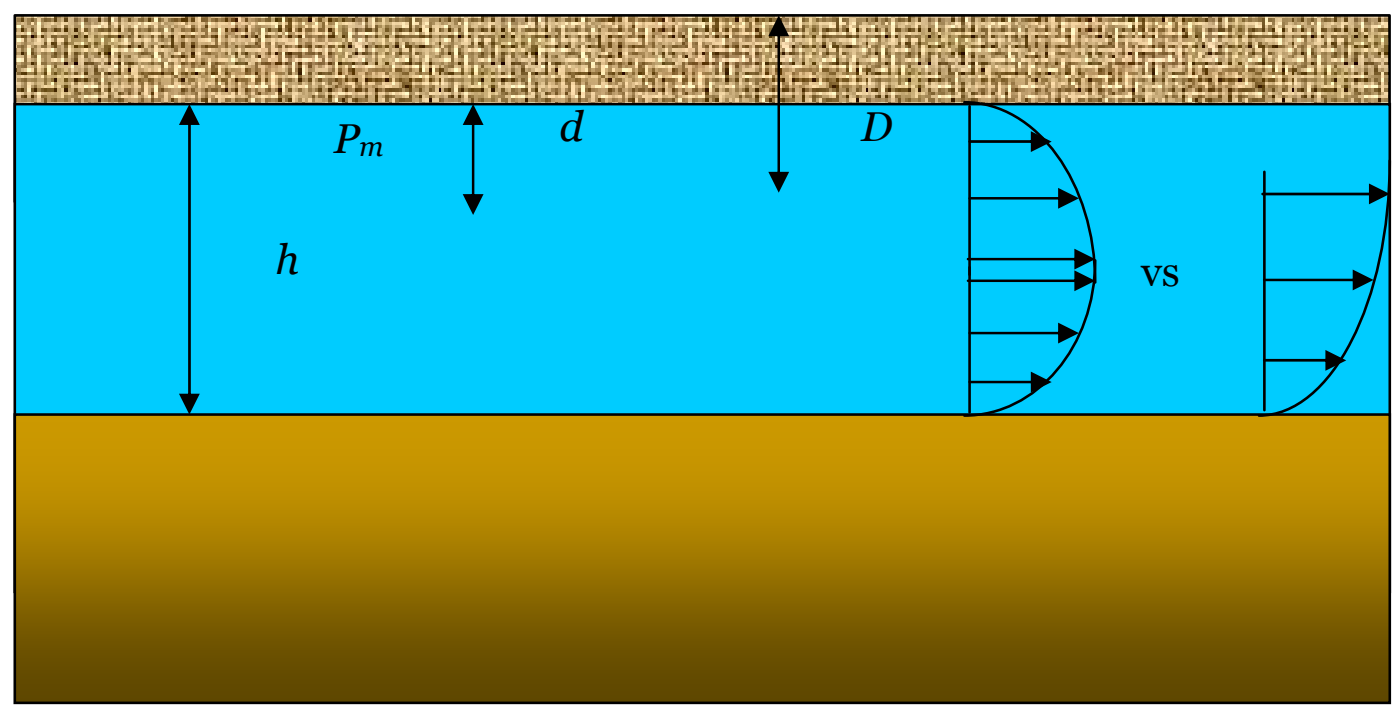

Figure A2. Schematic of floatant marsh parameters.

The effective flow area per unit width will be

$$
h-d+P_{m} d
$$

Expressing this area as a fractional area of the full depth area gives a "marsh porosity factor" of 


$$
\begin{aligned}
K & =1-d\left(1-P_{m}\right) / h & \text { for } \mathrm{h}>\mathrm{d} \\
& =P_{m} & \text { for } \mathrm{h}<\mathrm{d}
\end{aligned}
$$

This factor is plotted in Figure A3 for $\mathrm{d}=1.0$ and $P_{m}=0.15$. The curve is nonlinear for values of $h>d$. In an attempt to linearize the distribution for application in RMA2 we can assume that after the depth gets larger than the submerged portion of the floating mat $(h>d)$, the flow is restricted to the area below the mat $(h-d)$. The mat may have some small movement, but that flow will be offset by the reduction in the velocity profile adjacent to the bottom of the mat (see Figure A2). We will therefore assume that there is no contribution of flow from the water within the mat. This will simplify the marsh porosity distribution to

$$
\begin{aligned}
K & =1-d / h & & \text { for } h>d \\
& =P_{m} & & \text { for } h<d
\end{aligned}
$$

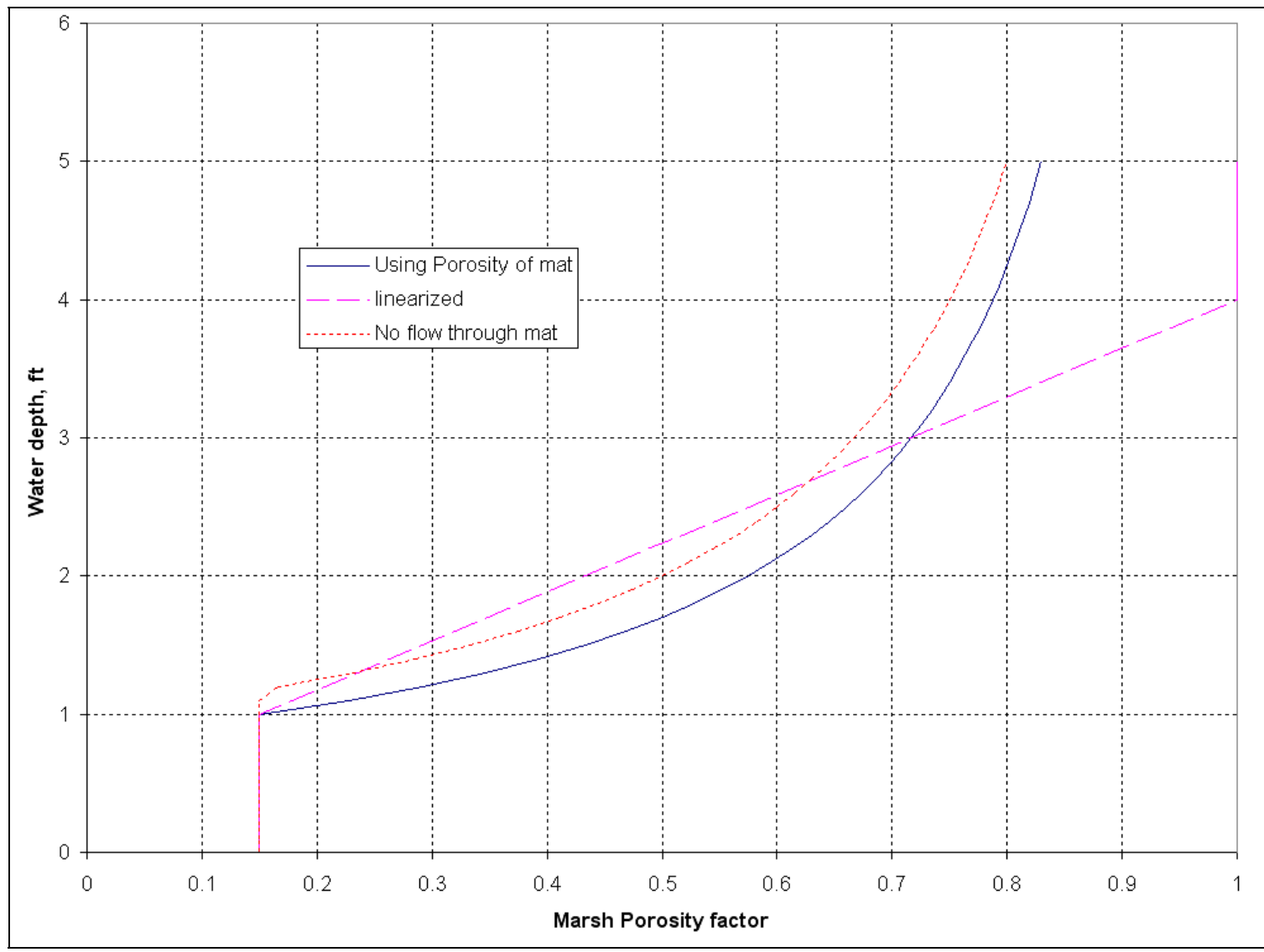

Figure A3. The marsh porosity factor for example $d=1.0, P_{m}=0.15$. 
For this simplification to work, we will need to recognize the further restriction that the value of $K$ must be greater than $P_{m}$. This is also nonlinear, and is presented in Figure A2. Note that for this simplification, the marsh porosity reaches the minimum value of $P_{m}$ at a greater water depth than for Equation A1. This effect is more severe for the case of $P_{m}=0.4$ with still $d=1.0$, as presented in Figure A4. This approach will therefore not be reasonable.

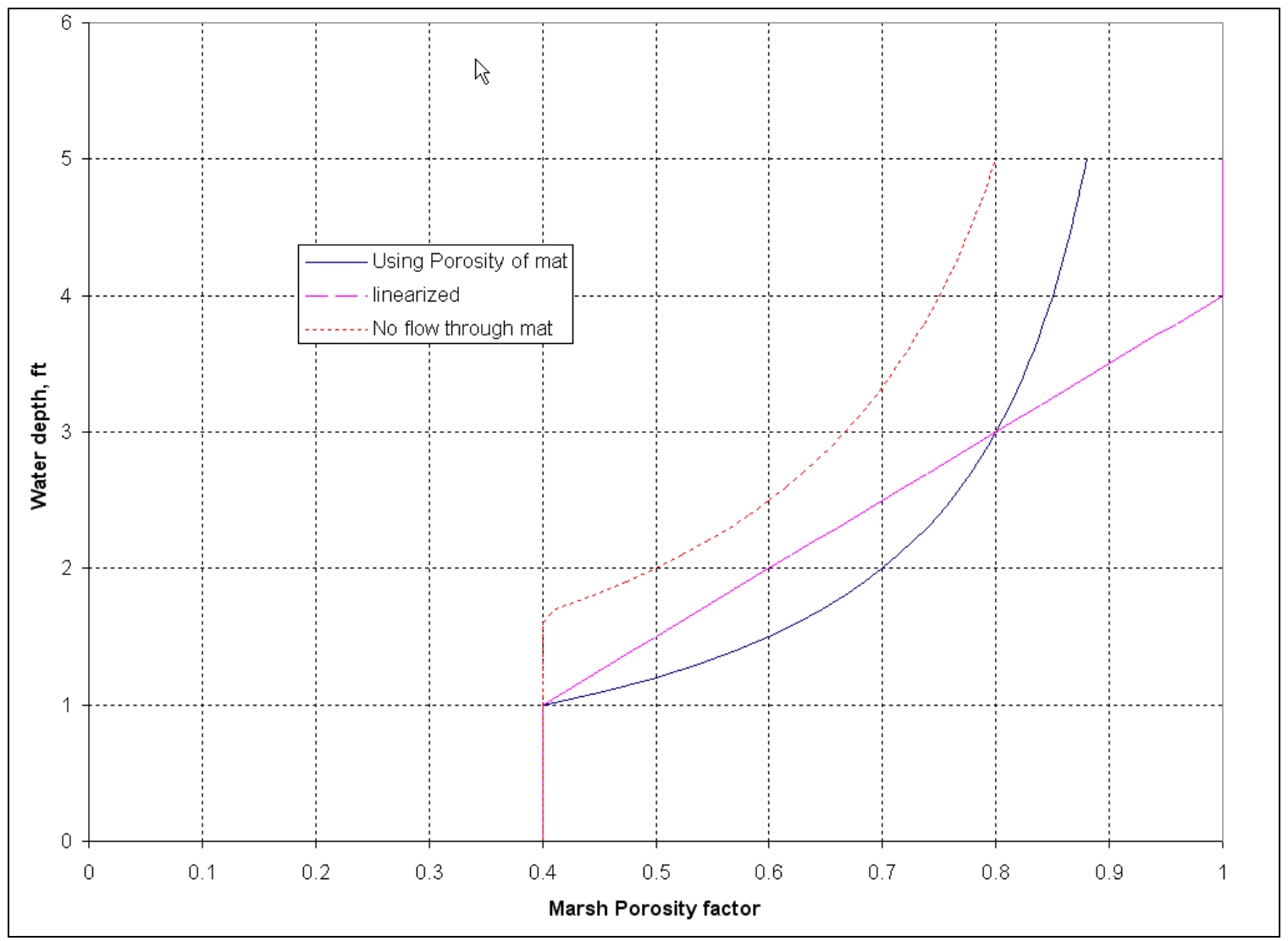

Figure A4. Marsh porosity representation for $d=1.0, P_{m}=0.4$.

So to assume a linear form of the marsh porosity factor, we assert the following form:

$$
K=P_{m}+\alpha(h-d)\left(1-P_{m}\right) \quad \text { still for } h>d
$$

In order to completely define this distribution we must select which is in fact the inverse of $\mathrm{AC}_{2}$ in the RMA2 input. For the case presented in Figure A3, we set $\alpha=1 / 3$. 
The selection of an appropriate value of $\alpha$ could come from a minimization of the deviation from the theoretical nonlinear curve. It could be estimated in one of several ways. First, the minimization integral can be defined as

$$
\int_{d}^{h_{\max }}\left(k_{\text {non }}-k_{\text {lin }}\right) d z
$$

where the $k_{\text {non }}$ is the nonlinear relation in Equation $\mathrm{A} 1$ and $k_{l i n}$ is the linear relationship in Equation A2. If we assume we know the maximum water depth $d_{\max }$, we can set the integral to zero. The difficulty in evaluating this integral is that the limits (up to $d_{\max }$ ) will likely involve the extension of Equation A2 to depths for which $k>1$. To accurately evaluate the integral requires that the integral be split into two pieces:

$$
\int_{d}^{h_{\max }}\left(k_{\text {non }}-k_{\text {lin }}\right) d z=\int_{d}^{z_{\text {top }}}\left(k_{\text {non }}-k_{\text {lin }}\right) d z+\int_{z_{\text {top }}}^{h_{\max }}\left(k_{\text {non }}-1\right) d z
$$

where $z_{\text {top }}=$ the top elevation of the ultimate linear transition $(\mathrm{Ao}+\mathrm{AC} 2 / 2)$. Unfortunately, $z_{t o p}$ is determined by $\alpha$, which we are attempting to solve for. Therefore, we would need to minimize the integrals in an iterative process.

$$
\begin{aligned}
& \int_{d}^{z_{\text {top }}}\left\{\left\{1-\frac{d}{h}\left(1-P_{m}\right)\right)-\left(P_{m}+\alpha(h-d)\left(1-P_{m}\right)\right)\right\} d h \\
& +\int_{z_{\text {top }}}^{h_{\max }}\left\{\left(1-\frac{d}{h}\left(1-P_{m}\right)\right)-1\right\} d h=0 \\
& \int_{d}^{z_{\text {top }}}\left\{\left(1-P_{m}\right)\left(1-\frac{d}{h}-\alpha(h-d)\right)\right\} d h-\int_{z_{\text {top }}}^{h_{\max }}\left\{\left(\frac{d}{h}\left(1-P_{m}\right)\right)\right\} d h=0
\end{aligned}
$$

These integrals can be evaluated to solve for $\alpha$ as

$$
\alpha=2 \frac{\left(1-P_{m}\right)}{\left(z_{\text {top }}-d\right)}\left\{1-\frac{d}{\left(z_{\text {top }}-d\right)}\left[\ln \left(\frac{h_{\max }}{d}\right)\right]\right\}
$$


Once $\alpha$ is estimated, then $z_{\text {top }}$ can be corrected as $z_{t o p}=d+1 / \alpha$, as shown in Table A1. The estimate for $z_{t o p}$ is then best taken as the average of the previous value and the corrected value. For our example above, if we use $d=1.0, P_{m}=0.4$ and assumed $h_{\max }=5$, using an initial estimate of $z_{\text {top }}$ as 4 we iterate to a value of 0.409 for $\alpha$ and $z_{\text {top }}$ as 3.44.

Table A1 Iterative solution of Equation A11.

\begin{tabular}{|l|l|l|}
\hline Estimate for $z_{\text {top }}$ & Computed value of $\alpha$ & Corrected value of $z_{\text {top }}$ \\
\hline 4 & 0.556225 & 2.797834 \\
\hline 3.398917 & 0.394918 & 3.532173 \\
\hline 3.465545 & 0.416674 & 3.399958 \\
\hline 3.432751 & 0.406115 & 3.462358 \\
\hline 3.447555 & 0.410916 & 3.433585 \\
\hline 3.44057 & 0.408658 & 3.447034 \\
\hline 3.442293 & 0.409216 & 3.443696 \\
\hline 3.442994 & 0.409443 & 3.44234 \\
\hline 3.442667 & 0.409338 & 3.442972 \\
\hline
\end{tabular}

There is an alternative way to optimize the linear fit. Expressing the depth as a function of $k$ for the transition range of depth gives

$$
\begin{aligned}
& h_{\text {non }}=\frac{d\left(1-P_{m}\right)}{(1-k)} \\
& h_{\text {lin }}=d+\frac{\left(k-P_{m}\right)}{\alpha\left(1-P_{m}\right)}
\end{aligned}
$$

The selection of an appropriate value of $\alpha$ could come from a minimization of the deviation from the theoretical nonlinear curve. Now the minimization integral can be defined as

$$
\int_{P_{\min }}^{k_{\max }}\left(h_{\text {non }}-h_{\text {lin }}\right) d k
$$

Notice that the integral is limited to some maximum value $k_{\max }$. This is required because the nonlinear depth estimate has a singularity at $k=1$. Therefore, if we assume a maximum marsh porosity $k_{\max }$ (corresponding to the value at $d_{\mathrm{max}}$ ), we can set the integral to zero and solve for $\alpha$. In this case we do not have to break the integral into two pieces. 


$$
\int_{P_{\min }}^{k_{\max }}\left\{\frac{d\left(1-P_{m}\right)}{(1-k)}-\left(d+\frac{\left(k-P_{m}\right)}{\alpha\left(1-P_{m}\right)}\right)\right\} d k=0
$$

This integral can be evaluated and solved for $\alpha$ as

$$
\alpha=\frac{\left(k_{\max }-P_{m}\right)^{2}}{2 d\left(1-P_{m}\right)\left[\left(1-P_{m}\right) \ln \left(\frac{1-P_{m}}{1-k_{\max }}\right)-k_{\max }+P_{\mathrm{m}}\right]}
$$

The best way to approach the estimate of $k_{\max }$ is to use equation 1 with $h_{\max }$ for $h$. Using the example from above, the estimated $k_{\max }$ would be 0.88 .

This yields a value of $\alpha$ as 0.395 , as compared with 0.409 from the method above.

These values of $\alpha$ can then be used to estimate the marsh porosity values for use in RMA2 for the flat mineral bottom case.

$$
\left.\begin{array}{l}
A C 1=d \\
A C 2=\frac{1}{\alpha\left(1-P_{m}\right)} \\
A C 3=P_{m}
\end{array}\right\}
$$

Table A2 presents calculations with varying values of $d, P_{m}$ and $h_{\max }$ for the flat bottom handling of the floatant marsh. 
Table A2 Floatant marsh on flat bottom. Variation of AC2 computations for variations in $d, P_{m}$ and $h_{\max }$.

\begin{tabular}{|c|c|c|c|c|c|c|c|}
\hline$d$ & $P_{m}$ & $h_{\max }$ & $k_{\max }$ & $\alpha$, via $d h$ & $\alpha$, via $d k$ & $\alpha$, avg & AC2 \\
\hline 0.5 & 0.2 & 5 & 0.920 & 0.563 & 0.577 & 0.570 & 2.2 \\
\hline 0.5 & \begin{tabular}{|l|}
0.2 \\
\end{tabular} & 4 & 0.900 & \begin{tabular}{|l|}
0.601 \\
\end{tabular} & 0.636 & 0.619 & 2.0 \\
\hline 0.5 & 0.2 & 3 & 0.867 & 0.658 & 0.725 & 0.692 & 1.8 \\
\hline 0.5 & 0.2 & 2 & 0.800 & 0.759 & 0.884 & 0.822 & 1.5 \\
\hline 0.5 & 0.2 & 1 & 0.600 & 1.029 & 1.294 & 1.162 & 1.1 \\
\hline 0.5 & 0.3 & 5 & 0.930 & 0.536 & 0.577 & 0.557 & 2.6 \\
\hline 0.5 & 0.3 & 4 & 0.913 & 0.570 & 0.636 & 0.603 & 2.4 \\
\hline 0.5 & 0.3 & 3 & 0.883 & 0.621 & 0.725 & 0.673 & 2.1 \\
\hline 0.5 & 0.3 & 2 & 0.825 & 0.711 & 0.884 & 0.798 & 1.8 \\
\hline 0.5 & 0.3 & 1 & 0.650 & 0.943 & 1.294 & 1.119 & 1.3 \\
\hline 0.5 & 0.4 & 5 & 0.940 & 0.504 & 0.577 & 0.541 & 3.1 \\
\hline 0.5 & 0.4 & 4 & 0.925 & 0.534 & 0.636 & 0.585 & 2.8 \\
\hline 0.5 & 0.4 & 3 & 0.900 & 0.578 & 0.725 & 0.652 & 2.6 \\
\hline 0.5 & 0.4 & 2 & 0.850 & 0.655 & 0.884 & 0.770 & 2.2 \\
\hline 0.5 & 0.4 & 1 & 0.700 & 0.848 & 1.294 & 1.071 & 1.6 \\
\hline 0.5 & 0.2 & 5 & 0.920 & 0.563 & 0.577 & 0.570 & 2.2 \\
\hline 1 & 0.2 & 5 & 0.840 & 0.447 & 0.395 & 0.421 & 3.0 \\
\hline 1 & 0.2 & 4 & 0.800 & 0.451 & 0.442 & 0.447 & 2.8 \\
\hline 1 & 0.2 & 3 & 0.730 & 0.518 & 0.514 & 0.516 & 2.4 \\
\hline 1 & 0.2 & 2 & 0.600 & 0.759 & 0.647 & 0.703 & 1.8 \\
\hline 1 & 0.2 & 1.5 & 0.470 & 0.970 & 0.770 & 0.870 & 1.4 \\
\hline 1 & 0.3 & 5 & 0.860 & 0.430 & 0.395 & 0.413 & 3.5 \\
\hline 1 & 0.3 & 4 & 0.825 & 0.476 & 0.442 & 0.459 & 3.1 \\
\hline 1 & 0.3 & 3 & 0.767 & 0.522 & 0.514 & 0.518 & 2.8 \\
\hline 1 & 0.3 & 2 & 0.650 & 0.711 & 0.647 & 0.679 & 2.1 \\
\hline 1 & 0.3 & 1.5 & 0.533 & 0.893 & 0.770 & 0.832 & 1.7 \\
\hline 1 & 0.4 & 5 & 0.880 & 0.409 & 0.395 & 0.402 & 4.1 \\
\hline 1 & 0.4 & 4 & 0.850 & 0.451 & 0.442 & 0.447 & 3.7 \\
\hline 1 & 0.4 & 3 & 0.800 & \begin{tabular}{|l}
0.518 \\
\end{tabular} & 0.514 & 0.516 & 3.2 \\
\hline 1 & 0.4 & 2 & 0.700 & 0.655 & 0.647 & 0.651 & 2.6 \\
\hline 1 & 0.4 & 1.5 & 0.600 & 0.807 & 0.770 & 0.789 & 2.1 \\
\hline 2 & 0.2 & 5 & 0.680 & \begin{tabular}{|l|}
0.372 \\
\end{tabular} & 0.285 & 0.329 & 3.8 \\
\hline 2 & 0.2 & 4 & 0.600 & \begin{tabular}{|l|l}
0.497 \\
\end{tabular} & 0.324 & 0.411 & 3.0 \\
\hline 2 & 0.2 & 3 & 0.467 & 0.696 & 0.385 & 0.541 & 2.3 \\
\hline 2 & 0.2 & 2.5 & 0.360 & 0.933 & 0.432 & 0.683 & 1.8 \\
\hline 2 & 0.3 & 5 & 0.720 & 0.391 & 0.285 & 0.338 & 4.2 \\
\hline 2 & 0.3 & 4 & 0.650 & 0.476 & 0.324 & 0.400 & 3.6 \\
\hline 2 & 0.3 & 3 & 0.533 & 0.656 & 0.385 & 0.521 & 2.7 \\
\hline 2 & 0.3 & 2.5 & 0.440 & 0.862 & 0.432 & 0.647 & 2.2 \\
\hline 2 & 0.4 & 5 & 0.760 & \begin{tabular}{|l}
0.375 \\
\end{tabular} & 0.285 & 0.330 & 5.1 \\
\hline 2 & 0.4 & 4 & 0.700 & 0.451 & 0.324 & 0.388 & 4.3 \\
\hline 2 & 0.4 & 3 & 0.600 & 0.608 & 0.385 & 0.497 & 3.4 \\
\hline 2 & 0.4 & 2.5 & 0.520 & \begin{tabular}{|l}
0.781 \\
\end{tabular} & 0.432 & 0.607 & 2.7 \\
\hline
\end{tabular}




\section{Combined effect of floating marsh and conventional marsh porosity}

The normal specification of marsh porosity will complicate the incorporation of the effects of the floating marsh. Therefore, for completeness we will evaluate the effects of the floating mat in combination with conventional marsh porosity specification.

There are several cases that need to be considered. These involve the relative floating mat thickness compared with the variation parameter (AC2 on the DM card) for conventional marsh porosity, and the water depth. The goal of this analysis is to develop the functional relationship between the effective marsh porosity (i.e., including floatant marsh effects) and water depth. These cases can be grouped by where the water surface elevation lies within the vertical variation of the marsh porosity (see Figure A1). These cases are:

1. Case 1: the water surface is higher than $z_{\text {top }}$.

2. Case 2: the water level; falls in the range $z_{b o t}<h<z_{t o p}$.

3. Case 3: the water level is lower than $z$ bot.

4. Case 4: the water surface is below zero and the node is dry (not considered).

Each case has sub-cases based on how deep the bottom of the floating mat reaches within the marsh porosity variation. These cases are defined in Table A3 and illustrated in Figure A5.

Table A3. Cases for floatant marsh in conjunction with marsh porosity bottom.

\begin{tabular}{|c|c|c|}
\hline Case & Water Surface Elevation & Bottom of Floating Mat \\
\hline $1 \mathrm{a}$ & $h>z_{\text {top }}$ & $h-d>z_{\text {top }}$ \\
\hline $1 b$ & $h>z_{\text {top }}$ & $Z_{\text {bot }}<h-d<Z_{\text {top }}$ \\
\hline $1 c$ & $h>z_{\text {top }}$ & $0<h-d<Z_{b o t}$ \\
\hline $1 d$ & $h>$ Ztop & $h-d=0$ \\
\hline $2 a$ & $Z_{\text {bot }}<h<Z_{\text {top }}$ & $Z_{\text {bot }}<h-d<Z_{\text {top }}$ \\
\hline $2 b$ & $z_{\text {bot }}<h<Z_{\text {top }}$ & $0<h-d<Z_{b o t}$ \\
\hline $2 c$ & $Z_{\text {bot }}<h<Z_{\text {top }}$ & $h-d=0$ \\
\hline 3a & $0<h<Z_{\text {bot }}$ & $0<h-d<Z_{b o t}$ \\
\hline $3 b$ & $0<h<Z_{\text {bot }}$ & $h-d=0$ \\
\hline
\end{tabular}




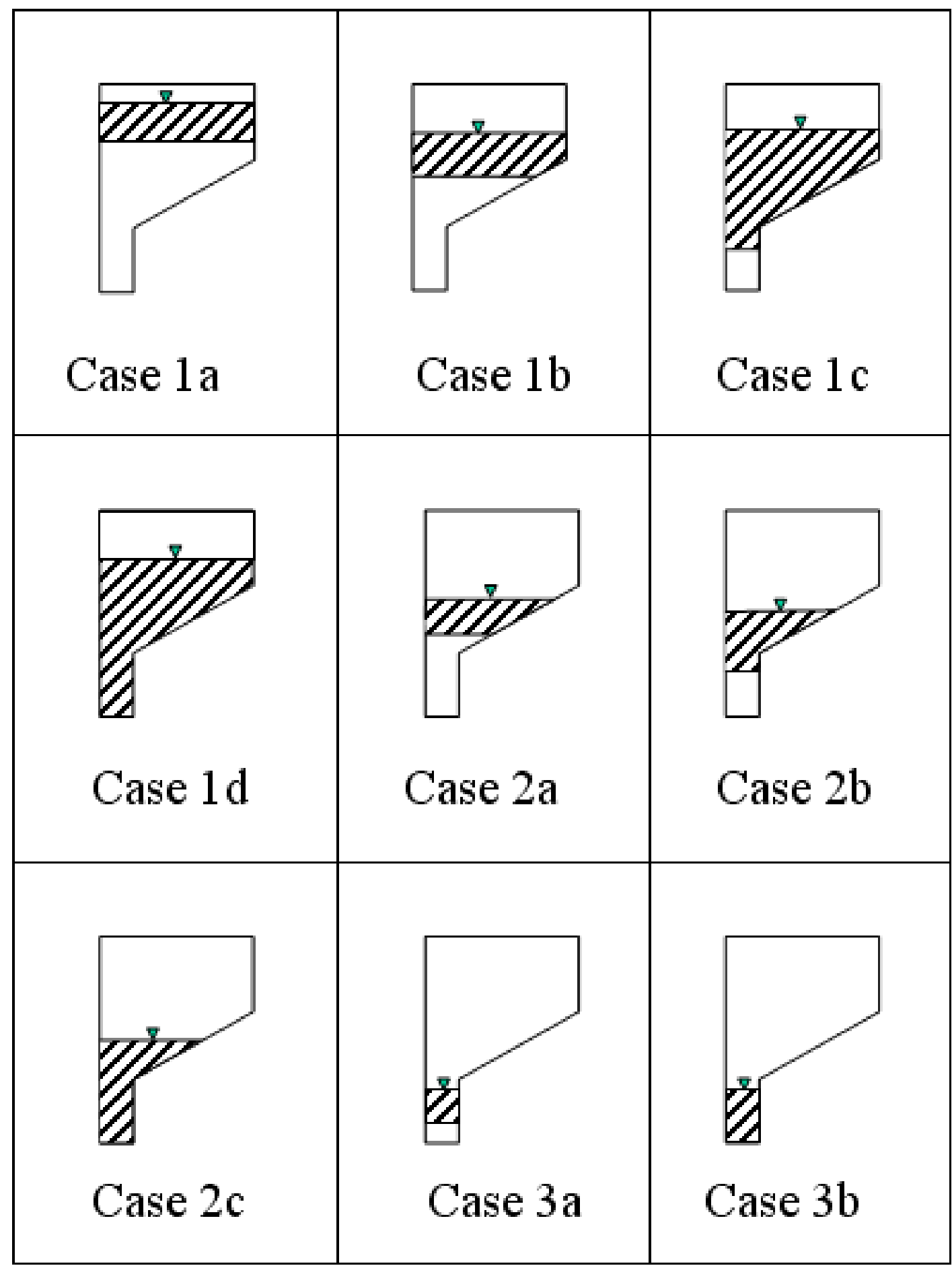

Figure A5. Definition of sub-cases for combined floating marsh with marsh porosity bottom elevation variation. 


\section{Case 1a}

This gives the marsh porosity factor vertical distribution as

$$
\begin{aligned}
K & =A C 3 & & \text { for } z<z_{b} \\
& =A C 3+\frac{(1-A C 3)\left(z-z_{b}\right)}{A C 2} & & \text { for } z_{b}<z<z_{t} \\
& =1 & & \text { for } z_{t}<z<(h-d) \\
& =P_{m} & & \text { for }(h-d)<z<h
\end{aligned}
$$

The integrated composite marsh porosity is then

$$
\begin{aligned}
h_{\sigma} & =\int_{0}^{h} K d z=\int_{0}^{z_{b}} A C 3 d z+\int_{z_{b}}^{z_{t}}\left[A C 3+\frac{(1-A C 3)\left(z-z_{b}\right)}{A C 2}\right] d z \\
& +\int_{z_{t}}^{h-d} d z+\int_{h-d}^{h} P_{m} d z \\
& =A C 3\left(z_{t}\right)+h-d-z_{t}+P_{m} d+\frac{(1-A C 3) A C 2}{2}
\end{aligned}
$$

For this case, the effective value of $K$ is

$$
K_{e f f}=\frac{1}{h} \frac{\partial h_{\sigma}}{\partial h}=1
$$

\section{Case 1b}

When the water level drops such that the floating marsh mat straddles the upper limit of the elevation $z_{t}$, but is higher than $z_{b}$ (see Case $1 \mathrm{~b}$ in Figure A5), we will have

$$
\begin{array}{rlrl}
K & =A C 3 & & \text { for } z<z_{b} \\
& =A C 3+\frac{(1-A C 3)\left(z-z_{b}\right)}{A C 2} & & \text { for } z_{b}<z<h-d \\
& =\left\{A C 3+\frac{(1-A C 3)\left(z-z_{b}\right)}{A C 2}\right\} P_{m} & & \text { for }(h-d)<z<z_{t} \\
& =P_{m} & \text { for } z_{t}<z<h
\end{array}
$$

The composite marsh porosity effective depth is then 


$$
\begin{aligned}
h_{\sigma} & =\int_{0}^{h} K d z=\int_{0}^{z_{b}} A C 3 d z+\int_{z_{b}}^{h-d}\left[A C 3+\frac{(1-A C 3)\left(z-z_{b}\right)}{A C 2}\right] d z \\
& +\int_{h-d}^{z_{t}}\left[A C 3+\frac{(1-A C 3)\left(z-z_{b}\right)}{A C 2}\right] P_{m} d z+\int_{z_{t}}^{h} P_{m} d z \\
& =\int_{0}^{z_{b}} A C 3 d z+\int_{z_{b}}^{z_{t}}\left[A C 3+\frac{(1-A C 3)\left(z-z_{b}\right)}{A C 2}\right] d z \\
& -\int_{h-d}^{z_{t}}\left[A C 3+\frac{(1-A C 3)\left(z-z_{b}\right)}{A C 2}\right]\left(1-P_{m}\right) d z+\int_{z_{t}}^{h} P_{m} d z \\
& =A C 3 \cdot z_{t}+P_{m} d-A C 2\left[\frac{P_{m}}{2}(1-A C 3)+A C 3\right] \\
& +h_{b}\left[A C 3+P_{m}(1-A C 3)\right]-\left(1-P_{m}\right) \frac{(1-A C 3)}{2 \cdot A C 2} h_{b}{ }^{2}
\end{aligned}
$$

where $h b=h-d-z b$.

For this case, the effective composite value of $K$ is

$$
K_{\text {eff }}=\frac{\partial h_{\sigma}}{\partial h}=A C 3+P_{m}(1-A C 3)-\frac{\left(1-P_{m}\right)(1-A C 3)}{A C 2} h_{b}
$$

This equation will apply as long as the floating mat straddles the upper marsh porosity elevation $z_{t}$, regardless of the thickness of the mat. If the thickness of the floating marsh mat is greater than $\mathrm{AC} 2$ we will obtain Case 1c.

\section{Case 1c}

$$
K=\left\{\begin{array}{lrl}
=A C 3 & \text { for } z_{\min }<z<h-d \\
=A C 3 P_{m} & \text { for } h-d<z<z_{\text {bot }} \\
& =P_{m}\left\{A C 3+\frac{(1-A C 3)}{A C 2}\left(z-z_{b o t}\right)\right\} & \text { for } z_{b o t}<z<z_{\text {top }} \\
=P_{m} & \text { for } z_{\text {top }}<z<h
\end{array}\right.
$$

Integrating to define the effective water depth: 


$$
\begin{aligned}
h_{\sigma} & =\int_{0}^{h} K d z=\int_{0}^{h-d} A C 3 d z+\int_{h-d}^{z_{b o t}} A C 3 P_{m} d z+ \\
& +\int_{z_{b o t}}^{z_{t o p}} P_{m}\left\{A C 3+\frac{(1-A C 3)}{A C 2}\left(z-z_{b o t}\right)\right\} d z+\int_{z_{t o p}}^{h} P_{m} d z \\
& =A C 3\left[\left(1-P_{m}\right)(h-d)+P_{m} z_{t o p}\right]+P_{m}\left\{\frac{(1-A C 3) A C 2}{2}+h-z_{t o p}\right\}
\end{aligned}
$$

For this case, the effective value of $K$ is

$$
K_{e f f}=\frac{\partial h_{\sigma}}{\partial h}=A C 3+P_{m}(1-A C 3)
$$

\section{Case 1d}

$$
K=\left\{\begin{array}{lrl}
=A C 3 P_{m} & \text { for } 0<z<z_{b o t} \\
& =P_{m}\left\{A C 3+\frac{(1-A C 3)}{A C 2}\left(z-z_{b o t}\right)\right\} & \text { for } \quad z_{b o t}<z<z_{\text {top }} \\
=P_{m} & \text { for } \quad z_{\text {top }}<z<h
\end{array}\right.
$$

Integrating to define the effective water depth:

$$
\begin{aligned}
h_{\sigma} & =\int_{0}^{h} K d z=\int_{0}^{z_{b o t}} A C 3 P_{m} d z \\
& +\int_{z_{b o t}}^{z_{t o p}} P_{m}\left\{A C 3+\frac{(1-A C 3)}{A C 2}\left(z-z_{b o t}\right)\right\} d z+\int_{z_{t o p}}^{h} P_{m} d z \\
& =P_{m}\left\{\frac{(1-A C 3) A C 2}{2}+h-(1-A C 3) z_{t o p}\right\}
\end{aligned}
$$

For this case, the effective value of $K$ is

$$
K_{e f f}=\frac{\partial h_{\sigma}}{\partial h}=P_{m}
$$




\section{Case 2a}

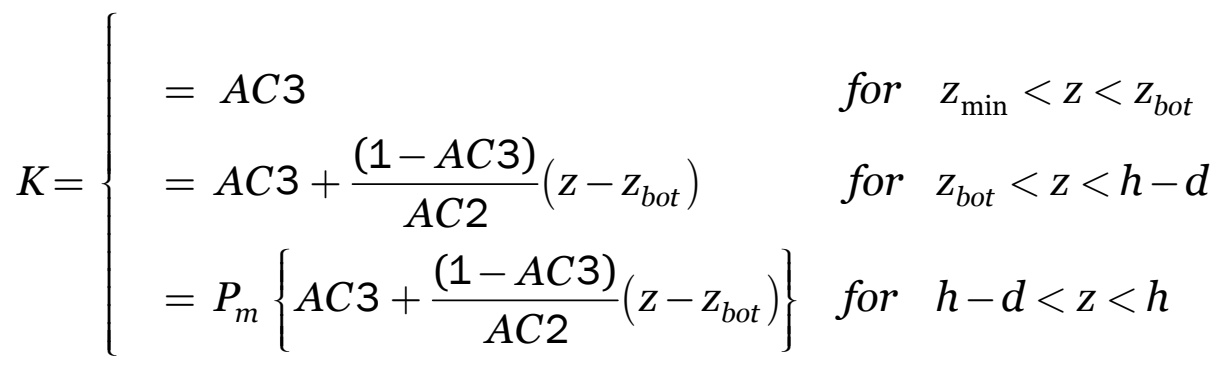

Integrating to define the effective water depth:

$$
\begin{aligned}
h_{\sigma} & =\int_{0}^{h} K d z=\int_{0}^{z_{b o t}} A C 3 d z+\int_{z_{b o t}}^{h-d}\left\{A C 3+\frac{(1-A C 3)}{A C 2}\left(z-z_{b o t}\right)\right\} d z \\
& +\int_{h-d}^{h} P_{m}\left\{A C 3+\frac{(1-A C 3)}{A C 2}\left(z-z_{b o t}\right)\right\} d z \\
= & A C 3\left(h-d+P_{m} d\right) \\
& +\frac{(1-A C 3)}{2 A C 2}\left\{\left(1-P_{m}\right)\left(h-d-z_{b o t}\right)^{2}+P_{m}\left(h-z_{b o t}\right)^{2}\right\}
\end{aligned}
$$

For this case, the effective value of $K$ is

$$
K_{e f f}=\frac{\partial h_{\sigma}}{\partial h}=A C 3+\frac{(1-A C 3)}{A C 2}\left\{h-d-z_{b o t}+P_{m} d\right\}
$$

\section{Case 2b}

$$
K=\left\{\begin{array}{lll}
=A C 3 & \text { for } z_{\min }<z<h-d \\
= & A C 3 P_{m} & \text { for } h-d<z<z_{b o t} \\
= & P_{m}\left\{A C 3+\frac{(1-A C 3)}{A C 2}\left(z-z_{b o t}\right)\right\} & \text { for } \quad z_{b o t}<z<h
\end{array}\right.
$$

Integrating to define the effective water depth: 


$$
\begin{aligned}
h_{\sigma} & =\int_{0}^{h} K d z=\int_{0}^{h-d} A C 3 d z+\int_{h-d}^{z_{b o t}} A C 3 P_{m} d z \\
& +\int_{z_{b o t}}^{h} P_{m}\left\{A C 3+\frac{(1-A C 3)}{A C 2}\left(z-z_{b o t}\right)\right\} d z \\
& =A C 3\left\{h-\left(1-P_{m}\right) d\right\}+\frac{(1-A C 3)}{2 A C 2} P_{m}\left(h-z_{b o t}\right)^{2}
\end{aligned}
$$

For this case, the effective value of $K$ is

$$
K_{\text {eff }}=\frac{\partial h_{\sigma}}{\partial h}=A C 3+P_{m} \frac{(1-A C 3)}{A C 2}\left\{h-z_{b o t}\right\}
$$

Case 2c

$$
K=\left\{\begin{array}{lll}
=A C 3 P_{m} & \text { for } & z_{\min }<z<z_{b o t} \\
=P_{m}\left\{A C 3+\frac{(1-A C 3)}{A C 2}\left(z-z_{b o t}\right)\right\} & \text { for } & z_{b o t}<z<h
\end{array}\right.
$$

Integrating to define the effective water depth:

$$
\begin{aligned}
h_{\sigma} & =\int_{0}^{h} K d z=\int_{0}^{z_{b o t}} A C 3 P_{m} d z \\
& +\int_{z_{b o t}}^{h} P_{m}\left\{A C 3+\frac{(1-A C 3)}{A C 2}\left(z-z_{b o t}\right)\right\} d z \\
& =P_{m}\left\{A C 3 h+\frac{(1-A C 3)}{2 A C 2}\left(h-z_{b o t}\right)^{2}\right\}
\end{aligned}
$$

For this case, the effective value of $K$ is

$$
K_{e f f}=\frac{\partial h_{\sigma}}{\partial h}=P_{m}\left[A C 3+\frac{(1-A C 3)}{A C 2}\left\{h-z_{b o t}\right\}\right]
$$

\section{Case 3a}

$$
K= \begin{cases}=A C 3 & \text { for } z_{\min }<z<h-d \\ =A C 3 P_{m} & \text { for } h-d<z<h\end{cases}
$$

Integrating to define the effective water depth: 


$$
\begin{aligned}
h_{\sigma} & =\int_{0}^{h} K d z=\int_{0}^{h-d} A C 3 d z+\int_{h-d}^{h} A C 3 P_{m} d z \\
& =A C 3\left\{h-\left(1-P_{m}\right) d\right\}
\end{aligned}
$$

For this case, the effective value of $K$ is

$$
K_{e f f}=\frac{\partial h_{\sigma}}{\partial h}=A C 3
$$

\section{Case 3b}

$$
K=A C 3 P_{m} \quad \text { for } z_{\text {min }}<z<h
$$

Integrating to define the effective water depth:

$$
h_{\sigma}=\int_{0}^{h} K d z=\int_{0}^{h} A C 3 P_{m} d z=A C 3 P_{m} h
$$

For this case, the effective value of $K$ is

$$
K_{e f f}=\frac{\partial h_{\sigma}}{\partial h}=A C 3 P_{m}
$$

The equations for $h_{\sigma}$ and $K_{\text {eff }}$ are summarized in Table A4 for each of the cases. At the bottom of the table are the equations for the cases without floatant marsh. These can be confirmed to be the same for each subcase by setting the mat porosity to a value of 1 . The value of $K_{\text {eff }}$ for the Case 1 subcases all is 1 for $P_{m}=1$. 
Table A4. Summary of combined floatant marsh with marsh porosity for bottom.

\begin{tabular}{|c|c|c|}
\hline Case & $h_{\sigma}$ & $K_{\text {eff }}$ \\
\hline $1 a$ & $A C 3\left(z_{t}\right)+h-d-z_{t}+P_{m} d+(1-A C 3) A C 2 / 2$ & $K_{e f f}=1$ \\
\hline $1 b$ & $A C 3(h-d)+\frac{h_{b}^{2}(1-A C 3)}{2 A C 2}+P_{m}\left\{h-z_{t}+\frac{\left[A C 2(1+A C 3) h_{b}(1-A C 3)\right]\left(A C 2-h_{b}\right)}{2 A C 2}\right\}$ & $A C 3+P_{m}(1-A C 3)-\frac{\left(1-P_{m}\right)(1-A C 3)}{A C 2} h_{b}$ \\
\hline $1 c$ & $A C 3\left[\left(1-P_{m}\right)(h-d)+P_{m} z_{\text {top }}\right]+P_{m}\left\{\frac{(1-A C 3) A C 2}{2}+h-z_{\text {top }}\right\}$ & $A C 3+P_{m}(1-A C 3)$ \\
\hline $1 d$ & $P_{m}\left\{\frac{(1-A C 3) A C 2}{2}+h-(1-A C 3) z_{t o p}\right\}$ & $P_{m}$ \\
\hline $2 a$ & $A C 3\left(h-d+P_{m} d\right)+\frac{(1-A C 3)}{2 A C 2}\left\{\left(1-P_{m}\right)\left(h-d-z_{b o t}\right)^{2}+P_{m}\left(h-z_{b o t}\right)^{2}\right\}$ & $A C 3+\frac{(1-A C 3)}{A C 2}\left\{h-d-z_{b o t}+P_{m} d\right\}$ \\
\hline $2 b$ & $A C 3\left\{h-\left(1-P_{m}\right) d\right\}+\frac{(1-A C 3)}{2 A C 2} P_{m}\left(h-z_{b o t}\right)^{2}$ & $A C 3+P_{m} \frac{(1-A C 3)}{A C 2}\left\{h-z_{b o t}\right\}$ \\
\hline $2 c$ & $P_{m}\left\{A C 3 h+\frac{(1-A C 3)}{2 A C 2}\left(h-z_{b o t}\right)^{2}\right\}$ & $P_{m}\left[A C 3+\frac{(1-A C 3)}{A C 2}\left\{h-z_{b o t}\right\}\right]$ \\
\hline $3 a$ & $A C 3\left\{h-\left(1-P_{m}\right) d\right\}$ & $A C 3$ \\
\hline $3 b$ & $A C 3 P_{m} h$ & $A C 3 P_{m}$ \\
\hline $1\left(P_{m}=1\right)$ & $(1-A C 3) A C 2 / 2+h-(1-A C 3) z_{t o p}$ & 1 \\
\hline $2\left(P_{m}=1\right)$ & $A C 3 h+\frac{(1-A C 3)}{2 A C 2}\left(h-z_{b o t}\right)^{2}$ & $A C 3+\frac{(1-A C 3)}{A C 2}\left\{h-z_{b o t}\right\}$ \\
\hline $3\left(P_{m}=1\right)$ & $A C 3 h$ & $A C 3$ \\
\hline
\end{tabular}




\section{Summary}

The previously discussed derivations have shown that floatant marsh can be represented using marsh porosity if extensive information on the characteristics of the area is available (i.e., marsh thickness, horizontal coverage, and frictional resistance). For the Davis Pond study, none of these characteristics was known, so it was deemed unnecessary to incorporate the additional capabilities into RMA2. The existing configuration is believed to produce an accurate representation of the behavior of the system. Modification of the code to achieve full representation of the floatant marsh would require input quantities for the unknown marsh thickness, coverage, and frictional resistance. Therefore, the RMA2 marsh porosity was not modified and was used as-is for this project. 


\section{Appendix B: Datum Analysis}

\section{Lake Cataouatche tidal datum}

In organizing the data for the Davis Pond verification, comparisons were performed on the Highway 90 and Lake Cataouatche U.S. Geological Survey (USGS) gages. The locations of these gages are shown in Figure B1, with the observed data plotted in Figure B2. The U.S. Army Engineer District, New Orleans (MVN) reported to the Engineer Research and Development Center (ERDC) that the Highway 90 gage was returning water surface elevations that were high by $0.132 \mathrm{ft}$. This shift was applied to the gage data, and henceforth any discussion of the Highway 90 water surface elevation data incorporates this correction. The plot in Figure B2 shows a significant head difference from Highway 90 to Lake Cataouatche even after prolonged periods with little to no inflow from the Davis Pond diversion, a situation that seems unlikely. It was decided that additional investigation should be performed to determine if this reported behavior is an accurate representation of the true performance of the system.

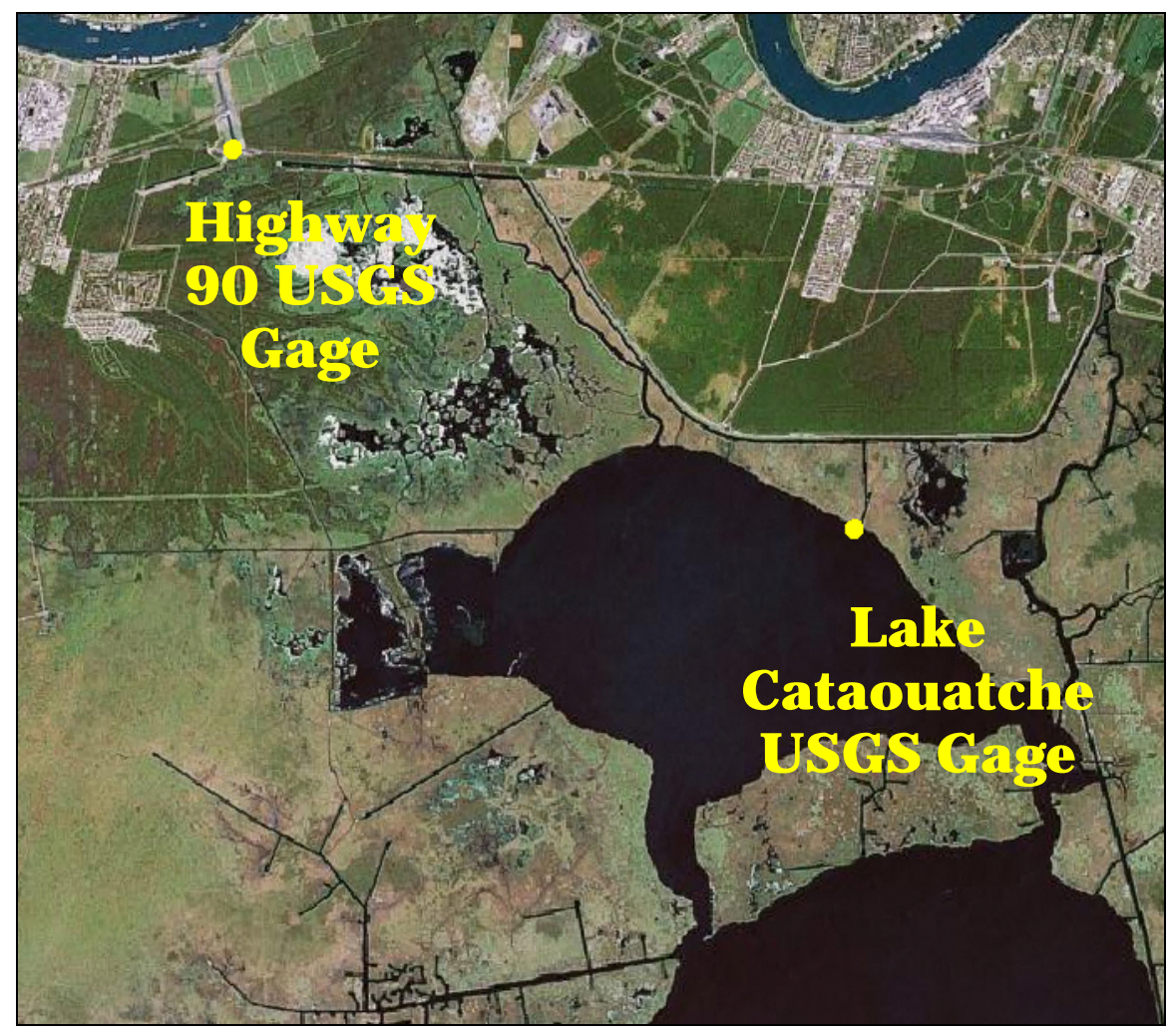

Figure B1. Location of the Highway 90 and Lake Cataouatche USGS gages. 


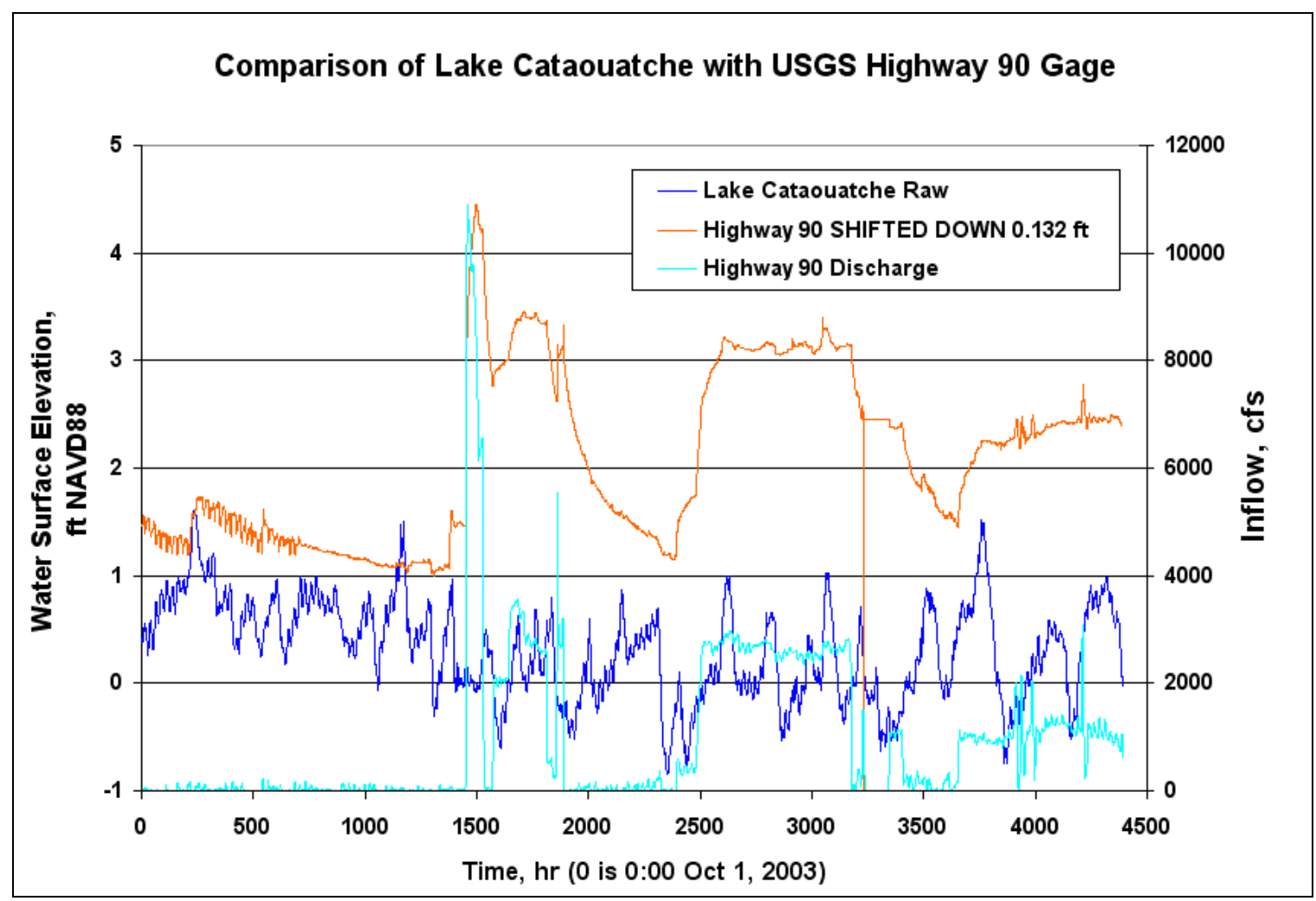

Figure B2. Plot of the Highway 90 and Lake Cataouatche gage data.

The gage analysis was performed using a two-pronged approach with comparisons being made with other USGS gages and National Oceanic and Atmospheric Administration (NOAA) gages. Since each organization has different personnel and methods for determining the vertical datum of its gages, any agreement between USGS and NOAA gages produces a high confidence level for accuracy. The locations of these USGS and NOAA gages are shown in Figure B3. The data for the USGS gages were provided in a gage datum with the conversion from this gage datum to NAVD88 also being provided by the USGS. The data for the NOAA gages were obtained from the NOAA website. The Port Fourchon and Grand Isle historical data were downloaded in Mean Sea Level (MSL). A conversion from MSL to NAVD88 was obtained from the NOAA website for the Grand Isle gage. (Port Fourchon had no conversion to NAVD88.) Due to their close proximity, this conversion was applied to the tidal data for both gages. 


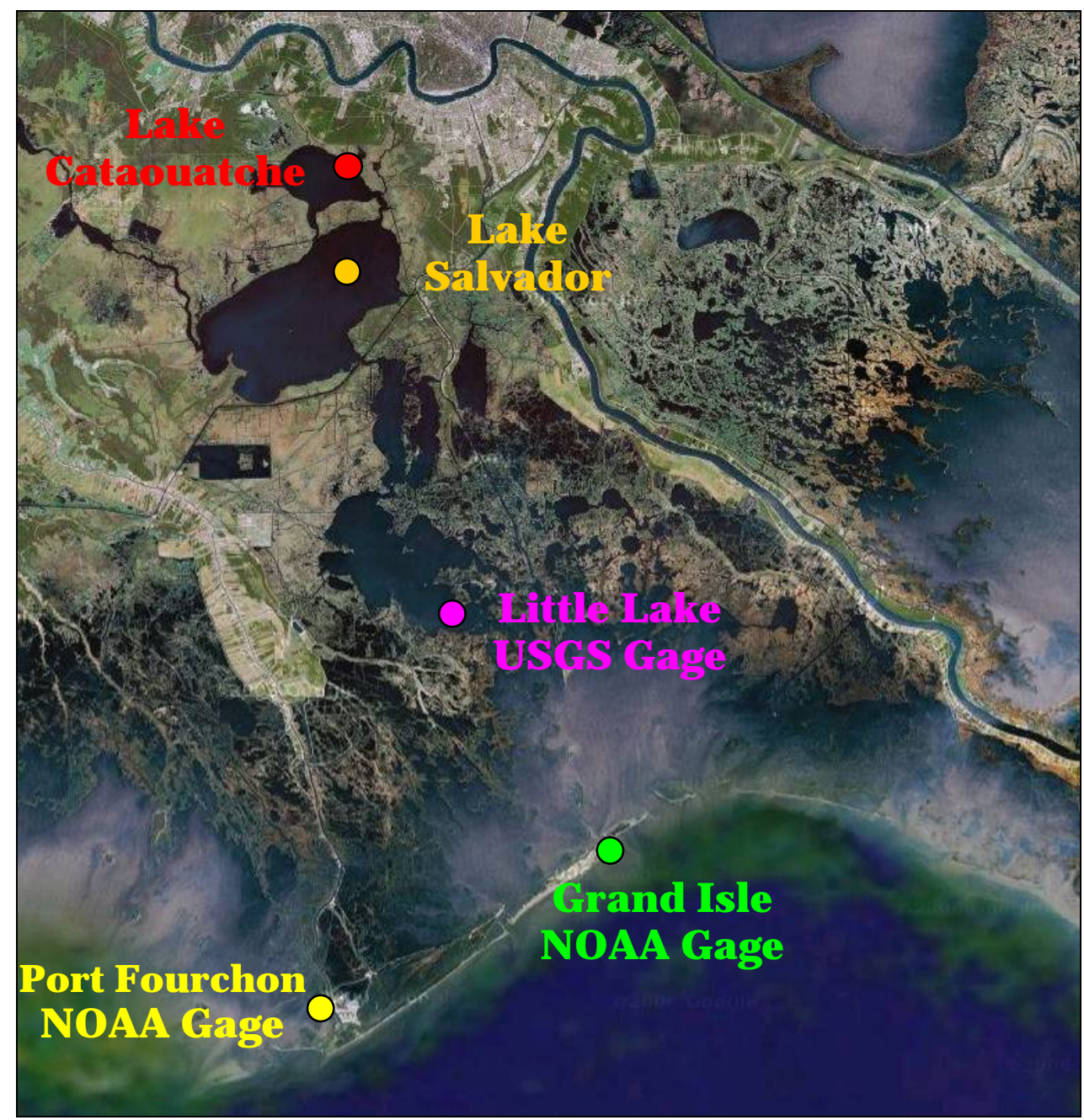

Figure B3. Location of gages used to investigate the Lake Cataouatche vertical datum issues.

The Lake Cataouatche gage data are plotted with the other USGS gages, Lake Salvador and Little Lake, in Figure B4; and with the NOAA gages, Grand Isle and Port Fourchon, in Figure B5. Both plots are in agreement that the Lake Cataouatche measurements are low. Short-term variations in tides and phase differences make it difficult to determine an appropriate shift using the raw tidal data. To avoid these complications, a filter was applied to the gage data to remove the high-frequency signals (Periods $<1,000 \mathrm{hr}$ ) from the data. This left only the extreme low-frequency signals, which tend to be a representation of the mean water level of the tidal signal. Plots of the raw data and the low frequency signals are shown in Figures B6 (USGS gages) and B7 (NOAA gages). It should be noted that there were gaps in the Lake Salvador data. The method used to fill these gaps to provide the most accurate filtered low-frequency signal is discussed in the Lake Salvador Gage Data Analysis section. 


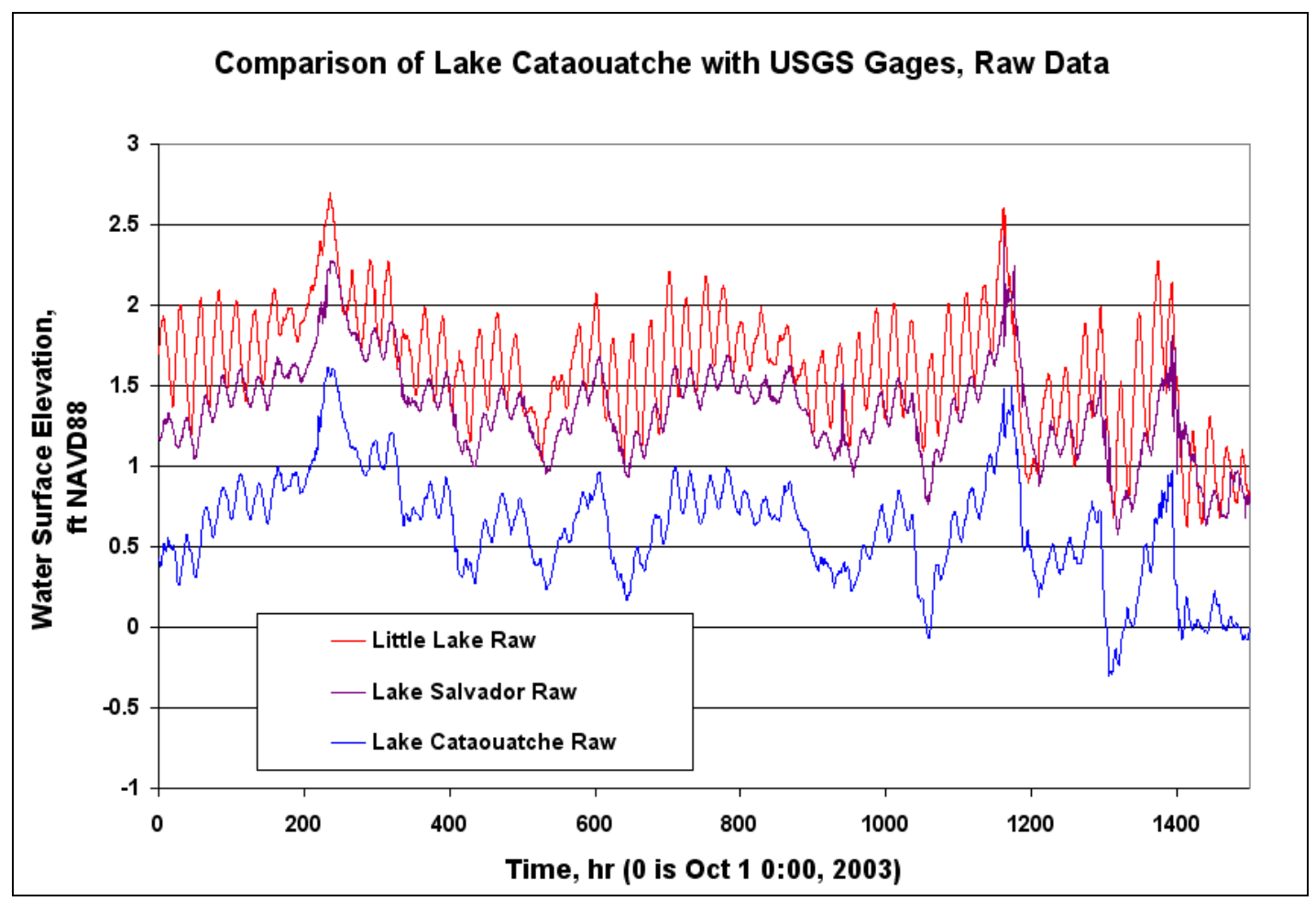

Figure B4. Plot of the Lake Cataouatche gage data with the data from other USGS gages.

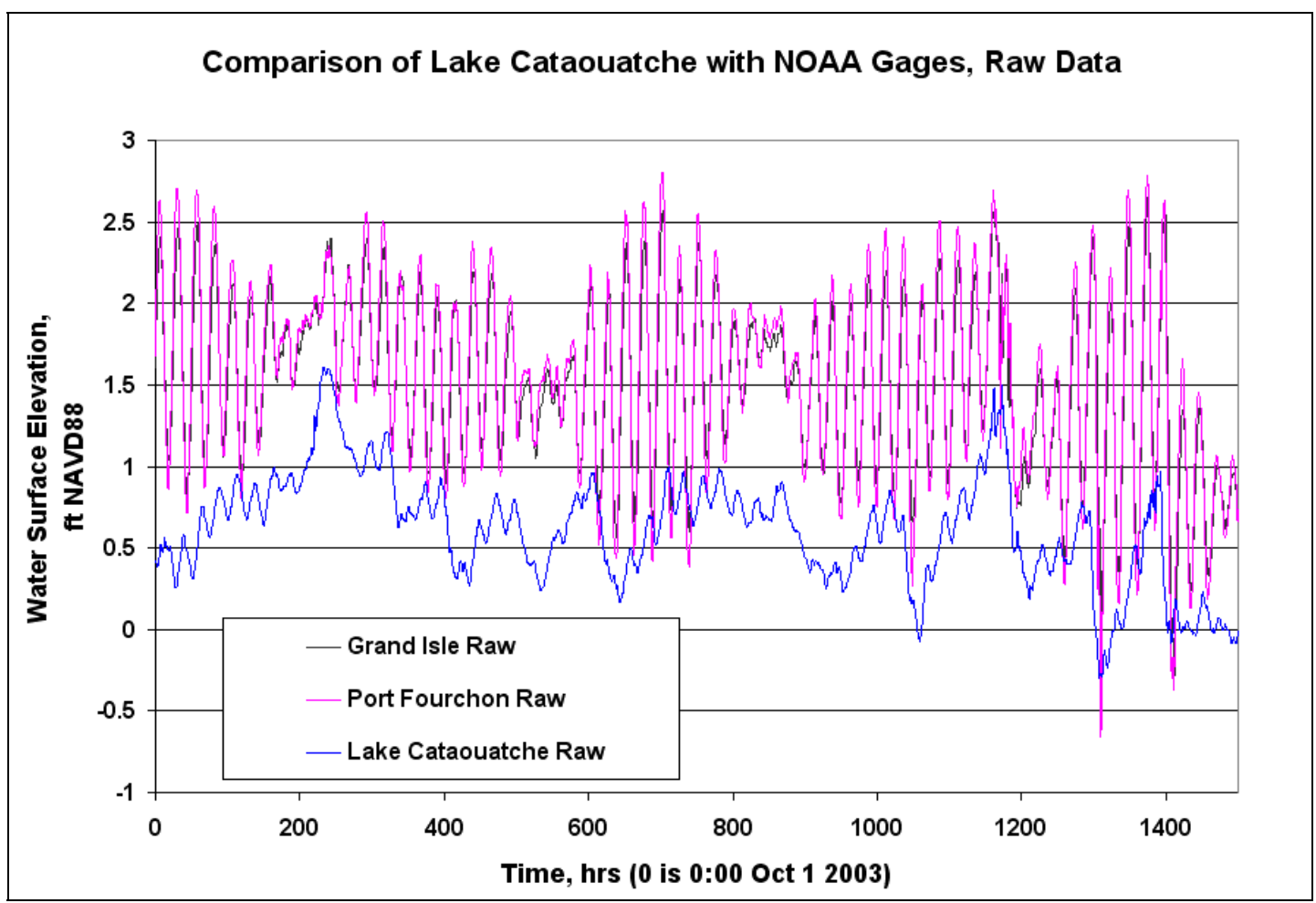

Figure B5. Plot of the Lake Cataouatche gage data with the data from the NOAA gages. 


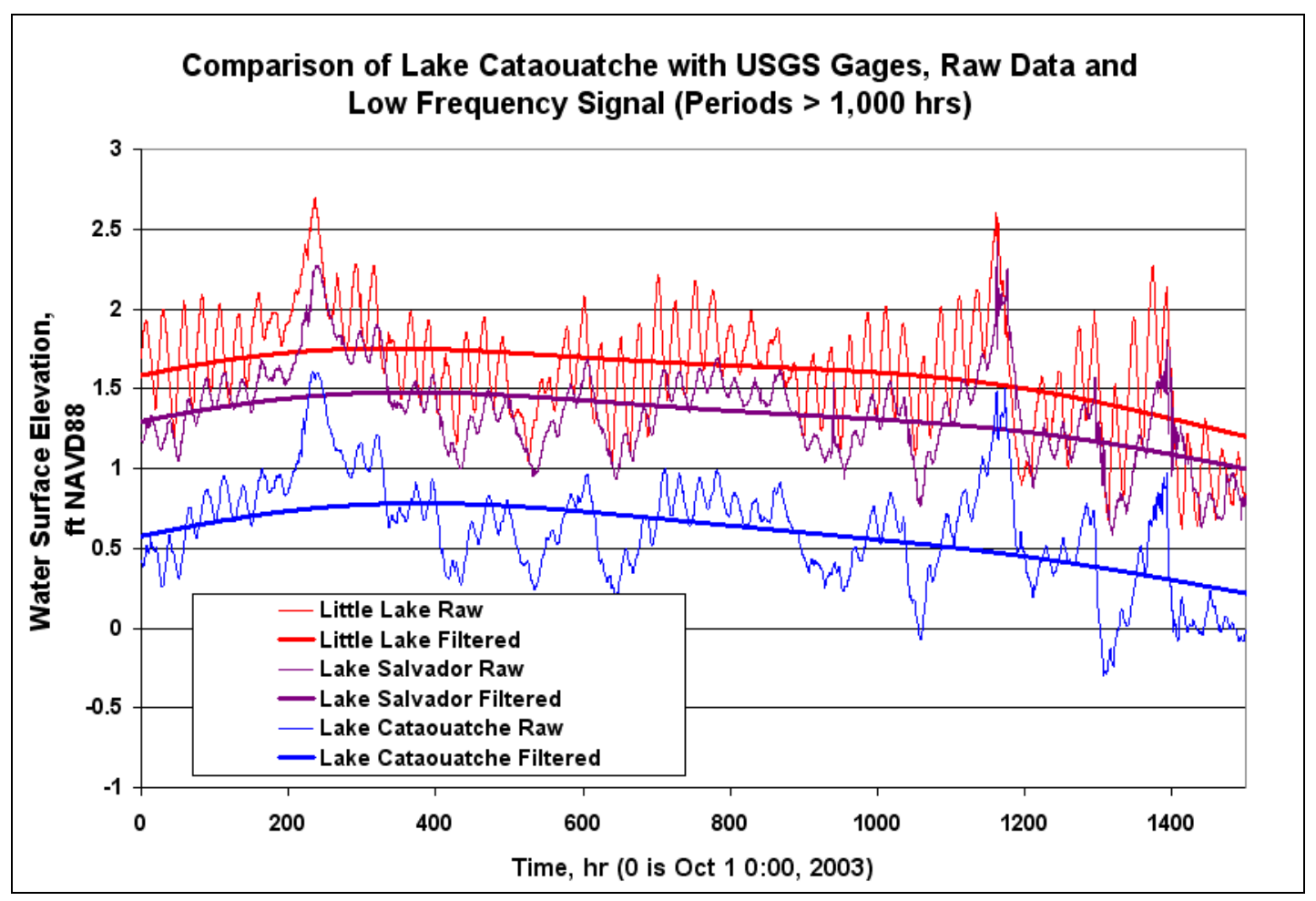

Figure B6. Plot of the raw data and low-frequency signals for Lake Cataouatche and USGS gages.

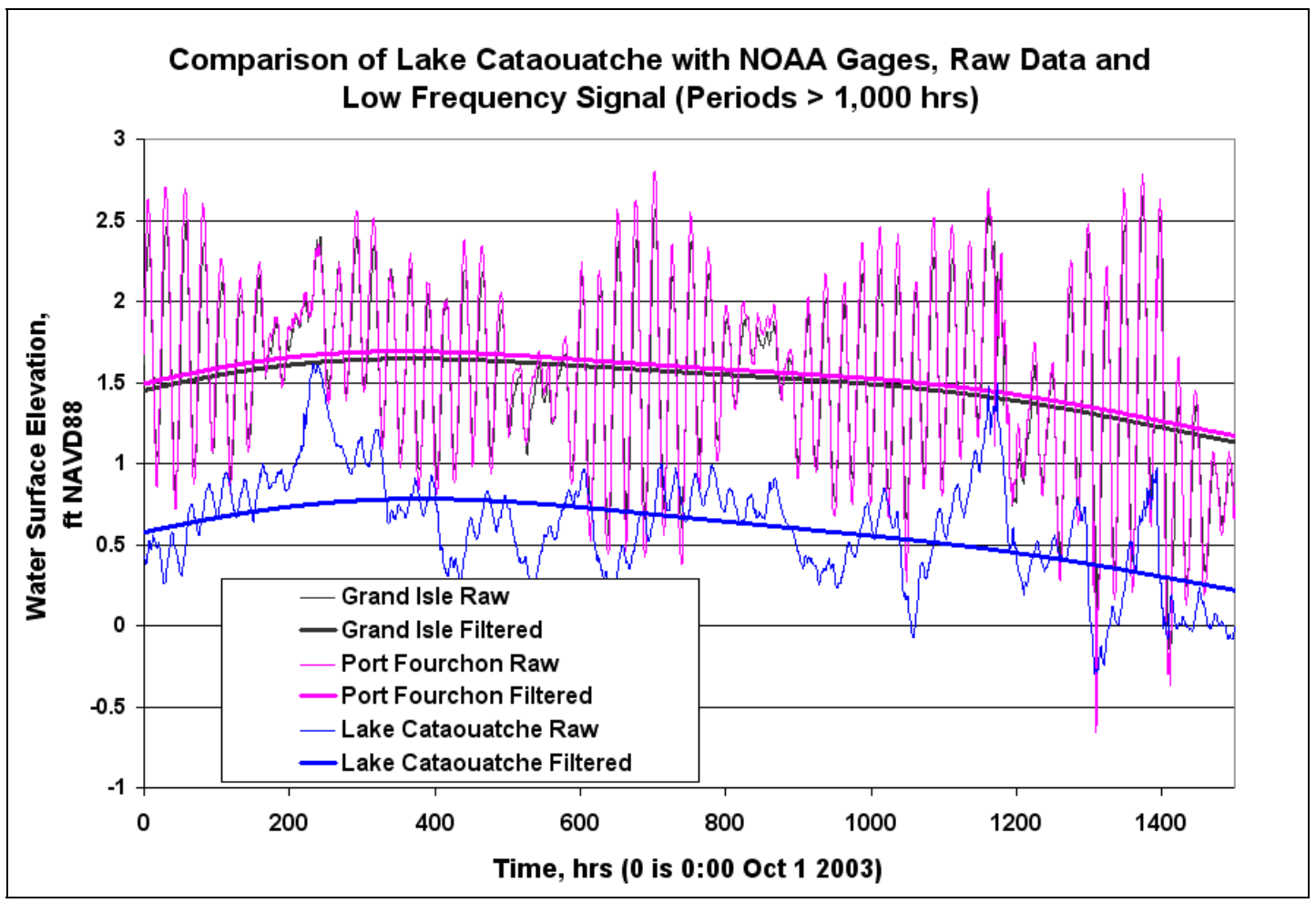

Figure B7. Plot of the raw data and low-frequency signal for Lake Cataouatche and the NOAA gages. 
From these low-frequency signals, an upward shift of $0.9 \mathrm{ft}$ was determined. By applying this shift, the Lake Cataouatche data lay between the two NOAA gage and between the two additional USGS gages. The shifted low-frequency signals are shown in Figures B8 (USGS) and B9 (NOAA). While this shift is believed to be the most likely vertical datum level for the Lake Cataouatche gage, it is by no means exact. Even with the extensive analysis performed on the Lake Cataouatche data, the vertical datum should only be considered accurate to within $\pm 0.2 \mathrm{ft}$. This $0.2 \mathrm{ft}$ uncertainty was chosen since in Figures B8 and B9, all filtered data signals seemed to be within $\pm 0.2 \mathrm{ft}$ of the shifted Lake Cataouatche filtered signal. Due to this uncertainty, the model was validated using the $0.9 \mathrm{ft}$ shift determined from this analysis, and then a sensitivity analysis was performed to determine the importance of the $0.2 \mathrm{ft}$ uncertainty associated with the vertical datum for the Lake Cataouatche gage. Plotted in Figures B1O and B11 are the filtered and unfiltered signals with the shifted Lake Cataouatche data as compared with the other USGS and NOAA gages. It should be noted that this procedure was applied to more current data (2007) and it showed no significant difference in mean water level between the Lake Cataouatche gage and the remaining gages used in this analysis. Therefore, it is assumed that the vertical datum issue addressed here has been corrected.

Plotted in Figure B12 is the Highway 90 data with the shifted Lake Cataouatche data. There is no longer a significant head difference between the Highway 90 and Lake Cataouatche gages during long periods of little to no inflow from the Davis Pond diversion. The remaining gages in the Davis Pond marsh area were shifted up or down to lay at the same vertical level as Highway 90 and Lake Cataouatche during long periods of little to no inflow. This was deemed appropriate since there should be no high water surface elevations in between two low water surface elevations for this system. The raw and adjusted data are plotted in Figures 4 and 5, presented previously in the main text.

\section{Lake Salvador gage data analysis}

The raw Lake Salvador gage data are plotted in Figure B13. There are two extended gaps in the data (hours 1609 to 2235 and hours 2350 to 2821). If there were no knowledge of the behavior of the system, the usual approximation would be to enter the mean of the data for these gaps, but by using the Lake Cataouatche data, a better approximation can be achieved. 


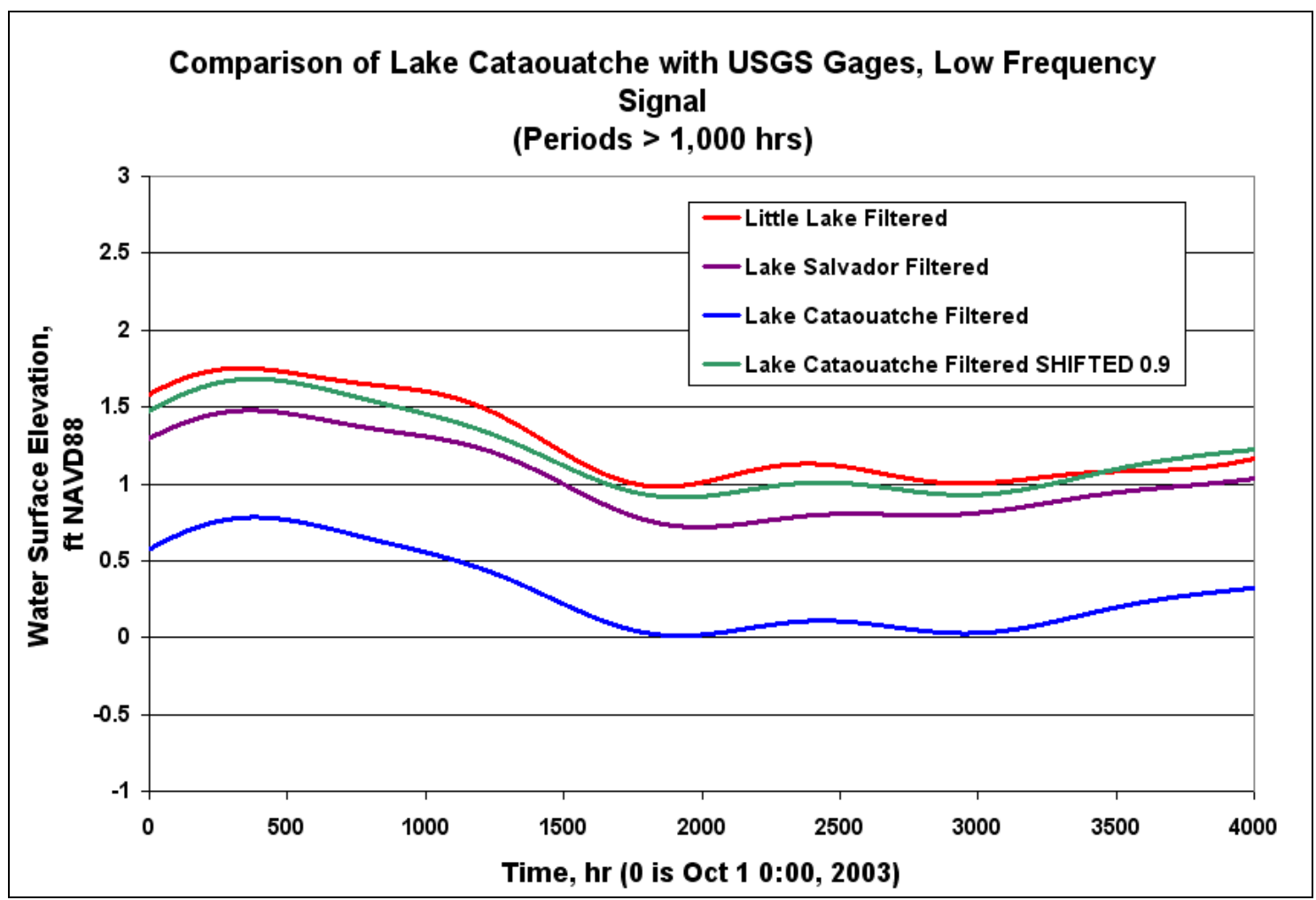

Figure B8. Low-frequency signal for USGS gages and shifted Lake Cataouatche data.

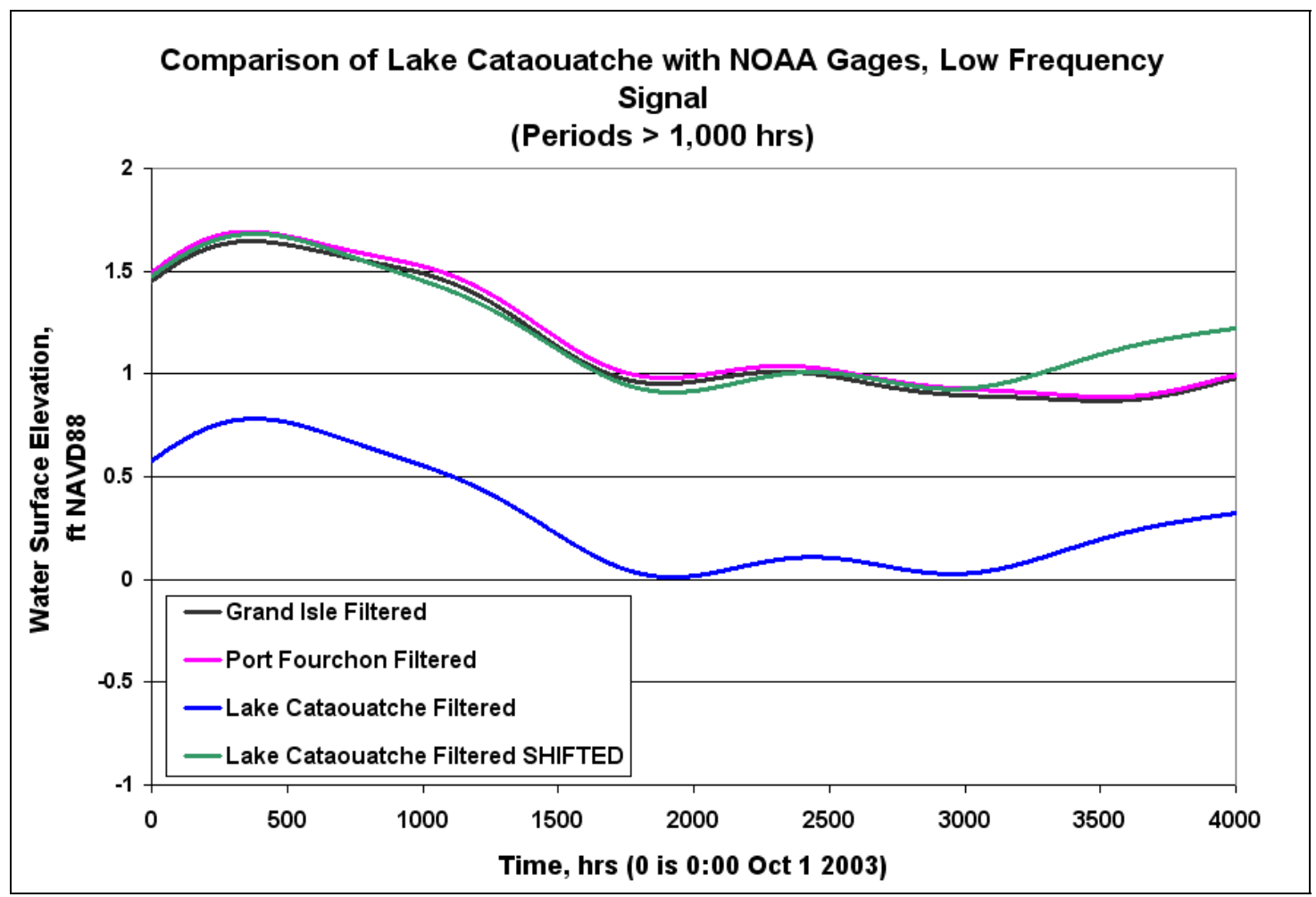

Figure B9. Low-frequency signal for NOAA gages and shifted and unshifted Lake Cataouatche data. 


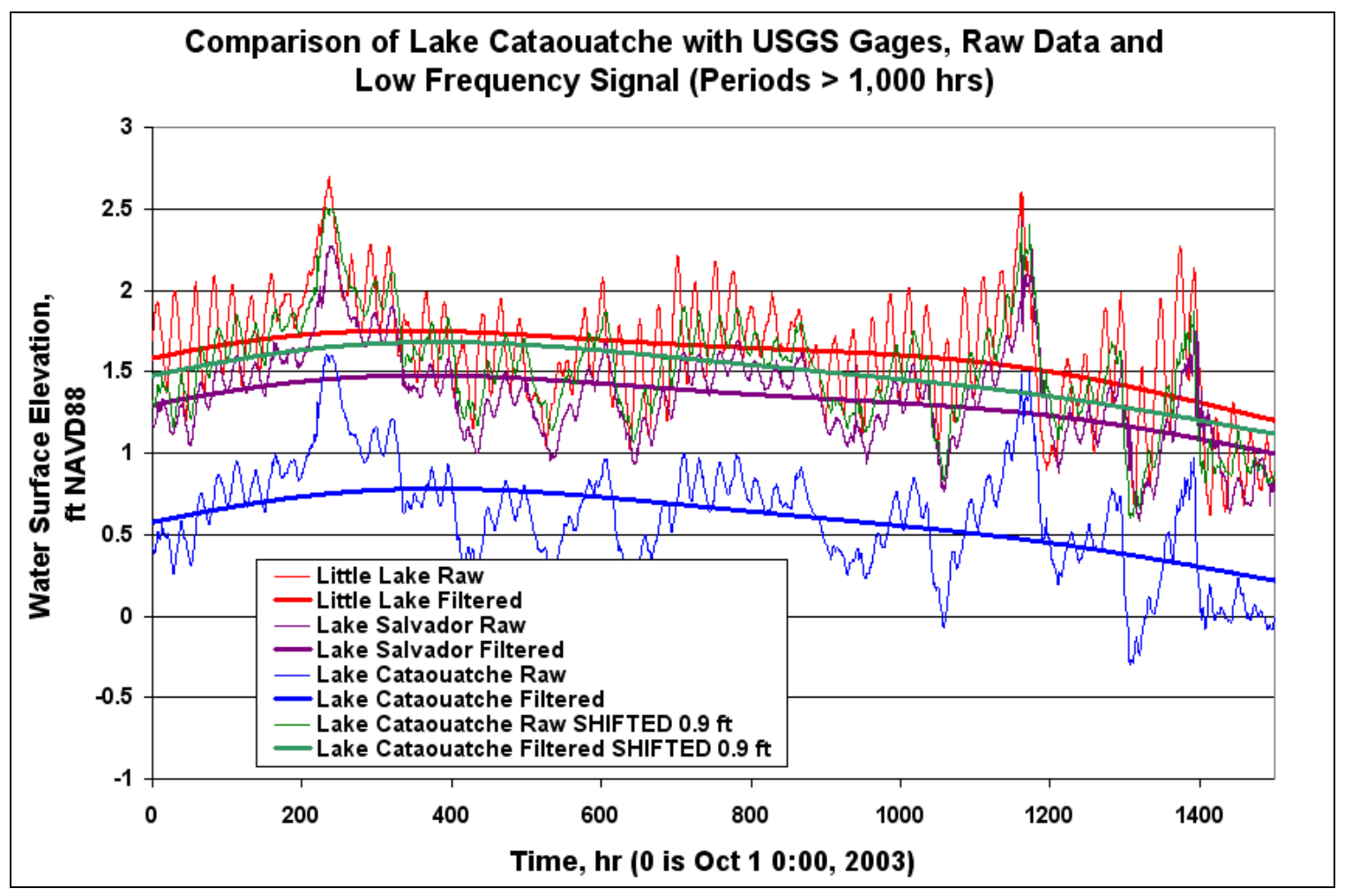

Figure B10. Raw data and low-frequency signal for USGS gages and shifted Lake Cataouatche data.

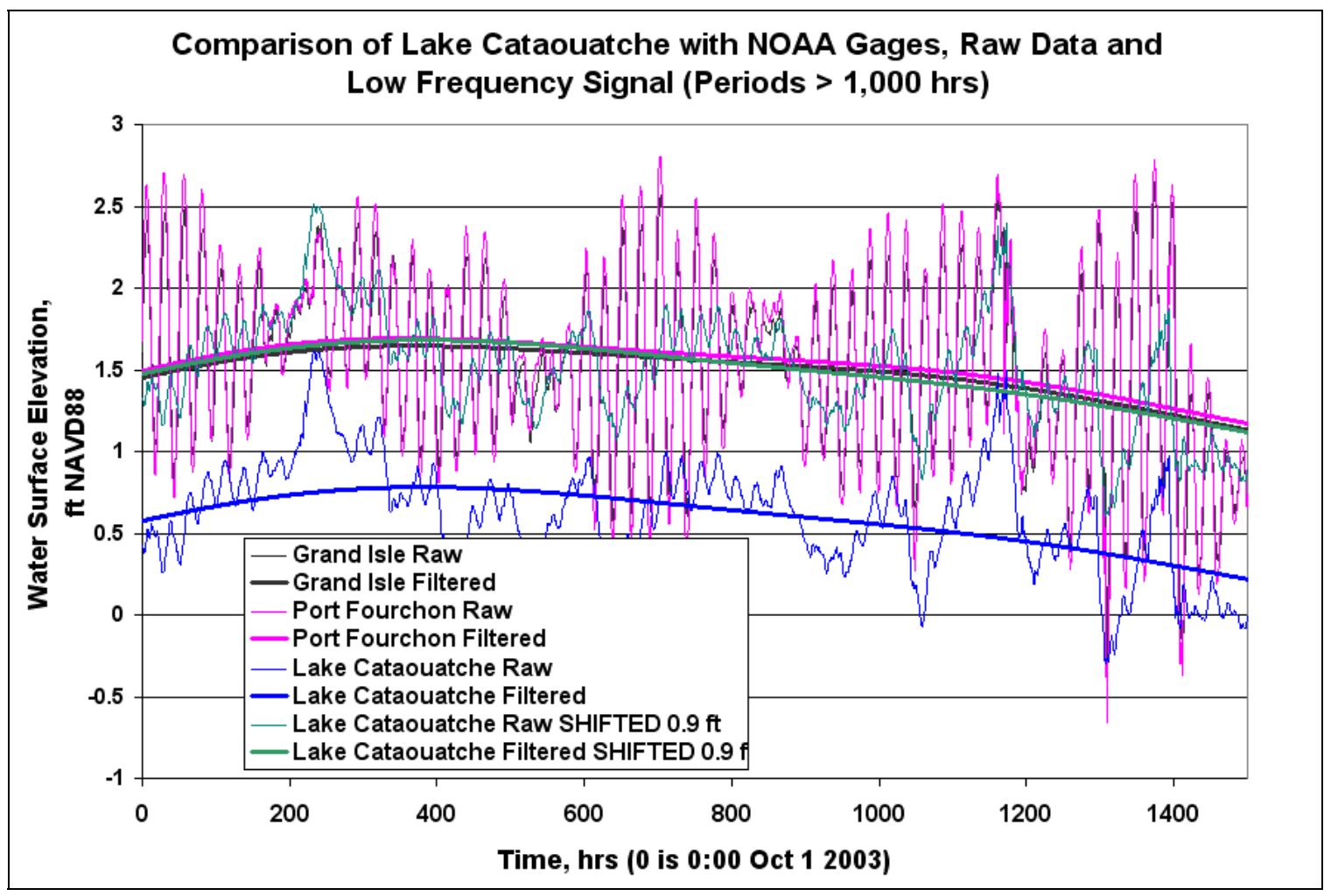

Figure B11. Raw data and low-frequency signal of NOAA gages and shifted Lake Cataouatche data. 


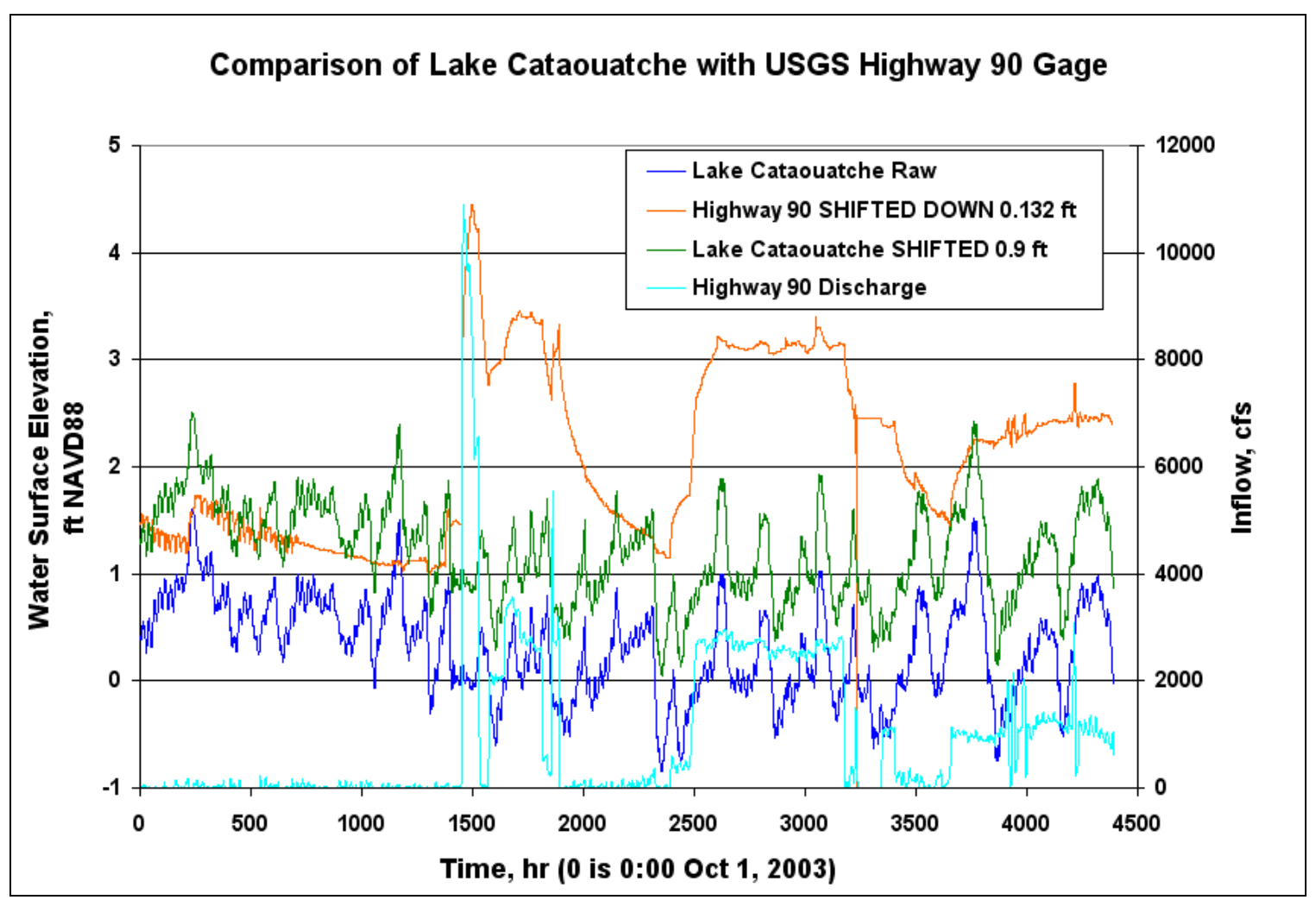

Figure B12. Plot of the Highway 90 and Lake Cataouatche gage data.

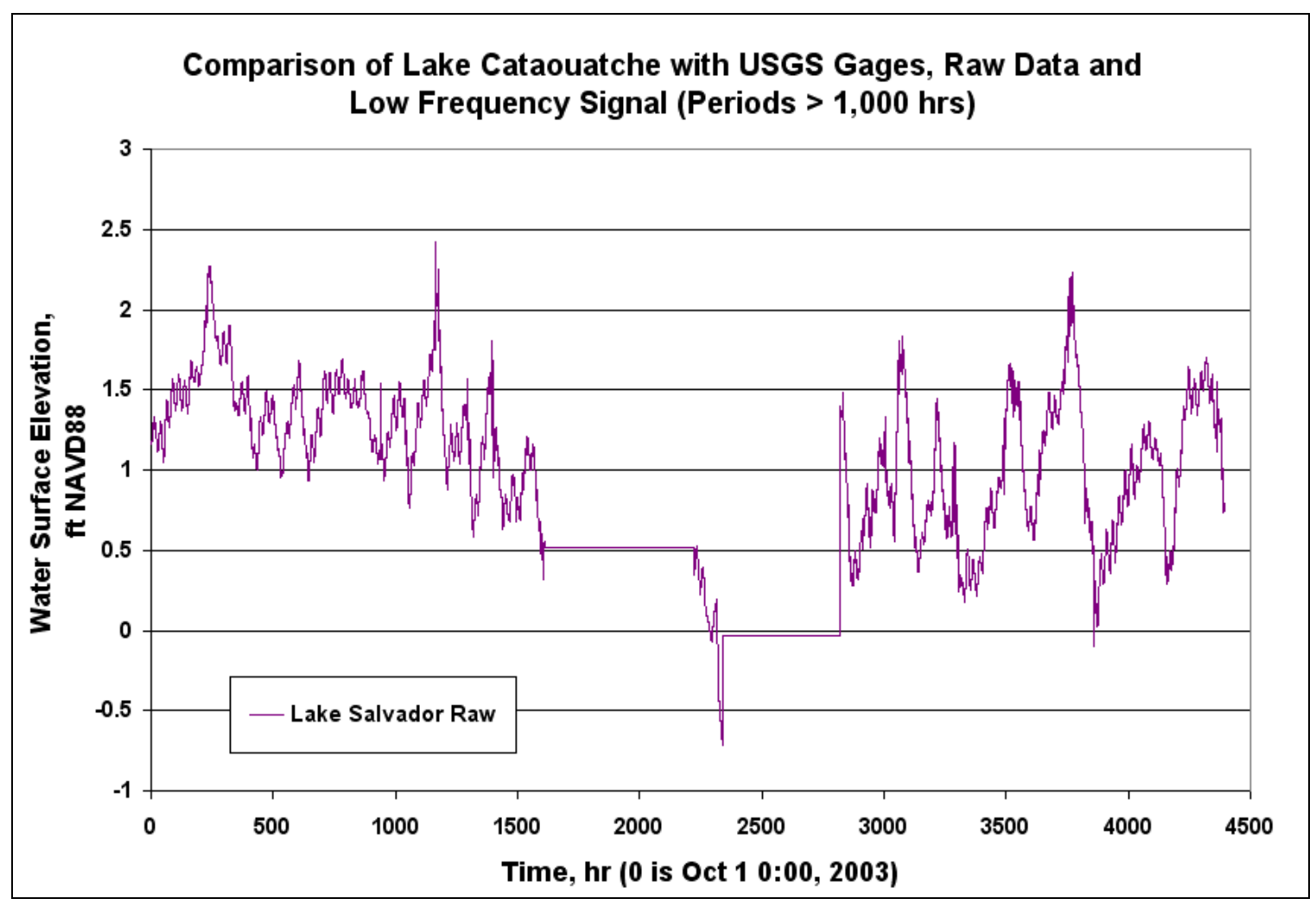

Figure B13. Lake Salvador raw data. 
Figure B14 displays a plot of the Lake Salvador data and the Lake Cataouatche data. With the exception of the vertical datum shift, these two signals are very similar. The Lake Cataouatche signal was shifted so as to best match the Lake Salvador signal (up $0.7 \mathrm{ft}$ ). The shifted Lake Cataouatche signal was used from hour 1609 to hour 2821 in place of missing Lake Salvador data. Figure B15 shows the raw signal and the new signal using the Lake Cataouatche data. To perform a sensitivity test on the effects of this missing data to our low-frequency signal, a filter was applied to the created Lake Salvador data set discussed above, and a filter was also applied to the Lake Salvador data set with the mean value inserted in the gaps. These two filtered data sets are plotted in Figure B16.

While there is a definite difference in the low-frequency signals, the difference appears to be mainly relegated to $\sim 300$ hours before and after the interruption in data. Both filtered signals are very similar for hours o to 1300 and hours 3100 to 4500 . Therefore the values inputted for the data gaps have a limited effect on the data prior to hour 1300 and after hour 3100.

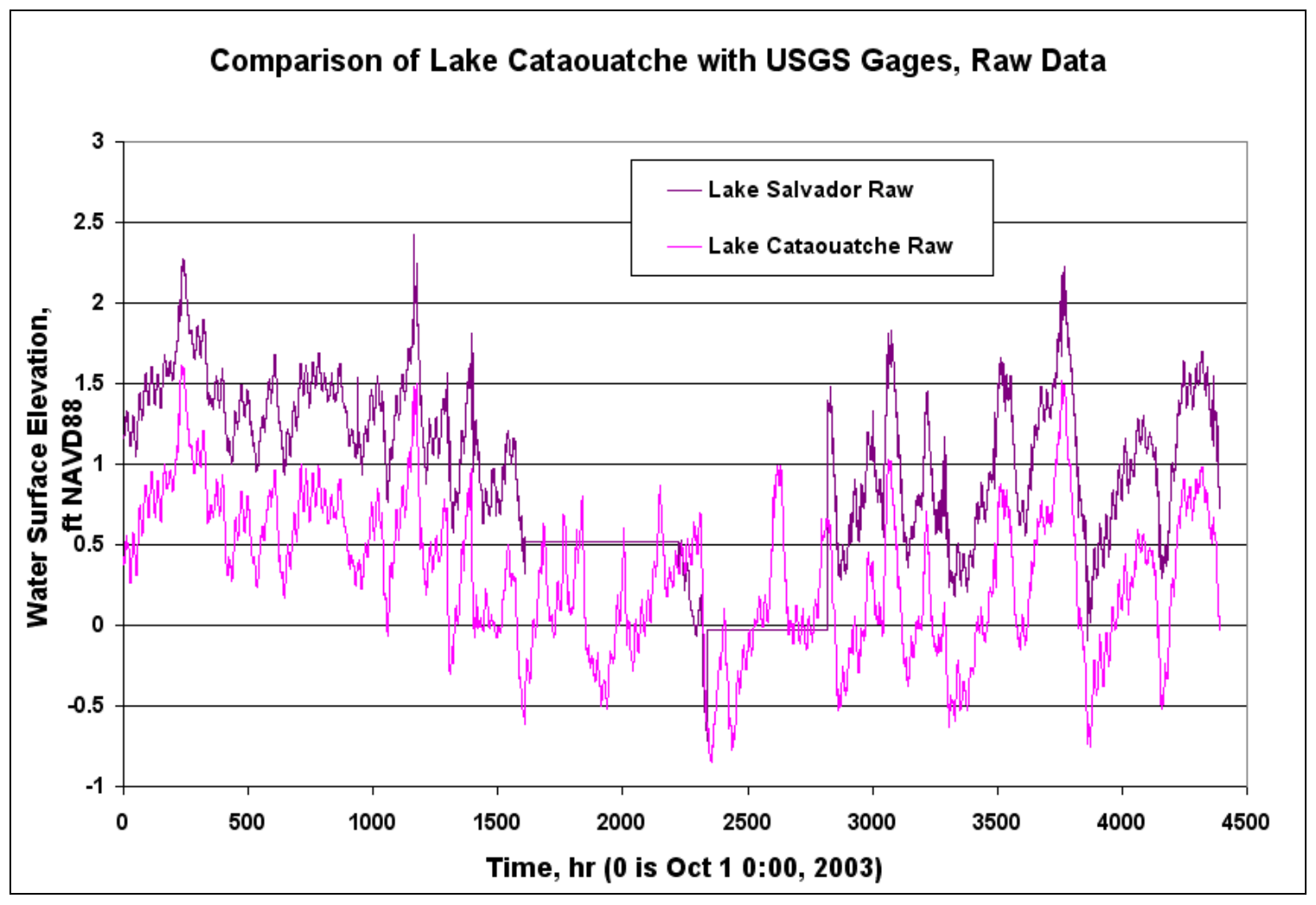

Figure B14. Lake Salvador and Lake Cataouatche raw data. 


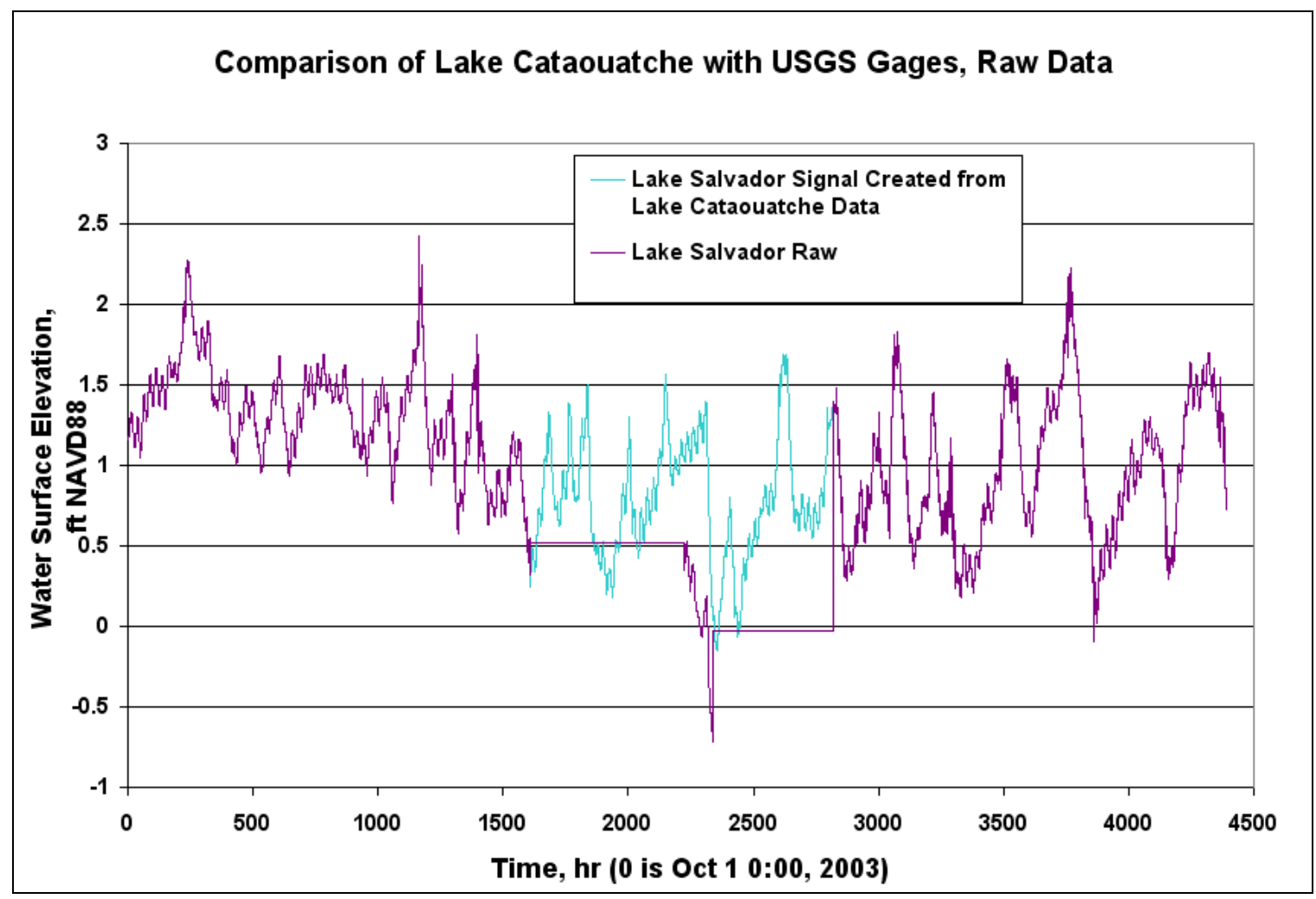

Figure B15. Lake Salvador raw signal and created signal.

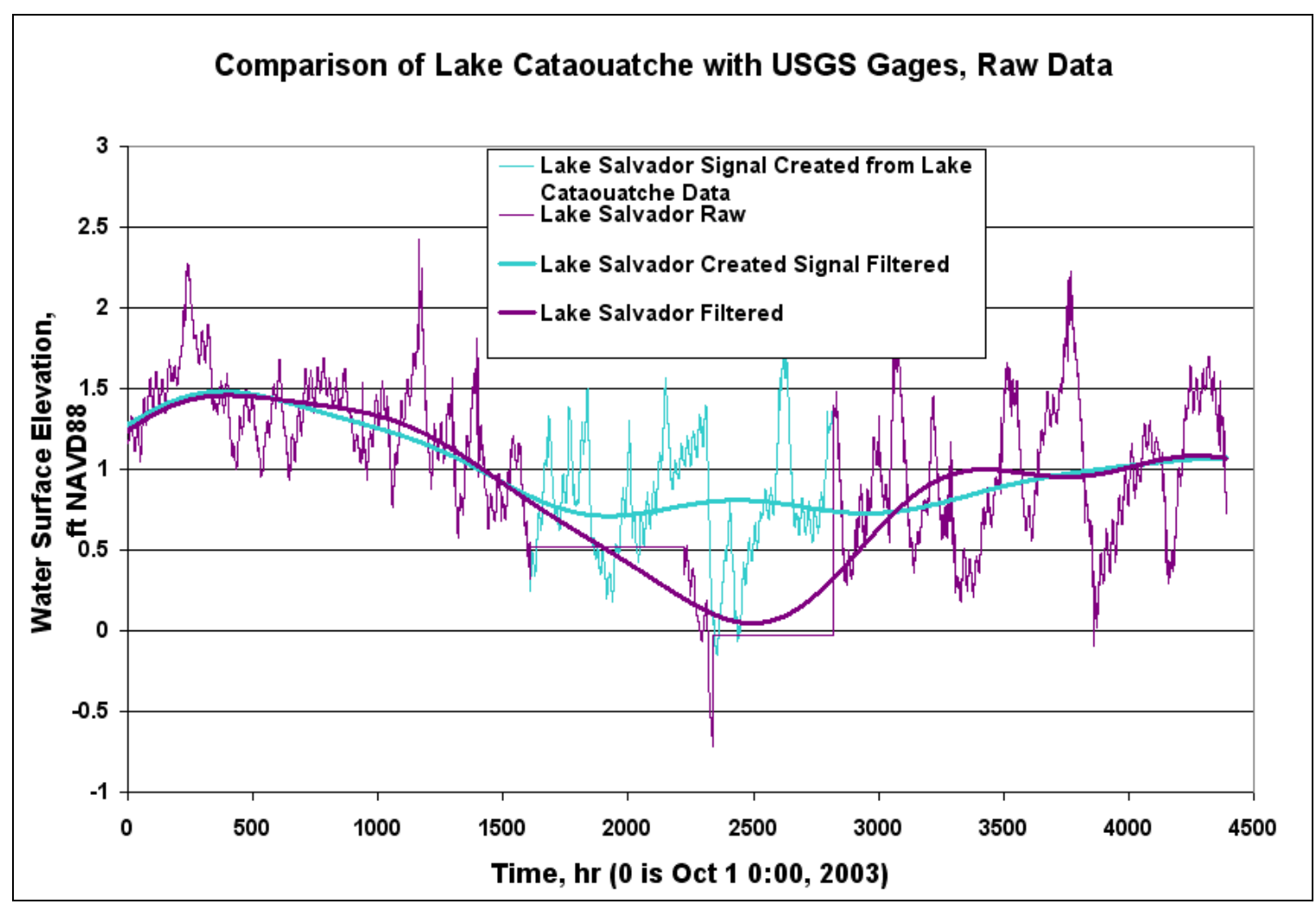

Figure B16. Lake Salvador raw signal and created signal with filtered signals. 


\section{Effects of frictional uncertainty}

An analysis was performed to determine an approximate effect of the $\pm 0.2 \mathrm{ft}$ uncertainty in the vertical datum used to validate the numerical model. This $\pm 0.2 \mathrm{ft}$ uncertainty could have affected the frictional values obtained from the model validation. Therefore, the model frictional values were perturbed to create water surface elevations that were increased and decreased by $\pm 0.2 \mathrm{ft}$. As discussed in Chapter 1 , the frictional values are separated into two categories: overbank and channel. There were three options for obtaining the $\pm 0.2 \mathrm{ft}$ perturbation in water levels:

1. Increase/decrease the overbank frictional values.

2. Increase/decrease the channel friction values.

3. Increase/decrease all frictional values.

Options 1 and 2 are assumed to produce the most extreme results. Both possibilities were examined. For option 1, the base conditions were run with the steady-state plan boundary conditions to obtain the most likely results. The overbank frictional values were perturbed until the water level was raised and lowered by $0.2 \mathrm{ft}$. This resulted in a high bound, "most likely" level, and a lower bound for the base conditions. To determine the approximate effect on the alternative water surface elevations, Alternative 10 was run with each of the three sets of frictional values. Alternative 10 was chosen because it was one of the more extreme alternatives. This same procedure was used for option 2 with the channel frictional values. Plots of the water surface elevation profiles for this analysis are shown in Figures B17 and B18.

The plots in Figures B17 and B18 show the importance of variation in overbank frictional values versus channel frictional values. It took little perturbation with the overbank frictional values to create the $0.2 \mathrm{ft} \mathrm{high}$ and low bounds (110 \% and $90 \%$ frictional values, respectively), while both channel frictional values took significantly more perturbation $(130 \%$ and $60 \%$ ) for the base conditions. From this analysis, it can be concluded that the overbank frictional values play a larger role than the channel frictional values in the water surface elevations for the base conditions. But because the channel frictional perturbation has the larger range with Alternative 10, the channel frictional values become more important after the modifications have been made to the system. Therefore, the water in the system has gone from moving through the overbank areas to moving primarily through the channels in the system. 


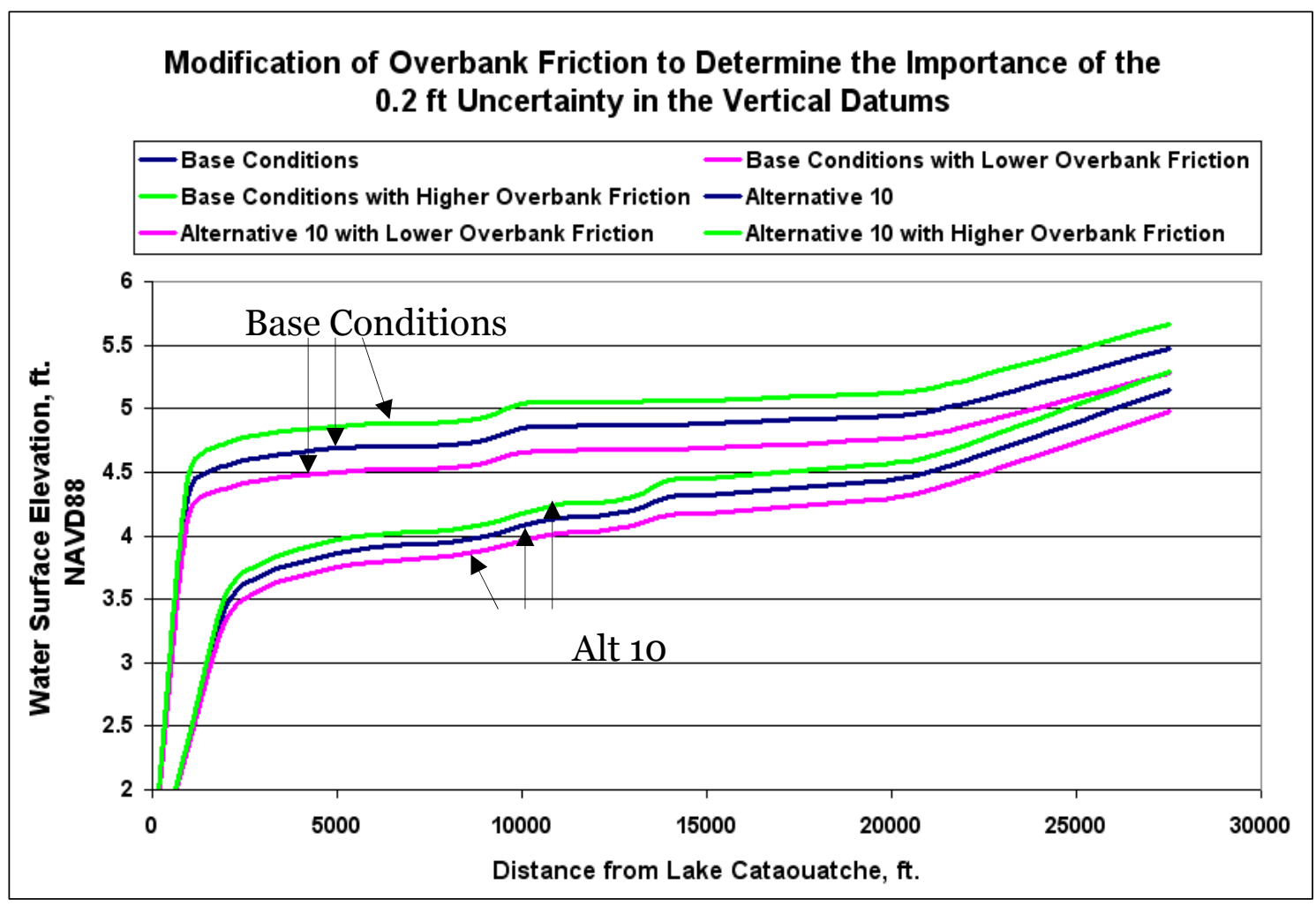

Figure B17. Plot of the effect of the $0.2 \mathrm{ft}$ uncertainty on the vertical datums by modifying the overbank frictional values.

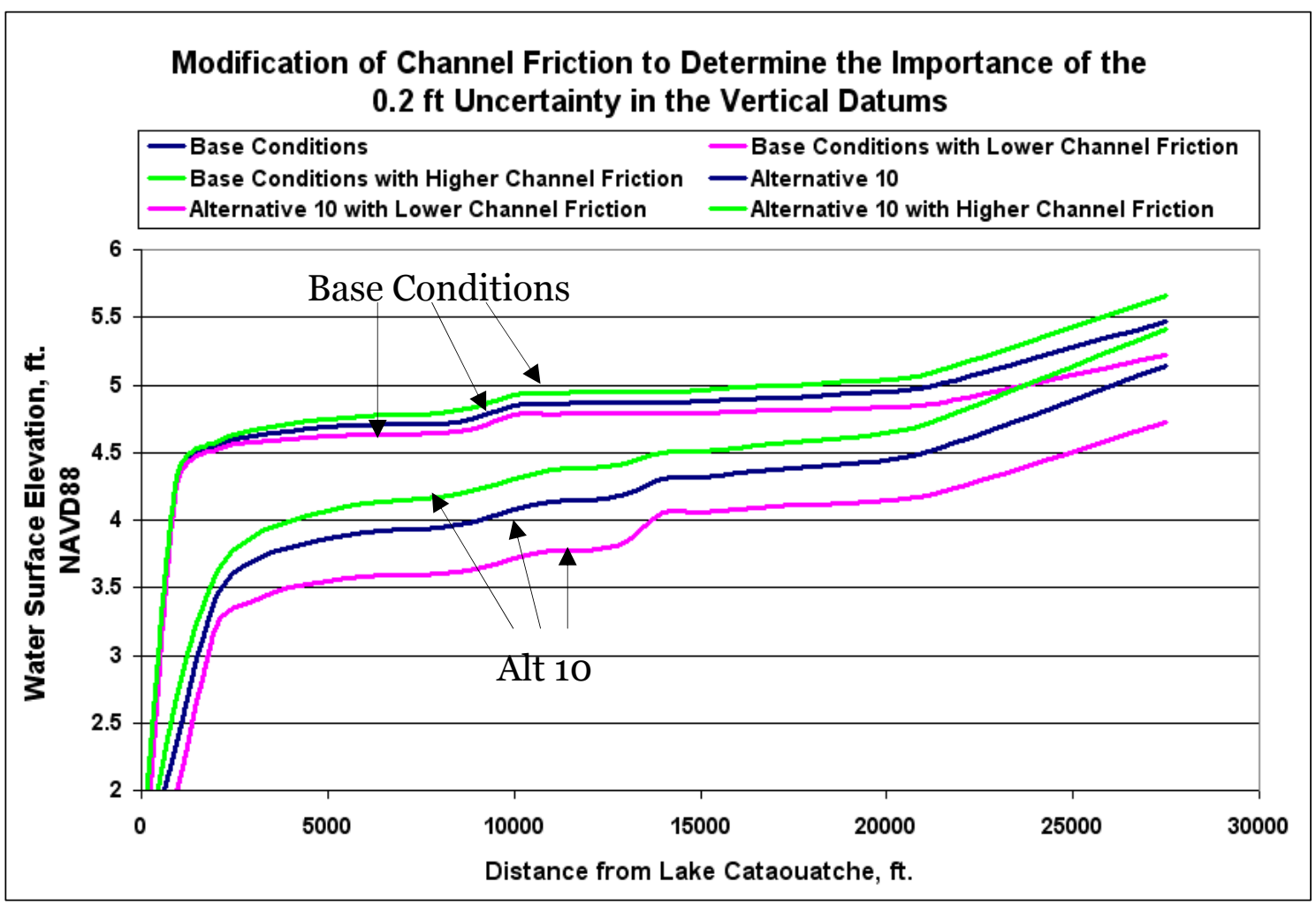

Figure B18. Plot of the effects of the $0.2 \mathrm{ft}$ uncertainty in the vertical datums by modifying the channel frictional values. 
This analysis determined that the planned water surface elevation profiles could be shifted up or down by as much as a half-foot in Alternative 10 based on the uncertainty of the vertical datum of the gage data used to validate the numerical model. It should be noted that the $0.5 \mathrm{ft}$ uncertainty for the alternative water surface elevation profiles would apply to the most extreme combination of cases. 


\section{Appendix C: The TABS-MD System}

TABS-MD is a collection of generalized computer programs and utility codes integrated into a numerical modeling system. TABS-MD is capable of one-, two-, and/or three-dimensional computations, but only the oneand two-dimensional vertically averaged capability will be discussed in this summary. The three-dimensional version of the code, TABS-MDS (Multi-Dimensional with Sediment), ERDC's version of RMA1o, will not be discussed here. The system is used for studying hydrodynamics, sedimentation, and transport problems in rivers, reservoirs, bays, and estuaries. A schematic representation of the system is shown in Figure C1. It can be used either as a stand-alone solution technique or as a step in a hybrid modeling approach. The basic concept is to calculate water-surface elevations, current patterns, sediment erosion, transport and deposition, the resulting bed surface elevations, and the feedback to hydraulics. Existing and proposed geometry can be analyzed to determine the impact on sedimentation of project designs and to determine the impact of project designs on salinity and on the stream system. The system is described in detail by Thomas and McAnally (1985).

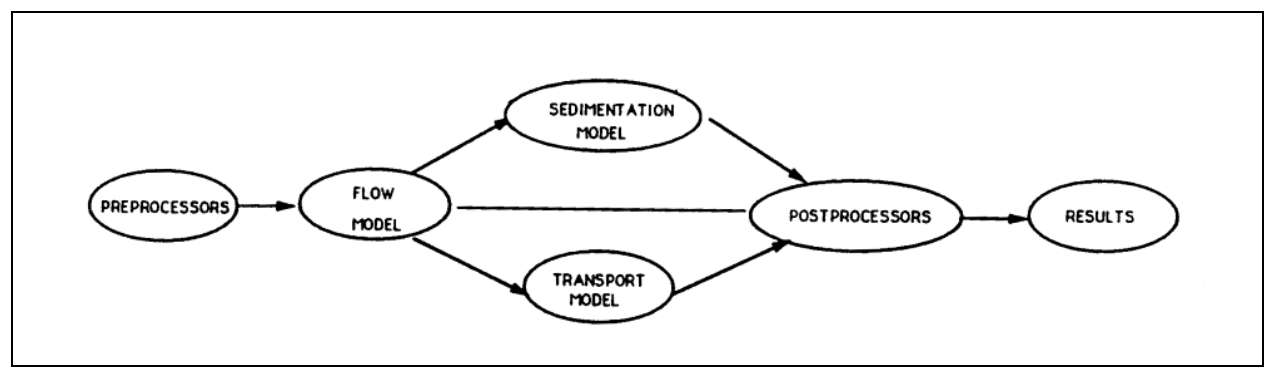

Figure C1. TABS-MD schematic.

The three basic $2 \mathrm{D}$ depth-averaged components of the system are as follows:

1. “A Two-Dimensional Model for Free Surface Flows," RMA2.

2. "Sediment Transport in Unsteady 2-Dimensional Flows, Horizontal Plane," SED2D.

3. "Two-Dimensional Finite Element Program for Water Quality," RMA4.

The U.S. Army Engineer Research and Development Center, Coastal and Hydraulics Laboratory (ERDC-CHL) developed and maintains TABS-MD. 
RMA2 is a finite element solution of the Reynolds form of the NavierStokes equations for turbulent flows. Friction is calculated with Manning's equation, and eddy viscosity coefficients are used to define the turbulent exchanges. A velocity form of the basic equation is used with side boundaries treated as either slip or static. The model has a marsh porosity option as well as the ability to automatically perform wetting and drying. Boundary conditions may be water-surface elevations, velocities, discharges, or tidal radiation.

The sedimentation model, SED2D, solves the convection-diffusion equation with bed source-sink terms. These terms are structured for either sand or cohesive sediments. The Ackers and White (1973) procedure is used to calculate a sediment transport potential for the sands from which the actual transport is calculated based on availability. Clay erosion is based on work by Partheniades (1962) and Ariathurai et al. (1977) and the deposition of clay used Krone's equations. Deposited material forms layers, and bookkeeping allows up to 10 layers at each node for maintaining separate material types, deposit thickness, and age. The code uses the same mesh as RMA2.

Consistent transport calculations, including salinity, are made under RMA4 using a form of the convective-diffusion equation that has general source-sink terms. Up to six conservative substances or substances requiring a decay term can be routed. The code uses the same mesh as RMA2. The model accommodates a mixing zone outside of the model boundaries for estimation of retrainment.

\section{Pre- and post-processing and analysis of TABS-MDS models}

The Surface Water Modeling System (SMS) (BYU 2002) is a comprehensive graphical user environment for performing model conceptualizations, mesh generation, statistical interpretation, and visual examination of surface water model simulations.

SMS is a pre- and post-processor for surface water modeling and analysis in shallow open water areas such as rivers, bays, and estuaries. It includes two-dimensional finite element, two-dimensional finite difference, threedimensional finite element, and one-dimensional step backwater modeling tools. Interfaces specifically designed to facilitate the utilization of several numerical models comprise the modules of SMS. Supported models 
include the TABS-MD (GFGEN, RMA2, RMA4, RMA10, SED2D-WES) system.

Each TABS-MD model is designed to address a specific class of problem. RMA2 calculates hydrodynamic data such as water surface elevations and flow velocities. RMA4 tracks contaminant migration, and SED2D calculates suspended sediment concentrations, erosion, and deposition. The models support both steady-state and dynamic analyses.

The finite element mesh or cross-section entities, along with associated boundary conditions necessary for analysis, are created within SMS and then saved to model-specific files. These files are used as input to the hydrodynamic, contaminant migration, and sediment transport analysis engines. The numerical models create solution files that contain the water surface elevations, flow velocities, contaminant concentrations, sediment concentrations, or other functional data at each node, cell, or section.

These files are then used to perform the analyses. Resulting solution files can be read into SMS to generate vector plots, color-shaded contour plots, time-history diagrams, and solution animation sequences.

\section{Finite element modeling}

The TABS-MD numerical models employ the finite element method to solve the governing equations. To help those who are unfamiliar with the method to better understand the system, a brief description of the method is given here.

The finite element method approximates a solution to governing equations by dividing the area of interest into smaller sub-areas, which are called elements. The dependent variables (e.g., water-surface elevations or sediment concentrations) are approximated over each element by continuous functions that interpolate based on unknown point (node) values of the variables. An error, defined as the deviation of the governing equations using the approximate solution from the equation using the correct solution, is minimized. Then, when boundary conditions are imposed, a set of solvable simultaneous equations is created. The solution is continuous over the area of interest.

In one-dimensional problems, elements are line segments. In twodimensional problems, the elements are polygons, either triangles or 
quadrilaterals. Nodes are located on the edges of elements and occasionally inside the elements. The interpolating functions may be linear or higher-order polynomials. Figure $\mathrm{C} 2$ illustrates a quadrilateral element with eight nodes and a linear solution surface where $\mathrm{F}$ is the interpolating function.

Most water resource applications of the finite element method use the Galerkin method of weighted residuals to minimize error. In this method, the residual-the local error in the equations' use of the approximate solution-is weighted by a function that is identical to the interpolating function and then minimized. Minimization results in a set of simultaneous equations in terms of nodal values of the dependent variable (e.g., water-surface elevations or sediment concentration). The time portion of time-dependent problems can be solved by the finite element method, but it is generally more efficient to express derivatives with respect to time in finite difference form.

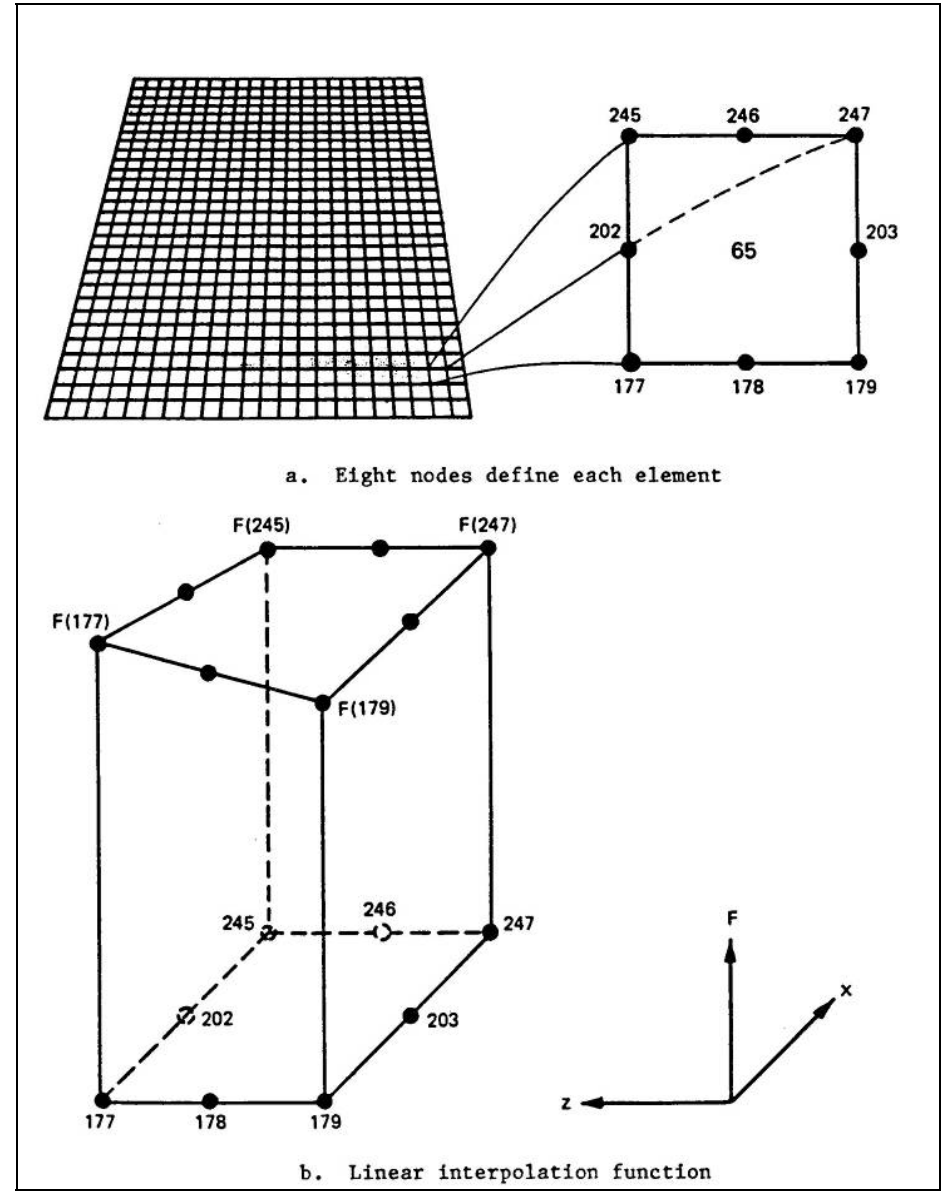

Figure C2. Two-dimensional finite element mesh. 


\section{Hydrodynamic model, RMA2}

\section{Applications}

RMA2 is designed for far-field problems in which vertical accelerations are negligible and the velocity vectors at a node generally point in the same directions over the entire depth of the water column at any instant of time. It expects a vertically homogeneous fluid with a free surface. The model will define the response to a specified horizontally inhomogeneous fluid. Both steady and unsteady state problems can be analyzed. A surface wind stress can be imposed and the effects of the earth's rotation (Coriolis effect) can be included.

RMA2 has been applied to calculate water levels and flow distribution around islands; flow at bridges having one or more relief openings, in contracting and expanding reaches, into and out of off-channel hydropower plants, at river junctions, and into and out of pumping plant channels; circulation and transport in water-bodies with wetlands; and general water levels and flow patterns in rivers, reservoirs, and estuaries.

\section{Limitations}

RMA2 is not designed for near-field problems where flow structure interactions (such as vortices, vibrations, or vertical accelerations) are of interest. Areas of vertically stratified flow are beyond this program's capability unless it is used in a hybrid modeling approach. It is twodimensional in the horizontal plane, so zones where the bottom current is in a different direction from the surface current must be analyzed with care. It is a free-surface calculation for sub-critical flow problems.

\section{Governing equations}

The generalized computer program RMA2 solves the depth-integrated equations of fluid mass and momentum conservation in two horizontal directions. The form of the solved equations is

$$
\begin{aligned}
& h \frac{\partial u}{\partial t}+h u \frac{\partial u}{\partial x}+h v \frac{\partial u}{\partial y}-\frac{h}{\rho}\left(\varepsilon_{x x} \frac{\partial^{2} u}{\partial x^{2}}+\varepsilon_{x y} \frac{\partial^{2} u}{\partial_{y}^{2}}\right)+g h\left(\frac{\partial a}{\partial x}+\frac{\partial h}{\partial x}\right) \\
& +\frac{g u n^{2}}{\left(1.486 h^{1 / 6}\right)^{2}}\left(u^{2}+v^{2}\right)^{1 / 2}-\zeta V_{a}^{2} \cos \psi-2 h \omega v \sin \varphi=0
\end{aligned}
$$




$$
\begin{gathered}
h \frac{\partial v}{\partial t}+h u \frac{\partial v}{\partial x}+h v \frac{\partial v}{\partial y}-\frac{h}{\rho}\left(\varepsilon_{y x} \frac{\partial^{2} v}{\partial x^{2}}+\varepsilon_{y y} \frac{\partial^{2} v}{\partial y^{2}}\right)+g h\left(\frac{\partial a}{\partial y}+\frac{\partial h}{\partial y}\right) \\
+\frac{g v n^{2}}{\left(1.486 h^{1 / 6}\right)^{2}}\left(u^{2}+v^{2}\right)^{1 / 2}-\zeta V_{a}^{2} \sin \psi+2 \omega h u \sin \varphi+0 \\
\frac{\partial h}{\partial t}+h\left(\frac{\partial u}{\partial x}+\frac{\partial v}{\partial y}\right)+u \frac{\partial h}{\partial x}+v \frac{\partial h}{\partial y}=0
\end{gathered}
$$

where:

$$
\begin{aligned}
h= & \text { depth } \\
u, v= & \mathrm{x} \text { and } \mathrm{y} \text { direction velocities, respectively } \\
x, y, t= & \text { Cartesian coordinates and time } \\
\rho= & \text { density of fluid } \\
\varepsilon= & \text { eddy viscosity coefficient, } \\
& \text { for } \mathrm{xx}=\text { normal direction on x-axis surface; } \\
& \text { yy }=\text { normal direction on } \mathrm{y}-\mathrm{axis} \text { surface; } \\
& \text { xy and yx }=\text { shear direction on each surface } \\
g= & \text { acceleration due to gravity } \\
a= & \text { elevation of bottom } \\
n= & \text { Manning's } \mathrm{n} \text { value } \\
1.486= & \text { conversion from SI (metric) to non-SI units } \\
\zeta= & \text { empirical wind shear coefficient } \\
V_{a}= & \text { wind speed } \\
\Psi= & \text { wind direction } \\
\omega= & \text { rate of earth's angular rotation } \\
\varphi= & \text { local latitude. }
\end{aligned}
$$

Equations $\mathrm{C}_{1}, \mathrm{C}_{2}$, and $\mathrm{C}_{3}$ are solved by the finite element method using Galerkin weighted residuals. The elements may be one-dimensional lines or two-dimensional quadrilaterals or triangles and may have curved (parabolic) sides. The shape functions are quadratic for velocity and linear for depth. Integration in space is performed by Gaussian integration. Derivatives in time are replaced by a nonlinear finite difference approximation. Variables are assumed to vary over each time interval in the form

$$
f(t)=f(0)+a t+b t^{c} \quad t_{o} \leq t \angle t_{0}+\Delta t
$$


which is differentiated with respect to time, and cast in finite difference form. Letters $a, b$, and $c$ are constants. It has been found by experiment that the best value for $c$ is 1.5 (Norton and King 1977).

The solution is fully implicit and the set of simultaneous equations is solved by Newton-Raphson nonlinear iteration.

\section{Sediment transport model, SED2D}

\section{Applications}

SED2D can be applied to clay and/or sand bed sediments where flow velocities can be considered two-dimensional (i.e., the speed and direction can be satisfactorily represented as a depth-averaged velocity). It is useful for both deposition and erosion studies and, to a limited extent, for stream width studies. The program treats two categories of sediment: noncohesive, which is referred to here as sand, and cohesive, which is referred to as clay.

\section{Limitations}

Both clay and sand may be analyzed, but SED2D considers a single, effective grain size for each and treats each separately. Fall velocity must be prescribed along with the water-surface elevations, $x$-velocity, y-velocity, diffusion coefficients and, for clay sediment, bed density, critical shear stresses for erosion, erosion rate constants, and critical shear stress for deposition.

The program does not compute water-surface elevations or velocities, so those data must be provided. For complicated geometries, the numerical model for hydrodynamic computations (i.e., RMA2) is used. However, at this time, SED2D can accept only a two-dimensional network.

\section{Governing equations}

SED2D solves the depth-integrated convection-dispersion equation in two horizontal dimensions for a single sediment constituent. For a more complete description, see Appendix G of Thomas and McAnally (1985). The form of the solved equation is 


$$
\frac{\partial C}{\partial t}+u \frac{\partial C}{\partial x}+v \frac{\partial C}{\partial y}=\frac{\partial}{\partial x}\left(D_{x} \frac{\partial C}{\partial x}\right)+\frac{\partial}{\partial y}\left(D_{y} \frac{\partial C}{\partial y}\right)+a_{1} C+a_{2}=0
$$

where:

$$
\begin{aligned}
C & =\text { concentration of sediment } \\
u & =\text { depth-integrated velocity in } \mathrm{x} \text {-direction } \\
D x & =\text { dispersion coefficient in x-direction } \\
v & =\text { Depth integrated velocity in y-direction } \\
D y & =\text { dispersion coefficient in y-direction } \\
\alpha_{1} & =\text { coefficient of concentration-dependent source/sink term } \\
a_{2} & =\text { coefficient of source/sink term. }
\end{aligned}
$$

The source/sink terms in Equation $\mathrm{C}_{5}$ are computed in routines that treat the interaction of the flow and the bed. Separate sections of the code handle computations for clay bed and sand bed problems.

\section{Sand transport}

The source/sink terms are evaluated by first computing a potential sand transport capacity for the specified flow conditions, comparing that capacity with the amount of sand actually being transported, and then eroding from or depositing to the bed at a rate that would approach the equilibrium value after sufficient elapsed time.

The potential sand transport capacity in the model is computed by the method of Ackers and White (1973), which uses a transport power (work rate) approach. It has been shown to provide superior results for transport under steady-flow conditions (White et al. 1975) and for combined waves and currents (Swart 1976). Flume tests at ERDC have shown that the concept is valid for transport by estuarine currents.

The total load transport function of Ackers and White is based upon a dimensionless grain size

$$
D_{g r}=D\left[\frac{g(s-1)}{v^{2}}\right]^{1 / 3}
$$


where:

$D=$ sediment particle diameter

$s=$ specific gravity of the sediment

$v=$ kinematic viscosity of the fluid

and a sediment mobility parameter

$$
F_{g r}=\left[\frac{\tau^{1 \eta_{\tau}(1-n)}}{\rho g D(s-1)}\right]^{1 / 2}
$$

where:

$$
\begin{aligned}
\tau^{\prime}= & \text { total boundary shear stress }=\rho g R S \\
R= & \text { hydraulic radius } \\
S= & \text { slope of water surface } \\
n= & \text { a coefficient expressing the relative importance of bed-load } \\
& \text { and suspended-load transport, given in Equation C9. }
\end{aligned}
$$

NOTE:

$$
\begin{aligned}
& n=1 \text { for fine sediments } \\
& n=0 \text { for coarse sediments } \\
& \tau=\text { boundary surface shear stress. }
\end{aligned}
$$

The surface shear stress is that part of total shear stress attributable to the rough surface of the bed only, i.e., not including the part attributable to bed forms and geometry. It therefore corresponds to the shear stress that the flow would exert on a plane bed.

The total sediment transport is (in $\mathrm{kg} / \mathrm{m}^{3}$ ) expressed as an effective concentration

$$
G_{P}=C_{a}\left[\frac{F_{g r}}{A}-1\right]^{m} \frac{s D}{h} G\left[\frac{\rho}{\tau} U\right]^{n}
$$

where $U$ is the average flow speed, and for $1<D_{g r} \leq 60$ 


$$
\begin{gathered}
n=1.00-0.56 \log D_{g r} \\
A=\frac{0.23}{\sqrt{D_{g r}}}+0.14 \\
\log C_{a}=2.86 \log D_{g r}-\left(\log D_{g r}\right)^{2}-3.53 \\
m=\frac{9.66}{D_{g r}}+1.34
\end{gathered}
$$

For $D_{g r}<60$

$$
\begin{gathered}
n=0.00 \\
A=0.17 \\
C_{a}=0.025 \\
m=1.5
\end{gathered}
$$

Note the $C_{a}$ has units consistent with $G_{p}\left(\mathrm{~kg} / \mathrm{m}^{3}\right.$ for SED2D).

Equations C6 through $\mathrm{C} 16$ result in a potential sediment concentration $G_{p}$. This value is the depth-averaged concentration of sediment that will occur if an equilibrium transport rate is reached with a limited supply of sediment. The rate of sediment deposition (or erosion) is then computed as

$$
R=\frac{G_{p}-C}{t_{c}}
$$

where:

$$
\begin{aligned}
C & =\text { present sediment concentration } \\
t_{c} & =\text { time constant }
\end{aligned}
$$


For deposition, the time constant is

$$
t_{c}=\text { larger of }\left\{\begin{array}{l}
\Delta t \\
\text { or } \\
\frac{C_{d} h}{V_{s}}
\end{array}\right.
$$

and for erosion it is

$$
t_{c}=\text { larger of }\left\{\begin{array}{l}
\Delta t \\
\text { or } \\
\frac{C_{e} h}{U}
\end{array}\right.
$$

where:

$$
\begin{aligned}
& \Delta t=\text { computational timestep } \\
& C_{d}=\text { response time coefficient for deposition } \\
& V_{s}=\text { sediment settling velocity } \\
& C_{e}=\text { response time coefficient for erosion. }
\end{aligned}
$$

The sand bed has a specified initial thickness which limits the amount of erosion to that thickness.

\section{Cohesive sediments transport}

Cohesive sediments (usually clays and some silts) are considered to be depositional if the bed shear stress exerted by the flow is less than a critical value $\tau_{d}$. When that value occurs, the deposition rate is given by Krone's (1962) equation

$$
S=\left\{\begin{array}{l}
-\frac{2 V_{s}}{h} C\left(1-\frac{\tau}{\tau_{d}}\right) \text { for } C<C_{c} \\
-\frac{2 V_{s}}{h C_{c}^{2 / 3}} C^{5 / 3}\left(1-\frac{\tau}{\tau_{d}}\right) \text { for } C>C_{c}
\end{array}\right.
$$


where:

$$
\begin{aligned}
S & =\text { source term } \\
V_{s} & =\text { fall velocity of a sediment particle } \\
h & =\text { flow depth } \\
C & =\text { sediment concentration in water column } \\
\tau & =\text { bed shear stress } \\
\tau_{d} & =\text { critical shear stress for deposition } \\
C_{c} & =\text { critical concentration }=300 \mathrm{mg} / \mathrm{L} .
\end{aligned}
$$

If the bed shear stress is greater than the critical value for particle erosion $\tau_{e}$, material is removed from the bed. The source term is then computed by Ariathurai's (Ariathurai et al. 1977) adaptation of Partheniades' (1962) findings:

$$
S=\frac{P}{h}\left(\frac{\tau}{\tau_{e}}-1\right) \text { for } \tau>\tau_{e}
$$

where $P$ is the erosion rate constant, unless the shear stress is also greater than the critical value for mass erosion. When this value is exceeded, mass failure of a sediment layer occurs and

$$
S=\frac{T_{L} \rho_{L}}{h \Delta t} \text { for } \tau>\tau_{s}
$$

where:

$T_{L}=$ thickness of the failed layer

$\rho_{L}=$ density of the failed layer

$\Delta t=$ time interval over which failure occurs

$\tau_{s}=$ bulk shear strength of the layer.

The cohesive sediment bed consists of 1 to 10 layers, each with a distinct density and erosion resistance. The layers consolidate with overburden and time.

\section{Bed shear stress}

Bed shear stresses are calculated from the flow speed according to one of four optional equations: the smooth-wall log velocity profile or Manning 
equation for flows alone; and a smooth bed or rippled bed equation for combined currents and wind waves. Shear stresses are calculated using the shear velocity concept

$$
\tau_{b}=\rho u_{*}^{2}
$$

where:

$$
\begin{aligned}
\tau_{b} & =\text { bed shear stress } \\
u_{*} & =\text { shear velocity }
\end{aligned}
$$

and the shear velocity is calculated by one of four methods:

1. Smooth-wall log velocity profiles

$$
\frac{\bar{u}}{u_{*}}=5.75 \log \left(3.23 \frac{u_{*} h}{v}\right)
$$

Equation C25 is applicable to the lower 15 percent of the boundary layer when

$$
\frac{u_{*} h}{v}>30
$$

where $\bar{u}$ is the mean flow velocity (resultant of $u$ and $v$ velocity components).

2. The Manning shear stress equation

$$
u_{*}=\frac{(\bar{u} n) \sqrt{g}}{C M E(h)^{1 / 6}}
$$

where $C M E$ is a coefficient of 1 for SI (metric) units and 1.486 for English units of measurement, and $n$ is the Mannings n-value.

3. A Jonsson-type equation for surface shear stress (plane beds) caused by waves and currents 


$$
u_{*}=\sqrt{\frac{1}{2 \cdot}\left[\frac{f_{w} u_{o m}+f_{c} \bar{u}}{u_{o m}+\bar{u}}\right]}\left(\bar{u}+u_{o m}\right)^{2}
$$

where:

$$
\begin{aligned}
f_{w} & =\text { shear stress coefficient for waves } \\
u_{o m} & =\text { maximum orbital velocity of waves } \\
f_{c} & =\text { shear stress coefficient for currents. }
\end{aligned}
$$

4. A Bijker-type equation for total shear stress caused by waves and current

$$
U_{*}=\sqrt{\frac{1}{2} f_{c} \bar{u}^{2}+\frac{1}{4} f_{w} u_{o m}^{2}}
$$

\section{Solution method}

Equation $\mathrm{C}_{5}$ is solved by the finite element method using Galerkin weighted residuals. Like RMA2, which uses the same general solution technique, elements are quadrilateral or triangular and may have parabolic sides. Shape functions are quadratic. Integration in space is Gaussian. Time-stepping is performed by a Crank-Nicholson approach with a weighting factor ( $\varnothing$ ) of 0.66 . A front-type solver similar to that in RMA2 is used to solve the simultaneous equations.

\section{Water quality transport model, RMA4}

\section{Applications}

The water quality transport model, RMA4, is designed to simulate the depth-average advection-diffusion process in most water bodies with a free surface. The model is used for investigating the physical processes of migration and mixing of a soluble substance in reservoirs, rivers, bays, estuaries, and coastal zones. The model is useful for evaluation of the basic processes or for defining the effectiveness of remedial measures. For complex geometries the model utilizes the depth-averaged hydrodynamics from RMA2.

The water quality model has been applied to define the horizontal salinity distribution, trace temperature effects from power plants, calculate residence times of harbors or basins, optimize the placement of outfalls, identify potential critical areas for oil spills or other pollutants spread, 
evaluate turbidity plume extent, and monitor other water quality criterion within game and fish habitats.

\section{Limitations}

The formulation of RMA4 is limited to one-dimensional (cross-sectionally averaged) and two-dimensional (depth-averaged) situations in which the concentration is fairly well mixed in the vertical. It will not provide accurate concentrations for stratified situations in which the constituent concentration influences the density of the fluid. In addition, the accuracy of the transport model is dependent on the accuracy of the hydrodynamics (e.g., as supplied from RMA2 or another flow solution).

\section{Governing equations}

The ERDC version of RMA4 is a revised version of RMA4 as developed by King and Rachide (1989). The generalized computer program solves the depth-integrated equations of the transport and mixing process. The form of the equations solved is:

$$
h\left(\frac{\partial c}{\partial t}+u \frac{\partial c}{\partial x}+v \frac{\partial c}{\partial y}-\frac{\partial}{\partial x} D_{x} \frac{\partial c}{\partial x}-\frac{\partial}{\partial y} D_{y} \frac{\partial c}{\partial y}-\sigma+k c\right)=0
$$

where:

$$
\begin{aligned}
h & =\text { water depth } \\
c & =\text { constituent concentration } \\
t & =\text { time } \\
u, v & =\text { velocity components } \\
D x, D y & =\text { turbulent mixing coefficients } \\
k & =\text { first order decay } \\
\sigma & =\text { source/sink of constituent. }
\end{aligned}
$$

Note that the basic governing equation for RMA4 is the same as for the sediment transport model, SED2D. The difference between the two models lies in the source/sink terms.

Equation C29 is solved by the finite element method using Galerkin weighted residuals. As with the hydrodynamic model, RMA2, the transport model RMA4 handles one-dimensional segments or two-dimensional quadrilaterals or triangles with the option for curved sides. Spatial 
integration of the equation is performed by Gaussian techniques and the temporal variations are handled by nonlinear finite differences, consistent with the method described for RMA2.

The boundary conditions for RMA4 are specified in several optional ways. The boundary concentration may be specified absolutely at a certain level regardless of the flow direction; the concentration can be specified to be applied only when the water is leaving the model; or a mixing zone may be specified just beyond the model boundary to provide the possibility of reentrainment of constituent into the model that may have crossed the boundary earlier. For a more detailed description of the constituent transport model, RMA4, see King and Rachiele (1989).

Within the one-dimensional formulation of the model, there is a provision for defining the constituent concentration mixing and transport at control structures as they may have been specified in RMA2. This allows for either a flow-through condition, as for example for a weir-type flow, or for a mixing chamber type of flux, which would be appropriate for a navigation lock. 


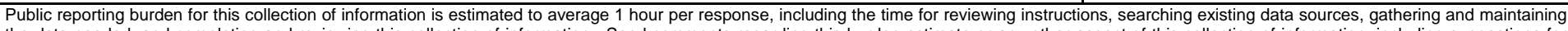

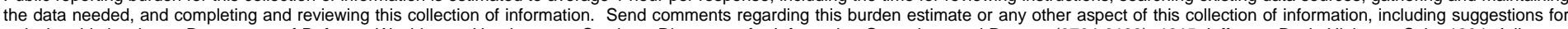

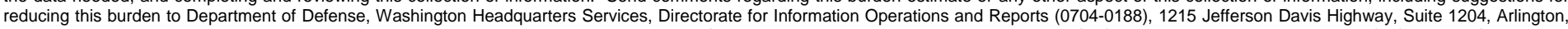

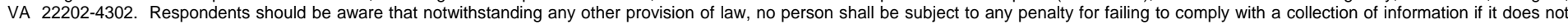
display a currently valid OMB control number. PLEASE DO NOT RETURN YOUR FORM TO THE ABOVE ADDRESS.
1. REPORT DATE (DD-MM-YYYY)
2. REPORT TYPE
3. DATES COVERED (From - To)

August 2008

Final report

\section{TITLE AND SUBTITLE}

A Hydrodynamic Study of Davis Pond, Near New Orleans, LA

5a. CONTRACT NUMBER

5b. GRANT NUMBER

5c. PROGRAM ELEMENT NUMBER

\section{AUTHOR(S)}

Tate O. McAlpin, Joseph V. Letter, Jr., and S. Keith Martin

5d. PROJECT NUMBER

5e. TASK NUMBER

5f. WORK UNIT NUMBER

\section{PERFORMING ORGANIZATION NAME(S) AND ADDRESS(ES)}

8. PERFORMING ORGANIZATION REPORT NUMBER

U.S. Army Engineer Research and Development Center

Coastal and Hydraulics Laboratory

ERDC/CHL TR-08-11

3909 Halls Ferry Road

Vicksburg, MS 39180-6199

\section{SPONSORING I MONITORING AGENCY NAME(S) AND ADDRESS(ES)}

10. SPONSOR/MONITOR'S ACRONYM(S)

U.S. Army Engineer District, New Orleans

PO Box 60267

New Orleans, LA 70160-0267

11. SPONSOR/MONITOR'S REPORT NUMBER(S)

\section{DISTRIBUTION / AVAILABILITY STATEMENT}

Approved for public release; distribution is unlimited.

\section{SUPPLEMENTARY NOTES}

\section{ABSTRACT}

This study characterizes water levels in the Davis Pond floating marsh created by the diversion of fresh water from the Mississippi River. The model was validated to observed field data collected from November 2003 to January 2004. After model validation, eight alternatives were tested to determine the benefits of extending the diversion canal (Alternatives 1-3), increasing the size of the cuts through the gabion weir (Alternatives 4-6), and creating breaches in the Cypress Lumber Canal (Alternatives $7-8$ ). These eight initial alternatives were analyzed and used to create four additional alternatives (Alternatives 9-12) consisting of the most beneficial aspects of each of the initial alternatives. The final four alternatives were tested to determine their expected benefits to the system.

\section{SUBJECT TERMS}

Davis Pond, floating marsh, freshwater diversion, Lake Cataouatche, Cypress Lumber Canal, RMA2, vertical datum analysis, flood profile, Mississippi River diversion

\section{SECURITY CLASSIFICATION OF:}

a. REPORT
UNCLASSIFIED

b. ABSTRACT
UNCLASSIFIED

17. LIMITATION OF ABSTRACT c. THIS PAGE UNCLASSIFIED

\section{NUMBER OF PAGES}

108 19a. NAME OF RESPONSIBLE PERSON

19b. TELEPHONE NUMBER (include
area code) 